Rafael Luiz da Silva

\title{
Caracterização do sinal do fenômeno de detonação utilizando filtros adaptativos e estimador de potência
}


Rafael Luiz da Silva

\section{Caracterização do sinal do fenômeno de detonação utilizando filtros adaptativos e estimador de potência}

Dissertação apresentada à Escola Politécnica da Universidade de São Paulo para obtenção do Título de Mestre em Ciências. 
Rafael Luiz da Silva

\title{
Caracterização do sinal do fenômeno de detonação utilizando filtros adaptativos e estimador de potência
}

\author{
Dissertação apresentada à Escola Politéc- \\ nica da Universidade de São Paulo para \\ obtenção do Título de Mestre em Ciências. \\ Área de concentração: \\ Sistemas Eletrônicos \\ Orientador: \\ Prof. Dr. Antonio Carlos Seabra
}


Este exemplar foi revisado e alterado em relação à versão original, sob responsabilidade única do autor e com a anuência de seu orientador.

São Paulo, 13 de Fevereiro de 2014

Assinatura do autor

Assinatura do orientador

Silva, Rafael Luiz da

Caracterização do sinal do fenômeno de detonação utilizando filtros adaptativos e estimador de potência / R.L. da Silva. -ed. corr. -- São Paulo, 2014.

$124 \mathrm{p}$.

Dissertação (Mestrado) - Escola Politécnica da Universidade de São Paulo. Departamento de Engenharia de Sistemas Eletrônicos.

1. Filtros elétricos adaptativos 2. Filtros elétricos digitais 3 . Detonação 4. Estimador de potência I. Universidade de São Paulo. Escola Politécnica. Departamento de Engenharia de Sistemas Eletrônicos II. t. 
Ao senhor de todas as ciências, mentor da verdade absoluta, Deus. 


\section{Agradecimentos}

O presente trabalho se deve a uma série de pessoas e fatores que o tornaram possível. A primeira pessoa a receber meus agradecimentos é o dedicado professor Laganá que, com seu altruísmo, mostra a nobreza da arte de transferir conhecimento e ajudar aos demais, assim como a habilidade de desenvolver resultados relevantes para a área de pesquisa independente do histórico dos indivíduos, motivando seu time para entregar sempre o melhor para a instituição e para si mesmos. A segunda pessoa a receber meus agradecimentos, e também importante, é o professor Seabra por prestar ajuda em momentos fundamentais ao desenvolvimento deste trabalho.

À Escola Politécnica da Universidade de São Paulo, onde fundei as bases do conhecimento de meu mestrado e com esta formei uma plataforma de onde vislumbro horizontes antes não vistos ou sequer imaginados.

À Fatec Santo André, à qual cedeu espaço e recursos para os experimentos deste trabalho, ao seu competente grupo de docentes e funcionários, assim como ao grupo de eletrônica automotiva que a cada dia busca uma contribuição maior para a formação de profissionais desenvolvedores de tecnologias para a área automotiva, seja para a indústria ou ao meio acadêmico.

Agradeço aos amigos que apoiaram e entenderam as dificuldades e ausências passadas no tempo de curso. Não há base de conhecimento que seja firme e útil se sustentada por si só, o suporte recebido seja direta ou indiretamente, fez com que o peso de tal conhecimento fosse levado e absorvido com mais naturalidade.

Não há merito nas conquistas se não há com quem compartilhá-las, não há motivação se não há com quem dividir. Na vida desenvolvida neste curso, dividi e compartilhei, recebi, faltei mas almejando comparecer, compus mas fui até dissolvido, a continuidade foi dada de forma paradoxal, sem crer na descrença por vezes de olhos fechados, postos foram atingidos, cicatrizes ficaram para orgulho e para dedicação. Nem sempre o devido mérito é atribuído, mas por mim será guardado, forma-se agora recomposto e erguido para a missão de empregar as experiências obtidas nesse período em prol dos que estão e os que estarão a minha volta. 


\section{Resumo}

O fenômeno de detonação que ocorre em motores de combustão interna é uma restrição de desempenho para baixas emissões de poluentes, altas solicitações de torque (as quais resultariam em mais potência entregue pelo motor), economia de combustível e também é uma fonte de ruídos desagradáveis ao condutor do veículo. No Brasil, tal fenômeno pode ter ainda uma utilidade benéfica se identificado de forma leal, tendo em vista que a detonação é mais fácil de ocorrer com gasolina do que com álcool. Assim, a ocorrência de detonação pode ser um auxílio no gerenciamento otimizado da injeção, ignição, bem como pode possibilitar a identificação do tipo de combustível. Para isso, técnicas de processamento de sinais podem ser utilizadas para caracterizar tal fenômeno. Este trabalho tem como foco a identificação (ocorrência) e caracterização (intensidade e duração) do sinal de detonação utilizando filtragem adaptativa e estimadores de potência, onde o desempenho individual e combinado destes algoritmos é avaliado. Inicialmente, um modelo do sinal de detonação é proposto e amostras do sinal real são obtidas e com isso, mostra-se que as técnicas propostas rendem eficientes caracterizadores do fenômeno.

Palavras-chave: Filtros adaptativos. Estimador de potência. Detonação. Sensor de detonação. Combustão anormal. 



\section{Abstract}

The knock phenomenon that happens in internal combustion engines is a constraint against performance in terms of low pollution rates, higher torque requests (which would imply higher delivered power by the engine), milage as well as it is an annoying source of noise to the user. In Brazil, such phenomenon may be useful if accurately identified, due to the fact that knock has a higher likelihood to happen with gasoline than ethanol. Thus, the occurrence of knock may be a support in an optimized management of fuel injection and sparking time, as well as it may provide means to identify the fuel being used. In order to achieve such goal, signal processing techniques may be used for characterization of such phenomenon. This work has the focus of identifying (occurence) and characterizing (intensity and duration) of knock signal using adaptive filtering and power estimators, where the individual and combined performance are assessed. To begin with, a knock signal model is proposed as well as samples of the real signal are taken, then, it is shown that the proposed techniques offer efficient characterization of the phenomenon.

Keywords: Adaptive filters. Power estimator. Knock. Knock sensor. Abnormal combustion. 



\section{Lista de ilustrações}

Figura 1 - a) Avanço de ignição b) Retardo de ignição. . . . . . . . . . . . . . 6

Figura 2 - Os quatro tempos do ciclo Otto de combustão. . . . . . . . . . . 7

Figura 3 - Primeiro tempo: aspiração. . . . . . . . . . . . . . 7

Figura 4 - Segundo tempo: compressão. . . . . . . . . . . . . . . . . 8

Figura 5 - Terceiro tempo: expansão. . . . . . . . . . . . . . . . 9

Figura 6 - Quarto tempo: descarga. . . . . . . . . . . . . . . . 9

Figura 7 - Sistema de injeção / ignição simplificado . . . . . . . . . . . . . 11

Figura 8 - Resumo das características envolvidas no fenômeno de combustão anormal ............................ 15

Figura 9 - Esquemático de propagação das chamas nas detonações por centelha. 16

Figura 10 - Imagens ciclo a ciclo da ocorrência de auto ignição no interior da câmara de combustão. . . . . . . . . . . . . . . . . . . 17

Figura 11 -Pressão no interior da câmara em função do ângulo de ignição $\alpha$. . . . 18

Figura 12 -Resumo dos tipos de combustão normal e anormal . . . . . . . . . . . 20

Figura 13 - Pressão do cilindro em função do ângulo de ignição 4000rpm, pedal totalmente pressionado, deslocamento de $381 \mathrm{~cm}^{3}$ por cilindro . . . . . 21

Figura 14 -Exemplo de fixação do sensor de detonação no bloco do motor . . . . . 24

Figura 15 - Intensidade da detonação (amplitude máxima do filtro passa faixa) em cem ciclos individuais . . . . . . . . . . . . . . . . . . . 24

Figura 16 -Características dos combustíveis gasolina e álcool . . . . . . . . . . 26

Figura 17 -Curvas do torque em função do ângulo de ignição para álcool e gasolina 26

Figura 18 -Indicação de diferentes pontos de detonação em combustíveis diferentes 27

Figura 19 - Torque em função do avanço de ignição sem utilizar o sensor de detonação 27

Figura 20 - Melhoria do aproveitamento da curva de torque em função do avanço com o sensor de detonação . . . . . . . . . . . . . . . . . . 28

Figura 21 -Efeito piezolétrico em um cristal de quartzo . . . . . . . . . . . . . . 29

Figura 22 -Construção de um sensor piezolétrico . . . . . . . . . . . . . . . 30

Figura 23 -Estruturas de cristais piezoelétricos . . . . . . . . . . . . . . 30

Figura 24 -Modos de vibração de sensores piezolétricos . . . . . . . . . . . . . 31

Figura 25 -Esquema básico de um acelerômetro piezolétrico . . . . . . . . . . . . . 32

Figura 26 -Representação do algoritmo gradiente descendente . . . . . . . . . . . 35

Figura 27 -Sinal real de detonação . . . . . . . . . . . . . . . . . . . . 39

Figura 28 -Sinal simulado do sensor de detonação representado como uma divisão de blocos . . . . . . . . . . . . . . . . . . . . 4 43

Figura 29 -Opções de geração de detonação ao sinal simulado do sensor . . . . . . 46 
Figura 30 -Combinação do algoritmo LMS com o estimador de potência . . . . . . 50

Figura 31 -Combinação do algoritmo $N L M S$ com o estimador de potência . . . . . 50

Figura 32 -Cenário 1 individual - Evolução dos coeficientes $w_{i}$ e saída do estimador de potência . . . . . . . . . . . . . . . . 5 55

Figura 33 -Cenário 1 individual - Ação de denoising e evolução dos valores estimados $\hat{d}$, saída do estimador de potência . . . . . . . . . . . . 57

Figura 34 -Cenário 2 individual - Evolução dos coeficientes $w_{i}$ e saída do estimador de potência . . . . . . . . . . . . . . . 6 60

Figura 35 -Cenário 2 individual - Ação de denoising e evolução dos valores estimados $\hat{d}$, saída do estimador de potência . . . . . . . . . . . . . . . 61

Figura 36 -Cenário 3 individual - Desempenho de remoção do ruído dos filtros adaptativos $L M S, N L M S$ e saída do estimador de potência . . . . . . .

Figura 37 -Cenário 3 individual - Evolução dos coeficientes $w_{i}$ e saída do estimador de potência . . . . . . . . . . . . . . . . . . . 64

Figura 38 -Cenário 4 individual - Evolução dos coeficientes $w_{i}$ e saída estimada do NLMS com sinal real de detonação . . . . . . . . . . . . . . . 66

Figura 39 -Cenário 4 individual - Saída estimada do estimador de potência com o sinal real de detonação . . . . . . . . . . . . . . . . . . . . . . . . . 67

Figura 40 -Cenário 1 combinado - Saída do estimador de potência, com $w_{i}$ do $L M S$ sendo a entrada . . . . . . . . . . . . . . . . . . 70

Figura 41 -Cenário 1 combinado - Saída do estimador de potência, com $\hat{d}$ do $L M S$ sendo a entrada . . . . . . . . . . . . . . . . . . . 71

Figura 42 -Cenário 1 combinado - Saída do estimador de potência, com $w_{i}$ do NLMS sendo a entrada . . . . . . . . . . . . . . . . . . . 72

Figura 43 - Cenário 1 combinado - Saída do estimador de potência, com $\hat{d}$ do $N L M S$ sendo a entrada . . . . . . . . . . . . . . . . . . . 73

Figura 44 -Cenário 2 combinado - Saída do estimador de potência, com $w_{i}$ do NLMS sendo a entrada . . . . . . . . . . . . . . . . . . . 74

Figura 45 - Cenário 2 combinado - Saída do estimador de potência, com $\hat{\boldsymbol{d}}$ do $N L M S$ sendo a entrada . . . . . . . . . . . . . . . . . . 75

Figura 46 -Cenário 3 combinado - Saída do estimador de potência, com $w_{i}$ do $L M S$ sendo a entrada . . . . . . . . . . . . . . . . . . 77

Figura 47 - Cenário 3 combinado - Saída do estimador de potência, com $\hat{d}$ do $L M S$ sendo a entrada . . . . . . . . . . . . . . . . . . 78

Figura 48 -Cenário 3 combinado - Saída do estimador de potência, com $w_{i}$ do NLMS sendo a entrada . . . . . . . . . . . . . . . . 79

Figura 49 -Cenário 3 combinado - Saída do estimador de potência, com $\hat{d}$ do $N L M S$ sendo a entrada . . . . . . . . . . . . . . . . . . . 80

Figura 50 -Saída estimada do NLMS sendo a entrada do estimador de potência . . 81 
Figura 51 - Curva de aprendizado da decomposição de Fourier do sinal de detonação 85

Figura 52 - A transformada de wavelet do sinal do sensor de detonação . . . . . . . 87

Figura 53 -A transformada de wavelet do sinal do sensor de pressão . . . . . . . . 88 



\section{Lista de tabelas}

Tabela 1 - Opções de geração de detonação . . . . . . . . . . . . . . . . . 43

Tabela 2 - Cenário 1 - Configurações para o LMS . . . . . . . . . . . . . . 53

Tabela 3 - Cenário 1 - Configurações para o NLMS . . . . . . . . . . . . 56

Tabela 4 - Cenário 2 - Configurações para o LMS . . . . . . . . . . . . . . 58

Tabela 5 - Cenário 2 - Configurações para o NLMS . . . . . . . . . . . . 58

Tabela 6 - Cenário 3 - Configurações para o LMS . . . . . . . . . . . . . . 62

Tabela 7 - Cenário 3 - Configurações para o NLMS . . . . . . . . . . . . . 62

Tabela 8 - Cenário 4 - Configurações para o NLMS . . . . . . . . . . . . 65

Tabela 9 - Tabela comparativa entre os 3 algoritmos propostos . . . . . . . . . . 68

Tabela 10 -Cenário 1 combinado - Configurações para o LMS . . . . . . . . . . . . 69

Tabela 11 -Cenário 1 combinado - Configurações para o NLMS . . . . . . . . . . . 71

Tabela 12 - Cenário 2 combinado - Configurações para o NLMS . . . . . . . . . . . 74

Tabela 13 -Cenário 3 combinado - Configurações para o LMS . . . . . . . . . . . . 76

Tabela 14 - Cenário 3 combinado - Configurações para o NLMS . . . . . . . . . 78

Tabela 15 - Cenário 4 combinado - Configurações para o NLMS . . . . . . . . . . 81 


\section{Lista de abreviaturas e siglas}

ACT Air Change Temperature sensor (sensor de Mudança da Temperatura do Ar) AF Áudio Frequência

Anfavea Associação Nacional dos Fabricantes de Veículos Automotores

ARMA Auto Regressive Moving Average (Média Móvel Auto Regressiva)

BBC British Broadcasting Corporation (Corporação Britânica de Transmissão)

CKP Crankshaft Position sensor (sensor de Posição do Virabrequim)

CUT Central Única dos Trabalhadores

ECT Engine Coolant Temperature (sensor de Refrigeração da Temperatura do Motor)

ECU Engine Control Unit (Unidade de Controle do Motor)

EPUSP Escola Politécnica da Universidade de São Paulo

FATEC Faculdade de Tecnologia

Fenabrave Federação Nacional da Distribuição de Veículos Automotores

FIR Finite Impulse Response (Resposta Finita ao Impulso)

HEGO Heated Exhaust Gas Oxygen (sensor de Oxigênio Aquecido de Exaustão)

IIR Infinite Impulse Response (Resposta Infinita ao Impulso)

LMS Least Mean Square (Média de Mínimos Quadrados)

MAF Mass Air Flow (sensor de Fluxo da Massa de Ar)

MAP Manifold Absolute Pressure (sensor de Pressão Absoluta do Coletor)

MME Ministério de Minas e Energia

NLMS Normalized Least Mean Square (Média de Mínimos Quadrados Normalizada)

NO Número de Octano

NTC Negative Temperature Coefficient (Coeficiente Negativo de Temperatura)

PMI Ponto Morto Inferior

PMS Ponto Morto Superior

Proconve Programas de Controle de Emissões Veiculares

PZT Lead Zirconate Titanate (Titanato Zirconato de Chumbo)

RPM Rotações por Minuto

SAW Surface Acoustic Wave (Onda Acústica de Superfície)

SNR Signal to Noise Ratio (Relação Sinal Ruído)

TPS Throttle Position Sensor (Sensor de Posição da Válvula borboleta)

V8 Oito válvulas

VA Válvula de Admissão 
VD Válvula de Descarga

VSS Vehicle Speed Sensor (Sensor de Velocidade do Veículo)

VW Volkswagen 



\section{Sumário}

1 Relevância do Tema . . . . . . . . . . . . . . . . . . . . . 1

2 Objetivo Geral . . . . . . . . . . . . . . . . . . 3

3 Introdução teórica . . . . . . . . . . . . . . . . . . . . 4

3.1 Definições para a teoria de motores e sistemas de gerenciamento . . . . . . 4

3.2 Revisão do funcionamento dos motores ciclo Otto a 4 tempos . . . . . . . . 6

3.2 .1 Primeiro tempo: aspiração . . . . . . . . . . . . . . . . 7

3.2 .2 Segundo tempo: compressão . . . . . . . . . . . . . . . . 8

3.2.3 Terceiro tempo: combustão (expansão) . . . . . . . . . . . . 8

3.2.4 Quarto tempo: descarga . . . . . . . . . . . . . 10

3.3 Sistema de gerenciamento do motor . . . . . . . . . . . . . . 10

3.4 Combustão anormal: detonação e ignição de superfície . . . . . . . . . . . 14

3.4.1 Causa de combustão anormal (detonação) por avanço ou adiantamento de ignição . . . . . . . . . . . . . . . . . . 15

3.4.2 Causa de combustão anormal (ignição de superfície) por resíduos incandescentes ou alteração na estrutura geométrica do motor . . 19

3.4 .3 Ignição de superfície: efeitos . . . . . . . . . . . . . . . . . . 20

3.4 .4 Detonação: efeitos . . . . . . . . . . . . . . . . 21

3.4.5 Prevenções à combustão anormal . . . . . . . . . . . . . . . . 22

3.4.6 Formas de tratamento do fenômeno de detonação . . . . . . . . . . 23

3.5 Número de octanagem do combustível . . . . . . . . . . . . . . . 25

3.5.1 Definições . . . . . . . . . . . . . . . . . 25

3.5.2 Taxas de compressão e tipos de combustíveis . . . . . . . . . . 26

3.6 O Sensor de detonação ou knock sensor $(K S)$. . . . . . . . . . . . . . . . . 29

3.7 Processamento do sinal do sensor de detonação . . . . . . . . . . . . . . 32

3.7.1 Tópicos dos fundamentos de filtros adaptativos . . . . . . . . . . . 33

3.7 .2 Predição adaptativa . . . . . . . . . . . . . . . 36

3.7.3 Estimador de Potência . . . . . . . . . . . . . . . . . . 37

4 Metodologia . . . . . . . . . . . . . . . . . 39

4.1 Afirmação do problema . . . . . . . . . . . . . . . . . . 39

4.2 Resolução do problema proposto . . . . . . . . . . . . . . . . . . 40

4.2 .1 Modelamento do sinal de detonação . . . . . . . . . . . . . . . . . . 41

4.2.2 Escolha e aplicação dos algoritmos de tratamento de sinais . . . . . 47

4.2 .3 Método de teste dos algoritmos . . . . . . . . . . . . . 50 
5 Resultados e análises . . . . . . . . . . . . . . . . 53

5.1 Desempenho individual dos algoritmos propostos . . . . . . . . . 53

5.1.1 Cenário 1: caso normal de ocorrência de detonação . . . . . 53

5.1.2 Cenário 2: caso crítico de deteç̧ão do fenômeno . . . . . . 58

5.1.3 Cenário 3: detonação e ruído branco com amplitudes pró-

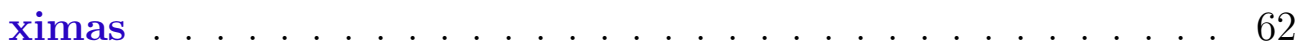

5.1.4 Cenário 4: sinal obtido de uma detonação real . . . . . . . 65

5.2 Desempenho combinado dos algoritmos propostos . . . . . . . . . 67

5.2.1 Cenário 1 combinado: caso normal de ocorrência de detonação . . . . . . . . . . . . . . . . . . . . . . . 69

5.2.2 Cenário 2: caso crítico de detecção do fenômeno . . . . . . . 73

5.2.3 Cenário 3: detonação e ruído branco com amplitudes pró-

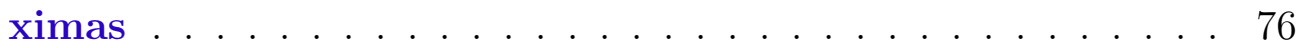

5.2.4 Cenário 4: sinal obtido de uma detonação real . . . . . . . 81

5.3 Comparação do método proposto com métodos existentes . . . . . . . . . 82

6 Conclusões e perspectivas . . . . . . . . . . . . . . . 89

6.1 Conclusões: simulações com o sinal modelado . . . . . . . . . . . . . . . 89

6.2 Conclusões: simulações com o sinal real . . . . . . . . . . . . . . . . . . . 91

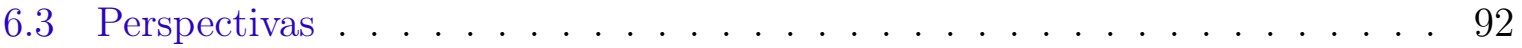

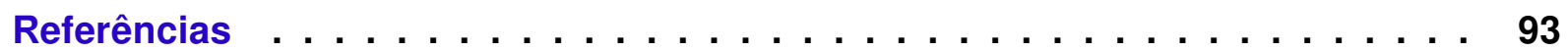

$\begin{array}{ll}\text { Apêndices } & 97\end{array}$

APÊNDICE A Códigos MATLAB $\ldots \ldots \ldots \ldots \ldots \ldots$

APÊNDICE B Especificações técnicas de um sensor de detonação comercial 122 


\section{Relevância do Tema}

O nosso planeta ultrapassou a quantidade de 1 bilhão de veículos automotores (carros, utilitários, ônibus e caminhões) em circulação (CHADE, 2013b).

No Brasil, os veículos em sua vida útil (de todos os tipos) percorrem anualmente uma média de $12.680 \mathrm{~km}$ cada um (BASTOS, 2011). Em 2012, consumiram cerca de 129,6 bilhões de litros de combustível (CHADE, 2013a) e emitiram mais de 71 milhões de toneladas de $\mathrm{CO}_{2}$ (UOL, 2013).

Nos últimos 20 anos, a tecnologia dos carros tem sido incrementada em boa parte com a introdução crescente da eletrônica nos mesmos. Isto tem se viabilizado graças ao custo decrescente dos componentes eletrônicos, principalmente, no que tange aos circuitos integrados (CI's) com integração cada vez maior.

O avanço tecnológico do carro que, por muitas décadas teve como preocupação principal o aumento da velocidade máxima, hoje tem como objetivo a dirigibilidade, a frenagem, o conforto, a durabilidade e também a segurança (AUTOMOTIVE-BUSINESS, 2011). No Brasil, dados da Fenabrave e Anfavea permitem concluir que a demanda por tecnologia também vem da mudança de perfil das exigências do consumidor, o que reflete em queda nas vendas de veículos de 1000 cilindradas, aumento das vendas de veículos com motorização mais potente, mais opcionais e acabamento mais sofisticado (CUT, 2011). Além disso, a preocupação com o meio ambiente se tornou um fator adicional de demanda de tecnologia como, por exemplo, o programa nacional Proconve e a série de normas européias da EURO5 (IBAMA, 2013; EUROPA.EU, 2013).

Em motores de combustão interna, os quesitos eficiência (economia de combustível e baixas emissões de poluentes) e desempenho (potência entregue ao usuário) são críticos para o usuário e para a estratégia das montadoras. Estes dois aliados aos últimos avanços tecnológicos em redução do tamanho dos motores (BBC, 2012), são diretamente afetados pelo fenômeno de detonação, que é um tipo de combustão anormal, o qual pode inclusive danificar o motor de forma permanente (HEYWOOD, 1988). A detonação ocorre sob altos níveis de pressão (HEYWOOD, 1988), o que é um fator característico em motores de tamanho reduzido, por conta da redução do volume interno das câmaras de combustão destes. Esta restrição também se aplica ao torque máximo que o motor pode fornecer com os combustíveis de mercado. Para cobrir os pontos básicos da teoria relacionada a motores, o funcionamento do ciclo Otto, assim como a teoria de combustão anormal, serão descritas nas seções 3.2 e 3.4, respectivamente.

O estudo de tal fenômeno possui outro caráter especial em nosso país por conta dos motores Flex, os quais funcionam movidos a etanol e/ou a gasolina. Estratégias alternati- 
vas de gerenciamento do motor podem ser definidas utilizando o fenômeno de detonação como parâmetro de otimização. A identificação precisa da ocorrência e as características do fenômeno possibilitam identificar o tipo de combustível utilizado, minimizar o consumo realizado pelo motor, aumentar a potência entregue e reduzir suas emissões de poluentes. A distinção entre combustíveis utilizados, possibilitada pelo fenômeno de detonação, deve-se às diferentes taxas de compressão que o etanol e a gasolina possuem, como poderá ser observado na seção 3.5. A exploração da potência, eficiência e redução de emissões do motor residem no conhecimento de quando e como o fenômeno de detonação pode ocorrer (seus diferentes níveis de intensidade e duração), será mostrado na seção 3.4.1. No entanto, identificar a ocorrência do fenômeno não é algo trivial a princípio. Por esta razão, a seção 3.7 abordará os fundamentos das técnicas que estão sendo propostas neste trabalho para desenvolver tais caracterizadores da ocorrência da detonação.

Pelo contexto supracitado e nas justificativas que serão dadas no decorrer deste trabalho, ficará claro que ainda é válido melhorar o desempenho dos motores à combustão interna tendo em vista também o potencial que estes ainda apresentam em nosso país em função da importância do etanol na matriz energética nacional (MME et al., 2013).

No Brasil, apesar dos já citados motores Flex e maior participação do mercado brasileiro nas estratégias globais das montadoras de veículos, a nossa dependência tecnológica no que se refere ao desenvolvimento de alguns segmentos ainda é muito grande (KUTNEY, 2013b). Apesar de algumas empresas do setor já possuírem centros de competência instalados em território nacional ou participar de forma significativa em projetos globais (KUTNEY, 2012; MERCEDES-BENZ, 2012; AUTOMOTIVE-BUSINESS, 2012), é comum nas indústrias de autopeças, por exemplo, as plataformas de hardware e software das unidades eletrônicas (sejam elas de gerenciamento de motores ou qualquer outro módulo eletrônico) serem desenvolvidas no exterior na maioria dos projetos, ocorrendo no Brasil apenas ajustes e/ou testes durante o processo de desenvolvimento (KUTNEY, 2013a). A falta de profissionais especialistas é muito grande (BASTIAN, 2013; FRANCO, 2013), fator que reforça o fato da necessidade de mais pesquisas voltadas para a área automotiva, como este estudo que será apresentado, em nosso país. 


\section{Objetivo Geral}

Este trabalho faz parte de uma série de estudos voltados para o gerenciamento de motores de combustão realizados pelo grupo de eletrônica automotiva composto de profissionais da indústria automotiva, alunos e professores da Escola Politécnica da Universidade de São Paulo e da Faculdade de Tecnologia de Santo André. O objetivo deste trabalho é encontrar um algoritmo que possa ser utilizado para caracterizar a ocorrência do fenômeno de detonação e seus diferentes perfis. Tal caracterização será feita utilizando técnicas de processamento de sinais, como filtros adaptativos e estimadores de potência, os quais terão seu desempenho comparado às técnicas já existentes, com o intuito de se explorar a viabilidade e robustez dos mesmos para uma possível aplicação em sistemas microprocessados e/ou microcontrolados. 


\section{Introdução teórica}

Neste capítulo estão contidas as seções que visam apresentar a teoria envolvida ao tema deste trabalho, tanto de forma descritiva como referenciada para o embasamento teórico necessário à compreensão do próximo capítulo onde o problema é estabelecido, assim como o método proposto para sua solução.

\subsection{Definições para a teoria de motores e sistemas de geren- ciamento}

Nesta seção estão definidos os termos necessários à compreensão do texto a seguir referente a motores e sistemas de gerenciamento.

\section{- Marcha lenta}

Modo de funcionamento do motor de combustão onde o mesmo funciona a rotações não superiores a 1000 RPM e sem carga mecânica.

\section{- Mistura}

É o composto de ar misturado com combustível. Neste composto, o ar é misturado com o combustível pulverizado, processo que ocorre no momento de injeção da mistura, como será explicado no próximo item. Quando a mistura possui quantidade de oxigênio suficiente para queimar todo o combustível, esta é chamada de mistura estequiométrica ou ideal. A mistura é dita rica quando possui mais combustível do que a mistura estequiométrica. Ao passo que a mistura é dita pobre quando possui mais ar do que a estequeométrica (MANAVELLA, 2000; PENIDO, 1991).

\section{- Válvula de admissão}

A válvula de admissão (VA) é o atuador que se abre por comando mecânico para que a mistura seja succionada para o interior do curso do cilindro.

\section{- Válvula de descarga ou exaustão}

A válvula de descarga ou exaustão (VD) é o atuador que se abre por comando mecânico após a abertura da válvula de admissão e ocorrência de combustão da mistura, a qual será explanada nos próximos itens.

\section{- Câmara de Combustão}

É o espaço compreendido entre a parte superior do cilindro, no seu ponto morto superior, e o local onde é fixado o centelhador (mais detalhes em 3.3). Na câmara 
de combustão ocorrem a compressão, a queima e o final da exaustão ou descarga da mistura admitida pela válvula de admissão.

\section{- Injeção}

É o processo em que a válvula de injeção (explicada na seção 3.3) é aberta sob o comando da unidade de gerenciamento do motor. Esta abertura ocorre quando a válvula de admissão é acionada e com isso, o combustível é pulverizado (pela válvula de injenção) na corrente de ar que neste momento está sendo succionada para o interior do curso do pistão. Sucção que ocorre devido ao vácuo criado por conta do deslocamento do pistão em direção ao ponto morto inferior. Desta forma, ocorre a mistura de ar com combustível mencionada anteriormente.

O processo mencionado refere-se ao caso de injeção indireta, no qual a mistura ocorre fora da câmara de combustão. Quando a injeção de combustível é dada diretamente no interior da câmara de combustão, o processo é chamado de injeção direta, o qual é mais eficiente do que o de injeção indireta, pois neste todo o combustível é utilizado na combustão, ao passo que no processo de injeção indireta parte do combustível se perde por ser pulverizado na parte anterior da válvula de admissão.

\section{- Virabrequim}

É o eixo que interliga todos os pistões do motor. O virabrequim é o eixo que transmite o movimento feito pelos pistões às rodas do veículo.

\section{- Banco de cilindros}

É o conjunto de cilindros que movem-se ao mesmo tempo durante o processo de combustão ou rotação do virabrequim. Os cilindros pertencentes a um determinado banco admitem a mistura a cada volta, assim como o acionamento de suas respectivas bobinas de ignição.

\section{- Bobina de Ignição}

Componente do módulo de potência responsável por transformar baixa tensão em alta tensão. Alimenta o centelhador, o qual é responsável pela ignição.

\section{- Ignição}

É o ato de se gerar a faísca (mais detalhes em 3.3) que inicia o processo de combustão ou queima da mistura. Tal faísca ou centelha, é produto da energização da bobina de ignição.

\section{- Avanço de Ignição}

É o processo de realização da ignição antes que o pistão atinja o ponto morto superior (PMS). A Figura 1a mostra o momento em que um avanço de ignição de $10^{\circ}$ é dado.

\section{- Retardo de Ignição}

É o processo de realização da ignição após o momento em que o pistão atingiu o 
ponto morto superior (PMS). A Figura 1b mostra o momento em que um retardo de ignição de $10^{\circ}$ é dado.

Figura 1 - a) Avanço de ignição b) Retardo de ignição.

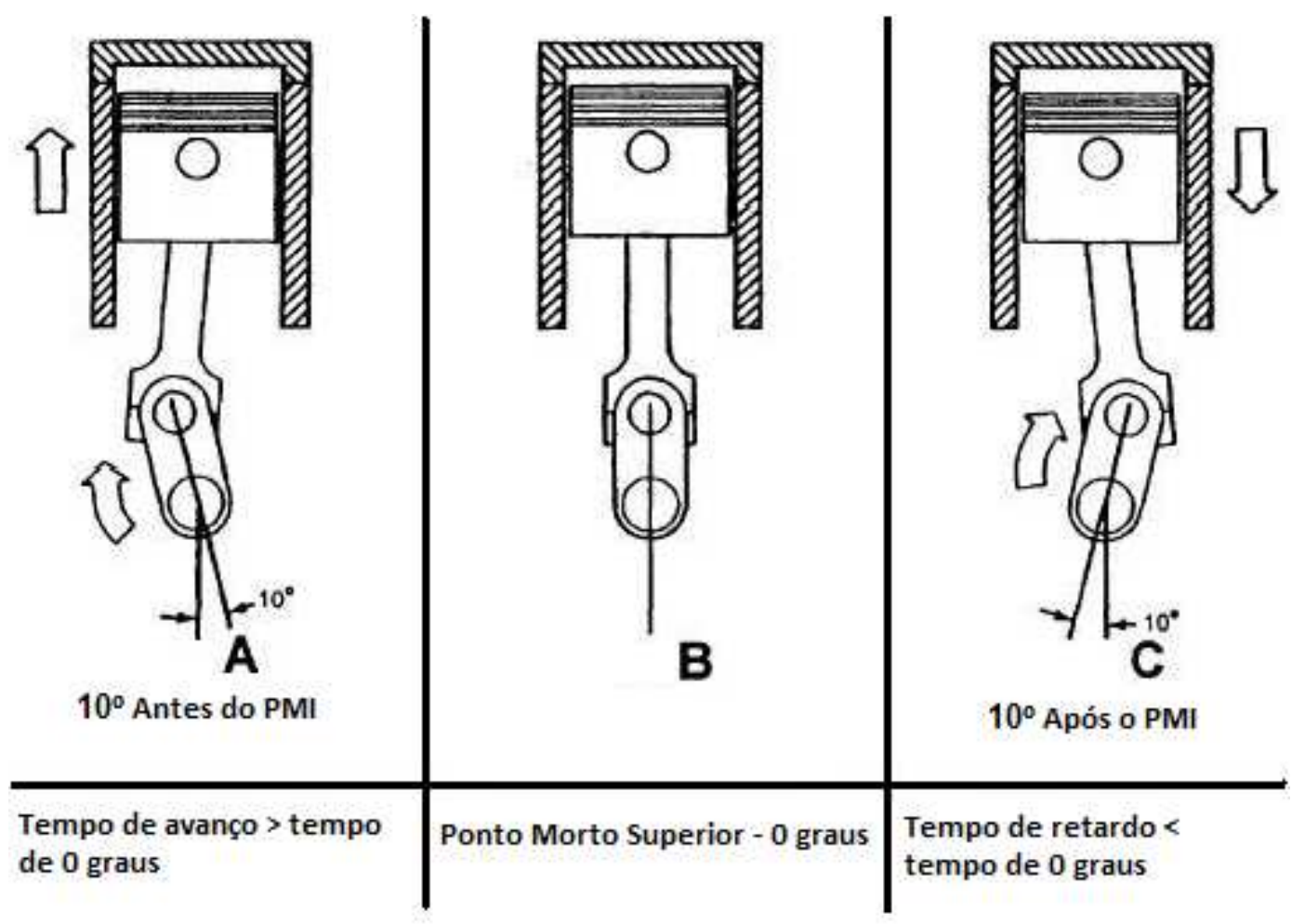

Fonte: Autor.

\subsection{Revisão do funcionamento dos motores ciclo Otto a 4 tem- pos}

Os motores de ciclo Otto a 4 tempos são os mais utilizados em veículos automotores.

Segundo (PENIDO, 1991) o ciclo dos motores de ciclo Otto a 4 tempos é composto de 4 fases em que cada uma é chamada de "tempo"do motor. Portanto, os respectivos 4 tempos dos motores em questão, representados na figura 2, são:

$$
\begin{aligned}
& 1^{\underline{O}} \text { tempo - aspiração } \\
& 2^{\underline{O}} \text { tempo - compressão } \\
& 3^{\underline{O}} \text { tempo - combustão } \\
& 4^{\underline{O}} \text { tempo - descarga }
\end{aligned}
$$


Figura 2 - Os quatro tempos do ciclo Otto de combustão.
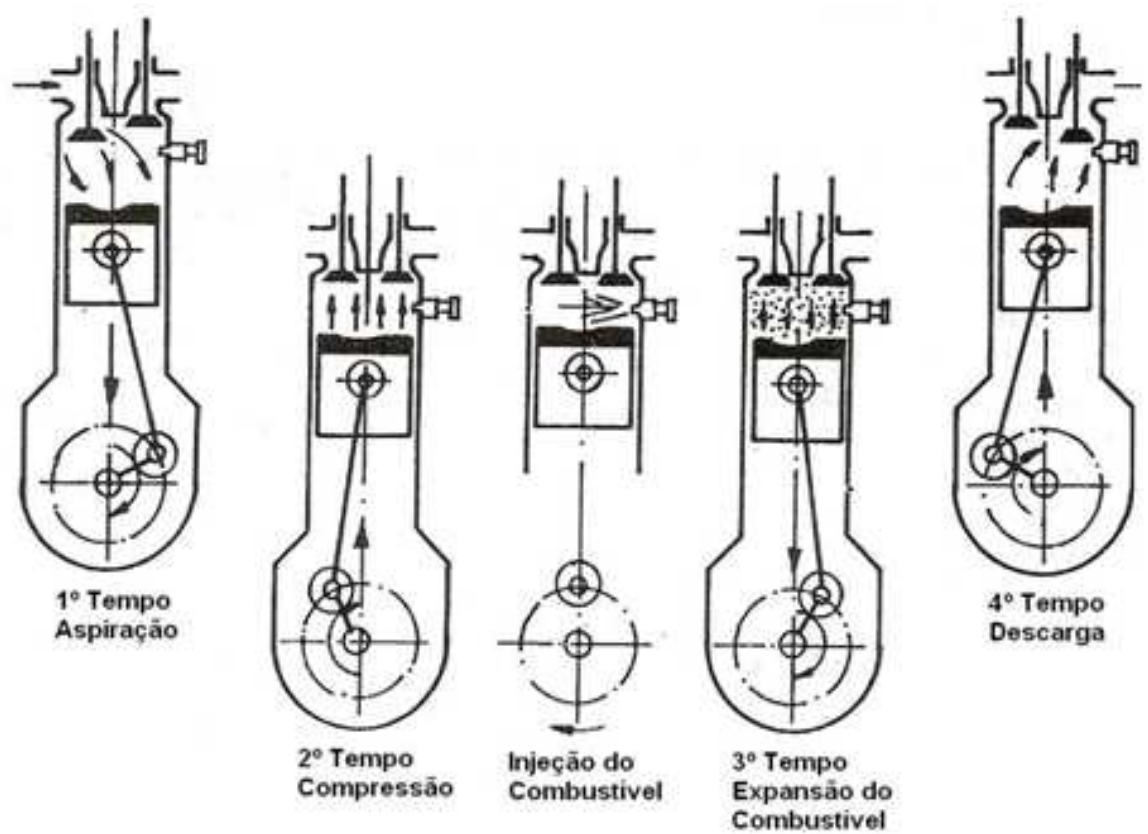

Fonte: (PENIDO, 1991).

\subsubsection{Primeiro tempo: aspiração}

Na fase de aspiração, o deslocamento do pistão do ponto morto superior (PMS) ao ponto morto inferior (PMI) cria uma depressão no interior da câmara, fazendo com que a mistura seja aspirada através da válvula de admissão (Figura 3).

Figura 3 - Primeiro tempo: aspiração.

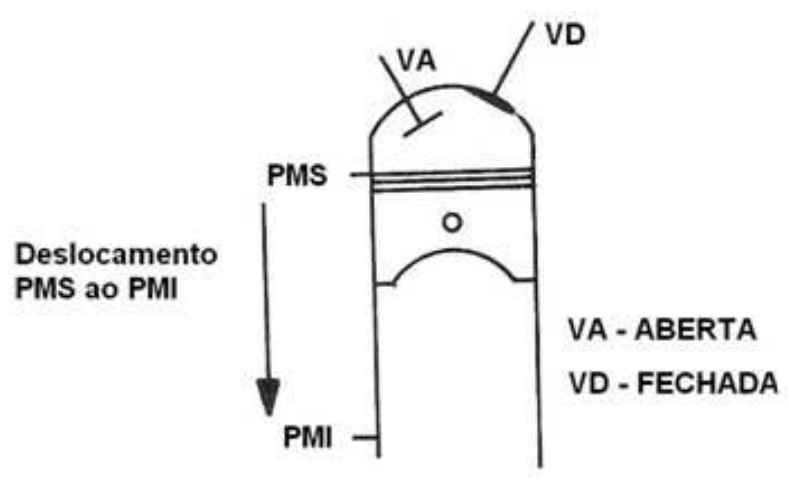

Fonte: (PENIDO, 1991). 


\subsubsection{Segundo tempo: compressão}

Na fase de compressão, após o fechamento da válvula de admissão, o pistão se desloca do PMI ao PMS, comprimindo a mistura na câmara de combustão (Figura 4).

Figura 4 - Segundo tempo: compressão.

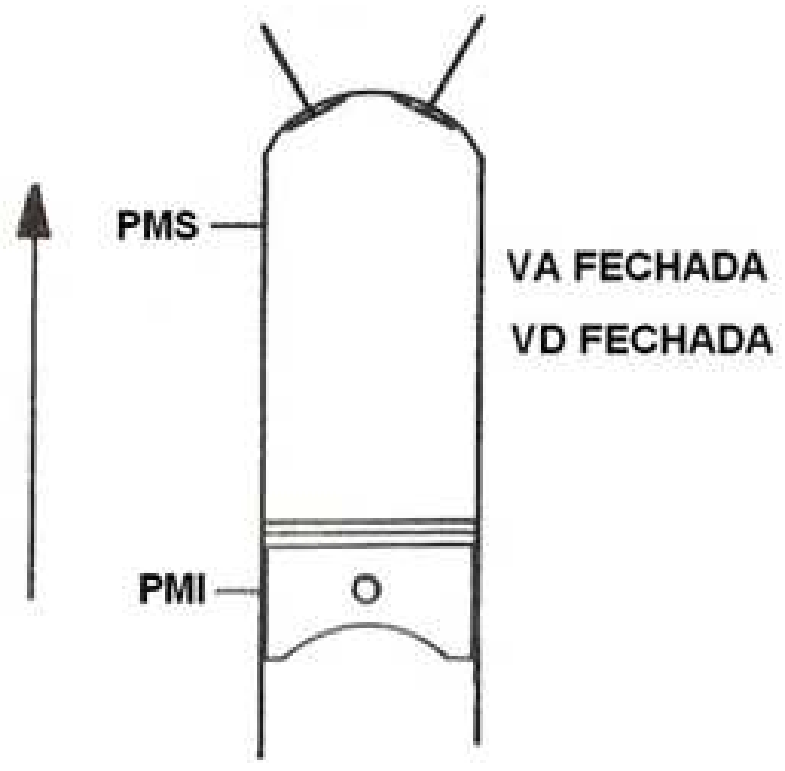

Fonte: (PENIDO, 1991).

\subsubsection{Terceiro tempo: combustão (expansão)}

Um pouco antes de o pistão atingir o PMS, uma centelha elétrica (ignição) ocorre entre os eletrodos da vela, dando início à combustão da mistura comprimida.

A temperatura dos gases cresce rapidamente, aumentado assim a pressão no interior da câmara, a qual empurrará o pistão para baixo, fazendo com que este retorne ao PMI (Figura 5). 
Figura 5 - Terceiro tempo: expansão.

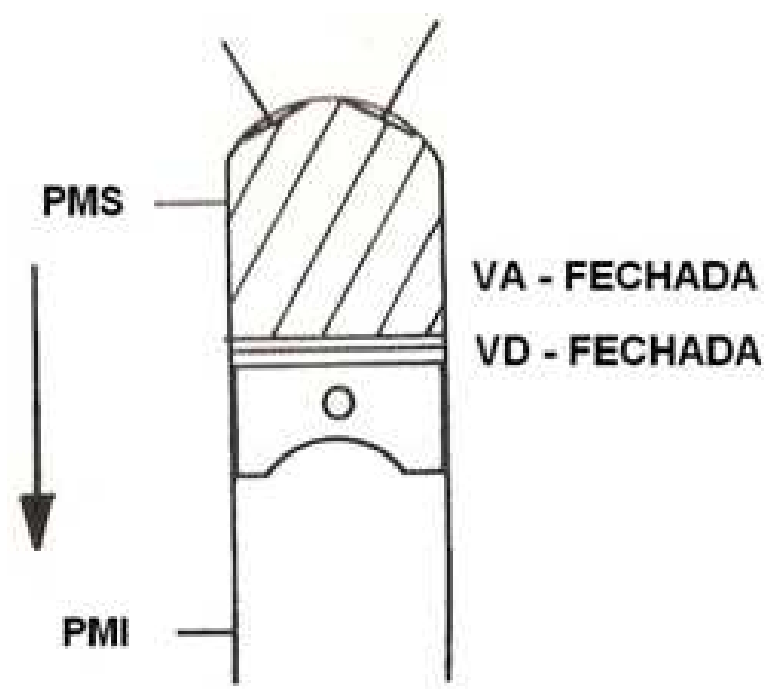

Fonte (PENIDO, 1991).

Figura 6 - Quarto tempo: descarga.

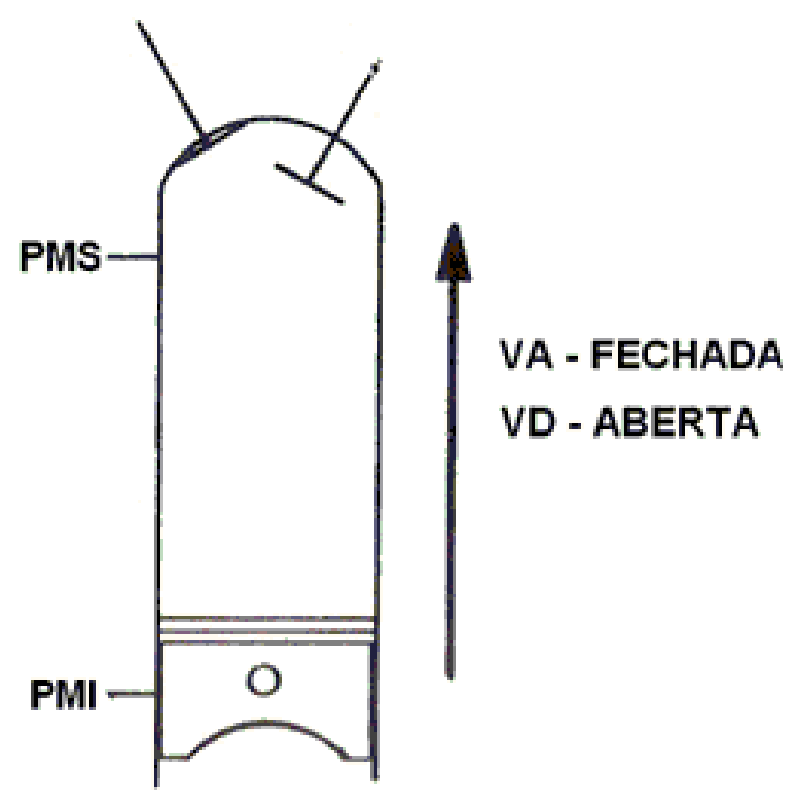

Fonte: (PENIDO, 1991). 


\subsubsection{Quarto tempo: descarga}

Um pouco antes de o pistão atingir o PMI, a válvula de descarga se abre, e os gases da combustão, que ainda estão a certa pressão, começam espontaneamente a sair.

Por conta de seu movimento, o pistão recém acionado é capaz de retornar ao PMS, expulsando assim, o restante dos gases queimados. O quarto tempo está representado na Figura 6.

Nota: A energia ativa fornecida ao pistão durante a fase de combustão, é transferida ao volante do motor na forma de energia cinética. Esta também é transferida às outras três fases passivas (aspiração, descarga e compressão).

\subsection{Sistema de gerenciamento do motor}

Antes de entrar no tema detonação, é interessante conhecer o sistema em que este ocorre, seus componentes e como estes interagem entre si para que o motor excerça seu papel motriz.

A Figura 7 mostra os componentes presentes em um sistema de gerenciamento de motor sem aplicação específica (não pertence a um veículo específico). A mesma serve como referência para identificarmos como o motor excerce suas funções interagindo com estes componentes.

Basicamente, a unidade de gerenciamento do motor ou engine control unit (ECU) é responsável por garantir a dosagem precisa da mistura a ser injetada nas câmaras de combustão de cada pistão. Por conta desta necessidade básica, a $E C U$ deve receber informações que possibilitem o cálculo da massa da mistura a ser injetada ou mesmo uma informação direta da tal massa (MANAVELLA, 2000; ALBALADEJO, 2013).

Os componentes ilustrados na figura estão descritos a seguir:

- Sensor de temperatura do motor - ECT

É um resistor $N T C$ em que sua resistência aumenta conforme a temperatura diminui. De forma resumida, este sensor auxilia em:

$\rightarrow$ Controlar a rotação de marcha lenta;

$\rightarrow$ Ajustar a relação ar-combustível da mistura;

$\rightarrow$ Determinar o avanço ideal de ignição;

- Sensor de rotação do motor - CKP

É o sensor que fornece um sinal de pulsos para a $E C U$. Cada pulso corresponde à leitura de um dente da roda dentada. Este sensor auxilia em:

$\rightarrow$ Controle do momento de atuação da ignição baseado na rotação do motor; 
Figura 7 - Sistema de injeção / ignição simplificado

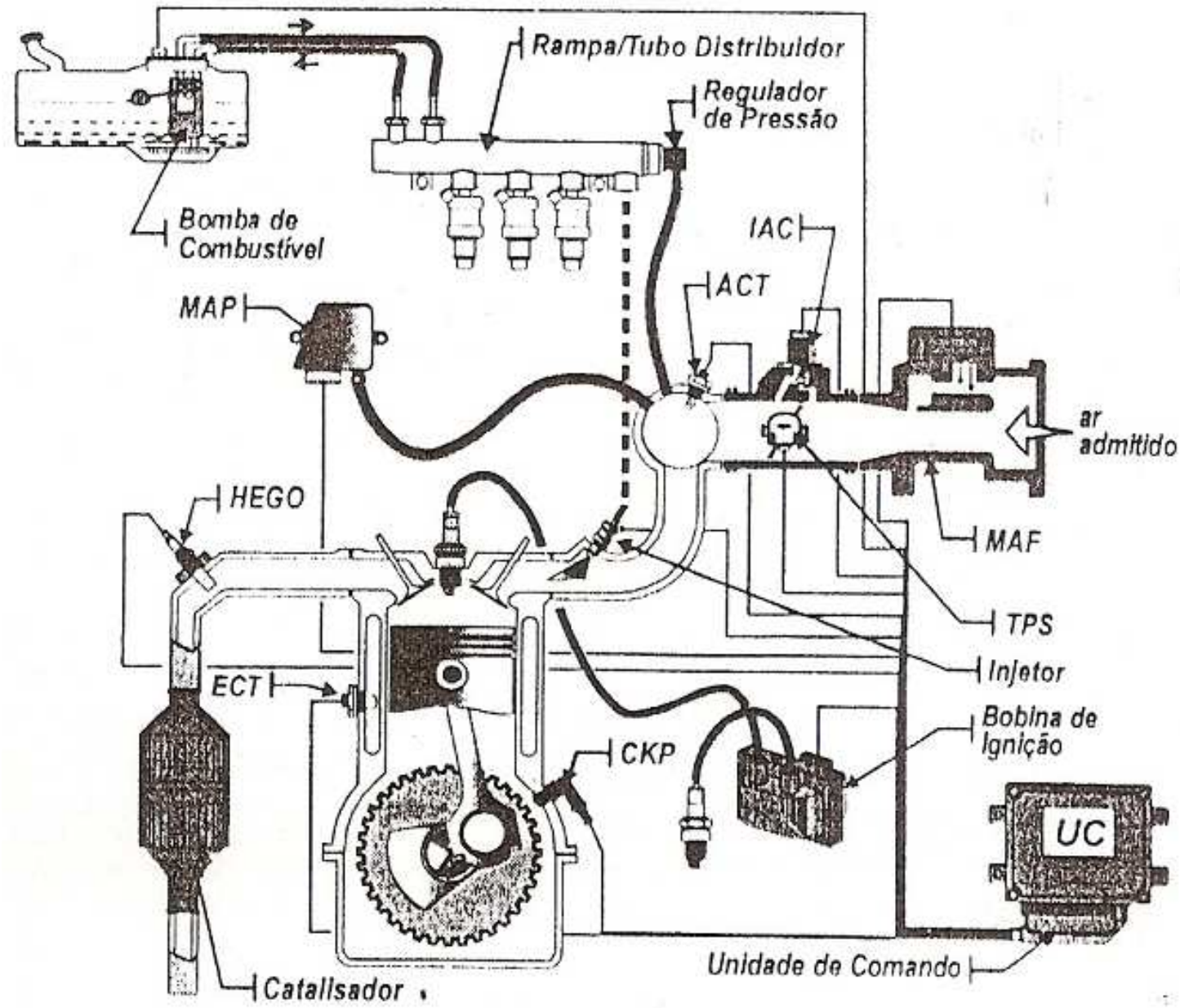

Fonte: (MANAVELLA, 2000).

$\rightarrow$ Controle do momento de injeção do combustível;

- Roda dentada ou roda fônica

É um disco metálico dentado acoplado ao virabrequim do motor. A roda dentada possui 58 dentes e uma falha correspondente a 2 dentes. Este dispositivo auxilia no sincronismo dos pulsos de controle de injeção e ignição com o movimento do pistão. Por meio desta, a $E C U$ sabe o momento em que um banco de cilindros está em seu PMS (ALBALADEJO, 2013).

- Sensor de posição da válvula de aceleração - TPS

É um potenciômetro que gira conforme a abertura da válvula borboleta e desta forma indica o ângulo de abertura da mesma. O mesmo é utilizado como retorno de sinal à $E C U$ para que o controle de malha fechada possa ser feito. Este sensor auxilia em: 
$\rightarrow$ Calcular a vazão do fluido (mistura) que passa pela válvula borboleta, conforme mostrado em (ALBALADEJO, 2013).

$\rightarrow$ Possibilitar o cálculo da vazão (por fornecer a área livre à passagem de ar) e auxiliar no cálculo de massa de ar admitida;

$\rightarrow$ Ajustar o momento de ignição, dependendo dos valores mencionados anteriormente.

$\rightarrow$ Controlar a mistura ar -combustível atuando na abertura da válvula borboleta.

- Sensor de pressão absoluta do coletor de admissão - MAP

São sensores piezoelétricos (mais detalhes na seção 3.6) que mediante alteração da pressão no coletor de admissão (a qual ocorre por conta da abertura ou fechamento da válvula borboleta) têm sua resistência alterada e por consequência o valor de tensão fornecido à $E C U$. Portanto, são provedores da informação do valor de pressão. Este sensor auxilia no:

$\rightarrow$ Cálculo da carga do motor em conjunto com os dados obtidos do sensor TPS, (por fornecer a informação de pressão, necessária ao cálculo da vazão);

$\rightarrow$ Ajuste do momento de ignição, o qual depende dos valores mencionados no último item e por isso também auxilia na atuação da ignição;

$\rightarrow$ Controle da mistura ar-combustível atuando na abertura da válvula borboleta.

- Sensor de temperatura do ar admitido - $A C T$

É um sensor do tipo $N T C$, geralmente acoplado ao sensor $M A P$. Este sensor auxilia em:

$\rightarrow$ Controlar a relação ar-combustível;

$\rightarrow$ Prover informação ao cálculo da densidade do ar;

$\rightarrow$ Ajustar o ponto de ignição de acordo com as informações acima.

- Sensor da massa de ar admitida - $M A F$

É um sensor que fornece de forma direta a massa do ar sendo admitida. Com o sensor $M A F$ não é necessário realizar cálculos para se determinar o valor da massa de ar por meio dos dados de outros sensores.

- Sensor de oxigênio (sonda lambda) - HEGO

Está instalado na tubulação de escape dos gases. Informa à $E C U$ a quantidade de oxigênio presente nos gases provenientes da combustão. Permite que a unidade de controle detecte se a mistura está rica ou pobre. Portanto, a informação deste sensor 
é utilizada pela $E C U$ para a dosagem de combustível no interior das câmaras de combustão.

- Sensor de velocidade - VSS

Este sensor fornece um sinal pulsado à $E C U$ cuja variação de frequência indica a velocidade. Geralmente é instalado na saída da transmissão ou no eixo do velocímetro.

- Válvula borboleta

É uma válvula de abertura ou fechamento gradual. Sob o comando da $E C U$, permite ou bloqueia a passagem do ar admitido (através da parte frontal do veículo) para o interior das câmaras de combustão.

- Válvula de injeção

É uma válvula solenóide que abre ou fecha totalmente para que seja feita a dosagem de combustível a ser pulverizada no interior da câmara de combustão. O posicionamento desta válvula deve permitir que o combustível a ser injetado seja pulverizado na mesma direção da corrente de ar que se dirige para o interior da câmara. Desta maneira, a mistura é formada. O tempo de abertura desta válvula é chamado de tempo de injeção.

- Bomba de combustível

É o componente que succiona o combustível do reservatório para encher o distribuidor para assim alimentar o injetor sob o comando da $E C U$. Em alguns sistemas, a bomba de combustível é acionada no momento em que a chave é girada sem partida do motor para que a linha de alimentação do distribuidor seja pressurizada.

Os sensores mencionados fornecem as informações necessárias para que a $E C U$ calcule a quantidade de mistura a ser injetada $(M A P, T P S)$, saiba a eficiência da combustão (sonda lambda) e como obter a quantia desejada de torque (ponto de ignição e ajuste de injeção). O gerenciamento do motor é baseado em grande parte no tempo de injeção, o qual depende da massa de ar admitida, rotação do motor, temperatura da água, da carga a qual o motor está submetido e do tipo de mistura (por conta da sonda lambda) (MANAVELLA, 2000; ALBALADEJO, 2013).

Em ciclos normais de combustão, após a explosão, a chama gerada se propaga com forma e velocidade constantes por toda a câmara. Tal forma de propagação possibilita a movimentação do cilindro sem excesso de vibração. No entanto, quando há o fenômeno de combustão anormal, este processo mecânico não ocorre e a eficiência da combustão é perdida, além de que a vida útil do motor pode ser reduzida. 


\subsection{Combustão anormal: detonação e ignição de superfície}

De acordo com (HEYWOOD, 1988) os principais ou mais comuns fenômenos de combustão anormal são: a detonação e a ignição da superfície. Quando ocorrem, estes fenômenos anormais de combustão podem, se severos, causar grandes danos ao motor. Caso não sejam severos, eles comprometem o desempenho e podem ser uma fonte de ruído desagradável.

Detonação ou knock é o nome dado ao fenômeno de combustão anormal caracterizado pela vibração acústica proveniente da propagação de ondas de choque que ocorreram no interior da câmara de combustão através da estrutura do motor. Isto pode acontecer quando há ignição espontânea nos gases resultantes de combustões anteriores (gás residual, ou seja, a mistura frente à chama que está sendo propagada devido à centelha), onde há uma extrema liberação de energia química vinda dos gases residuais, causando picos locais de pressão com altas amplitudes, os quais se propagam através das paredes do motor.

A ignição de superfície é a combustão da mistura ar - combustível causada por um ponto isolado com temperatura acima do restante do interior da câmara de combustão, tal como velas ou válvulas sobreaquecidas ou depósitos incandescentes. Esta pode ocorrer antes (pré ignição) ou depois (pós ignição) da centelha.

Ambos os fenômenos citados são classificados como ignição espontânea ou autoignição. Estes dois termos serão utilizados de forma indiferente neste trabalho.

A Figura 8 representa o resumo das formas de manifestação de combustão anormal a serem abordadas neste trabalho. Os itens mencionados nestas, serão descritos a seguir. Os ícones elipsoidais representam eventos participantes do processo de combustão anormal, enquanto que os ícones retangulares representam manifestações da mesma. 
Figura 8 - Resumo das características envolvidas no fenômeno de combustão anormal

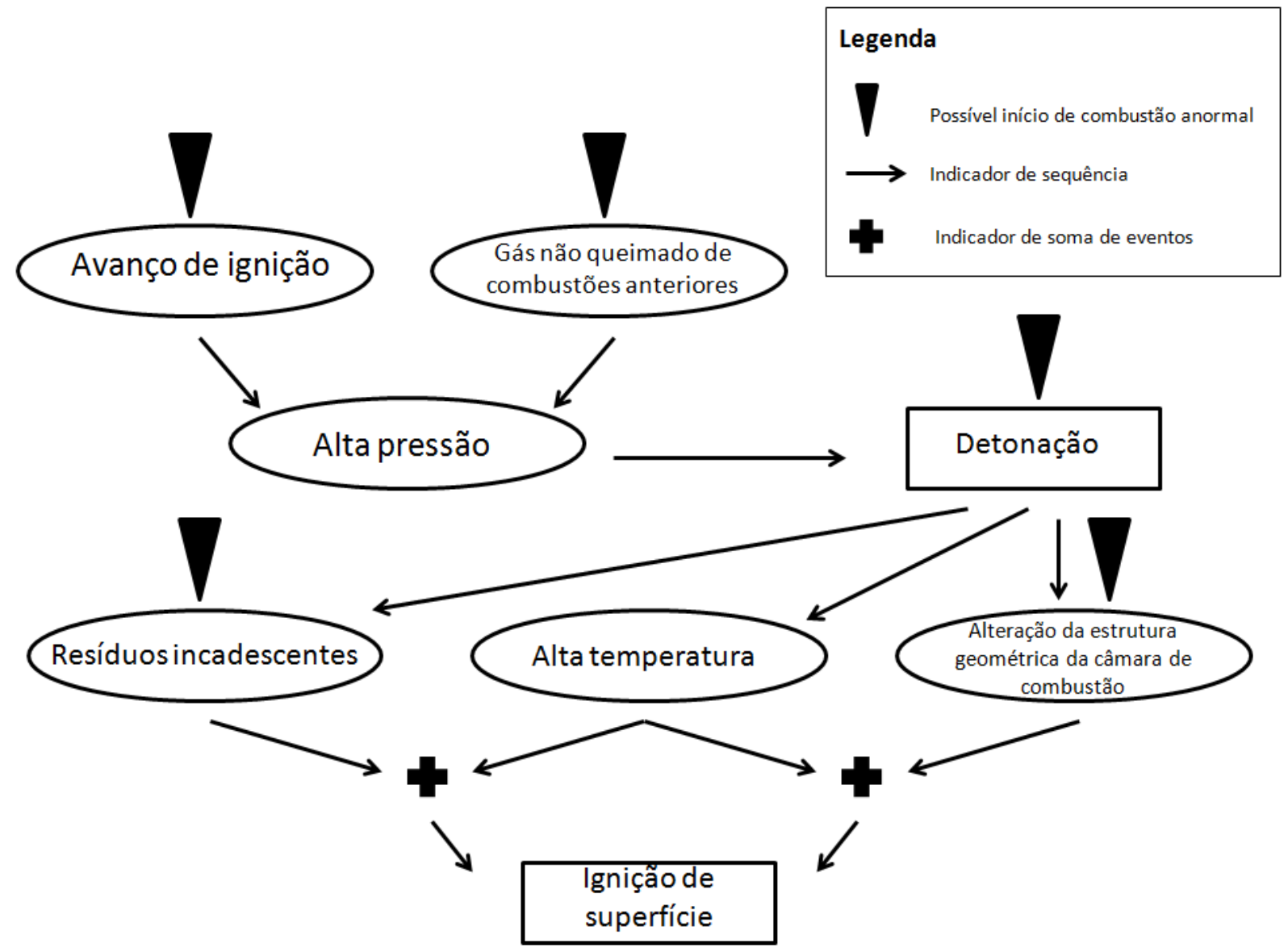

Fonte: Autor.

\subsubsection{Causa de combustão anormal (detonação) por avanço ou adianta- mento de ignição}

Quando a autoignição ocorre repetidamente, o fenômeno é chamado detonação por centelha. A detonação por centelha é controlável pelo avanço da mesma: adiantando o instante em que a centelha é acionada, faz com que a severidade da detonação aumente, ao passo que retardando o mesmo, diminui-se a ocorrência de tal fenômeno. Além destes, a detonação por centelha pode ser influenciada por carga elevada no motor em baixa rotação e temperatura elevada da mistura (PENIDO, 1991).

A Figura 9, do autor (PENIDO, 1991), mostra a representação de uma câmara de combustão ocupada por uma mistura sendo consumida por um processo de combustão seguido de detonação. A massa "MC" representa a mistura já queimada por conta do acionamento da centelha e a outra massa designada por " $\mathrm{M}$ ", representa a soma do 
Figura 9 - Esquemático de propagação das chamas nas detonações por centelha.

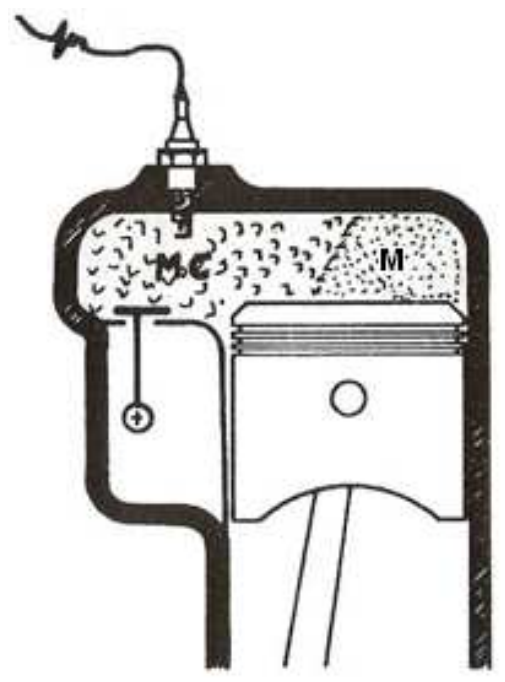

Fonte: (PENIDO, 1991).

restante da mistura ainda não consumida pela chama com gases provenientes de combustões anteriores e que não foram eliminados durante tais processos. Com o acionamento da centelha, a massa MC passou a ser consumida pela chama e com isso se propaga para a direita. O cilindro, por sua vez, move-se em direção ao PMS (por conta da inércia do movimento anterior). A pressão proveniente do deslocamento da chama (MC), somada à pressão dada pela redução do volume da câmara (por conta do movimento do cilindro em direção ao PMS), resultam em um nível de pressão muito maior que o de ciclos normais de combustão, fazendo assim, com que a massa $M$ exploda, ocasionando desta forma, uma segunda frente de chama que se propaga em direção oposta à chama MC. O encontro entre estas duas chamas, geram picos de pressão no interior da câmara, picos que são propagados como ondas de choque por toda a estrutura do motor, as quais possuem uma frequência audível. Tal frequência gera um som que é característico da ocorrência do fenômeno. Segundo (PENIDO, 1991), a detonação ocorre em uma fração de $4 \%$ a $8 \%$ da mistura.

A Figura 10 mostra uma imagem real de como uma autoignição pode ocorrer no interior da câmara de combustão.

De forma simples pode-se explicar o porquê do avanço de ignição resultar em maiores pressões no interior da câmara de combustão e, consequentemente, maior torque. Primeiramente, recorreremos à equação (3.1) e à Figura 11 extraídas de (KIENCKE; 
Figura 10 - Imagens ciclo a ciclo da ocorrência de auto ignição no interior da câmara de combustão.

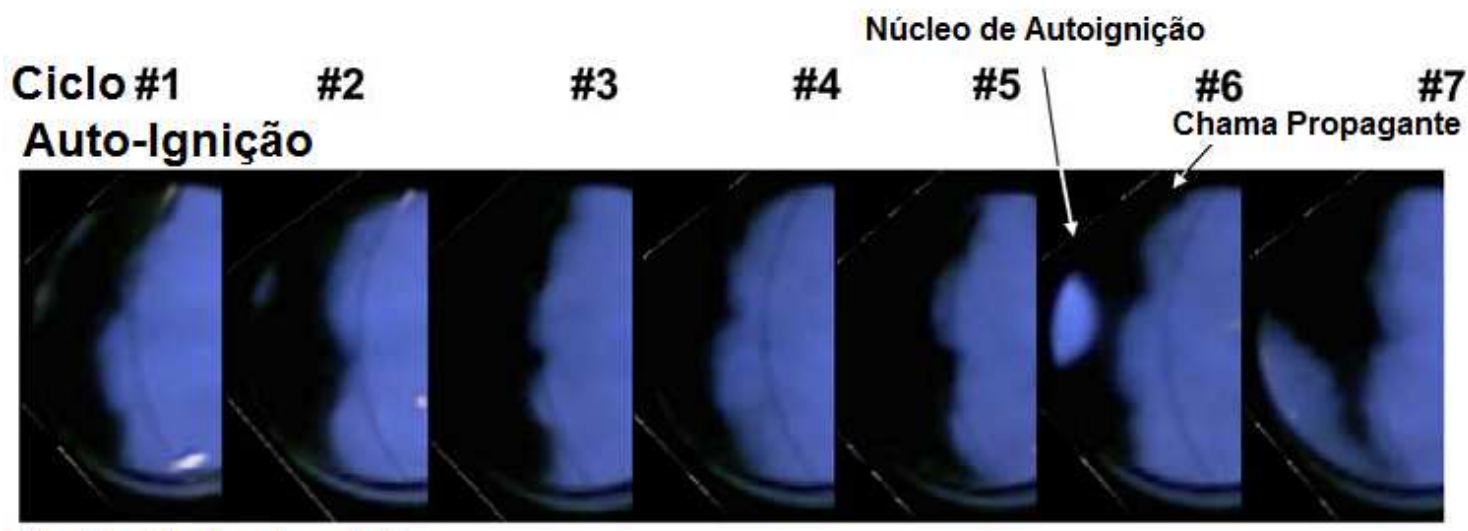

\section{Após Auto-Ignição}

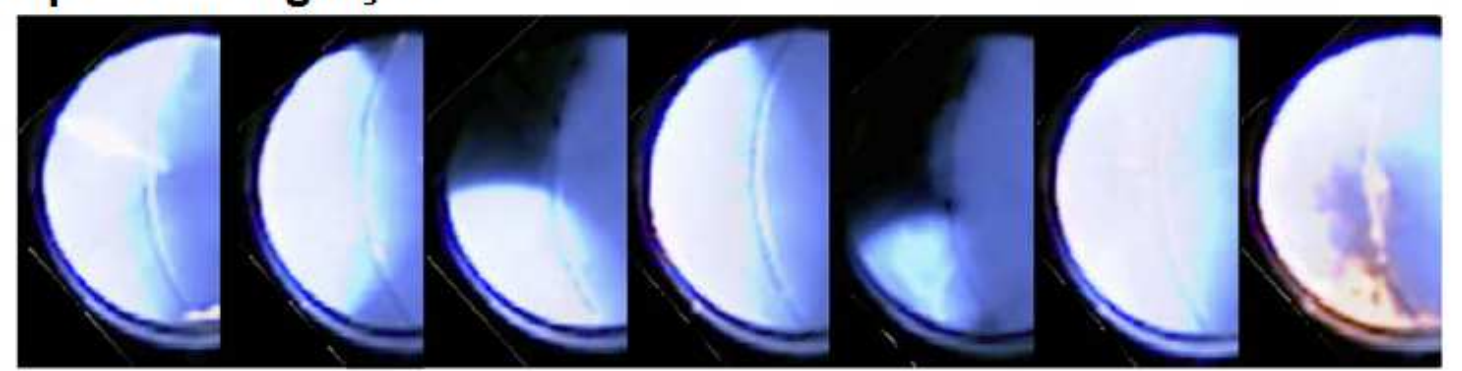

Fonte: Adaptado de (KAWAHARA; TOMITA, 2009).

NIELSEN, 2005) para entender como tal processo ocorre.

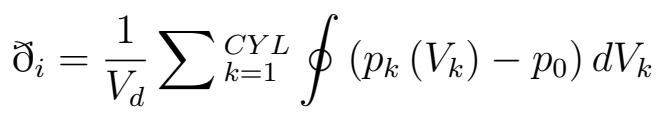

na qual:

$V_{d}=C Y L\left(V_{1}-V_{2}\right)$ é o volume de deslocamento de todos os cilindros; $C Y L$ é o número de cilindros e ð̃ é o trabalho específico (normalizado). O índice $i$ denota iteração.

Na equação (3.1), tem-se o trabalho específico obtido pela integração da pressão desenvolvida por variação do volume. Esta integral serve para mostrar que quanto maior for a diferença entre a pressão inicial $p_{0}$ e a final, $p_{j}$, desenvolvida por volume instântaneo $V_{j}$, maior será o trabalho específico desenvolvido e por conseguinte o torque, como pode ser visto em (KIENCKE; NIELSEN, 2005). Tendo dito isto, analisemos o perfil de pressão desenvolvida em uma determinada câmara de combustão do cilindro $k$ observando a Figura 11. Tendo a ignição dada no instante $\alpha_{i}$ (supondo que este seja o ponto em que a combustão ocorra no instante em que há menor volume no interior da câmara, em outras palavras, 
Figura 11 - Pressão no interior da câmara em função do ângulo de ignição $\alpha$.

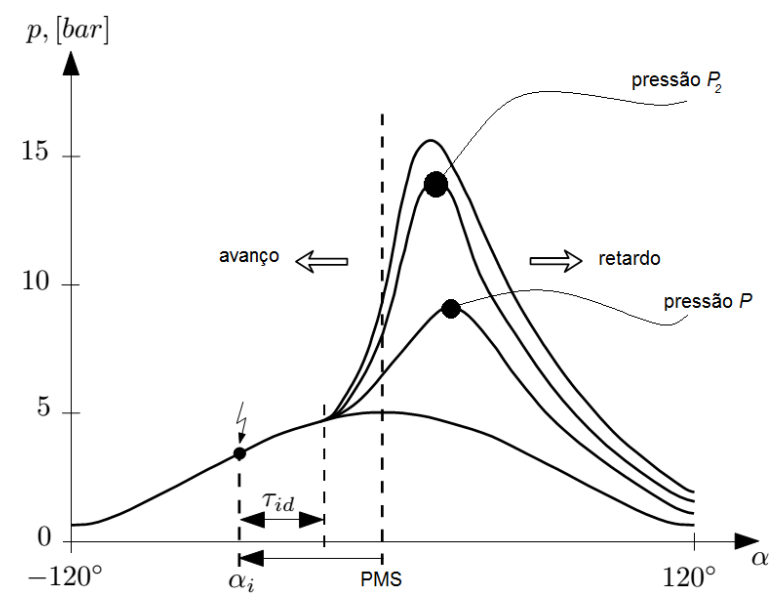

Fonte: Adaptado de (KIENCKE; NIELSEN, 2005).

no PMS), um tempo de combustão da mistura e propagação da chama é tomado e com duração $\tau_{i}$. Tal duração é dependente de vários fatores como temperatura, pressão, tipo de combustível e outros fatores, como pode ser conferido em (KIENCKE; NIELSEN, 2005). Conforme a centelha é dada antes do instante $i$, um perfil maior de pressão é observado, devido à seguinte equação:

$$
\frac{P V}{T}=\text { constante }
$$

na qual,

$P$ é a pressão, $V$ representa o volume e $T$ refere-se à temperatura.

A equação (3.2) conhecida como a Lei do gás ideal (PERUZZO; CANTO, 2003). A pressão $P$ e a temperatura $T$ são grandezas diretamente proporcionais mas inversamente proporcionais ao volume $V$ (PERUZZO; CANTO, 2003; KIENCKE; NIELSEN, 2005).

Dado o instante de acionamento da centelha $i$, a pressão $P$ de perfil mostrado na Figura 11 é desenvolvida. Caso no ciclo seguinte, a centelha seja acionada num instante anterior a este, seja $i-1$, a pressão desenvolvida seria $P_{2}$, em que $P_{2}>P$. Tal diferença de pressão justifica-se em razão de que o cilindro ainda move-se em direção ao PMS no instante em que a propagação da chama é iniciada (considerando o tempo de atraso $\tau_{i-1}$ ), causando assim o delta de pressão existente entre ambos. Tal fenômeno físico obedece à equação (3.2), em que a compressão dada pelo movimento do cilindro diminui o volume no interior da câmara, aumentando assim a pressão e a temperatura neste local. Se este processo for feito até que a pressão do interior da câmara (dos gases remanescentes) ultrapasse o nível que o combustível injetado suporta, então teremos detonação. 
Uma vez que o fenômeno ocorreu, o retardo de ignição deve ser dado, pois, com o seu acionamento após o PMS, o volume está aumentando com o movimento do cilindro em direção ao PMI e consequentemente, a pressão e a temperatura diminuem.

\subsubsection{Causa de combustão anormal (ignição de superfície) por resíduos incandescentes ou alteração na estrutura geométrica do motor}

A ignição de superfície causa um rápido aumento de pressão no gás residual e na temperatura do interior da câmara frente ao que acontece quando há o acionamento normal de centelha (devido à chama começar antes do PMS ou propagar a partir de mais de uma fonte). A detonação é um provável sucessor da ocorrência de ignição de superfície. A pré ignição pode ser gerada por pontos quentes no interior da câmara de combustão, em que estes podem ser decorrentes de resíduos incandescentes ou alterações na estrutura geométrica da mesma. Devido a estes fatores, a superfície da câmara pode ser a causadora da pré ignição (HEYWOOD, 1988). As seguidas ocorrências de ignição de superfície podem ser irreversíveis uma vez que uma "superfície detonante"não pode ser controlada com o tempo de centelha como no caso de detonação por centelha, devido à combustão não ter sido causada pela mesma.

A pré ignição pode ser um fator decorrente do histórico de um motor que apresentou detonações severas durante sua vida útil.

Várias combinações dos fenômenos de ignição de superfície e detonação podem ocorrer. Estas foram categorizadas em (HEYWOOD, 1988), como indicado na Figura 12: 
Figura 12 - Resumo dos tipos de combustão normal e anormal

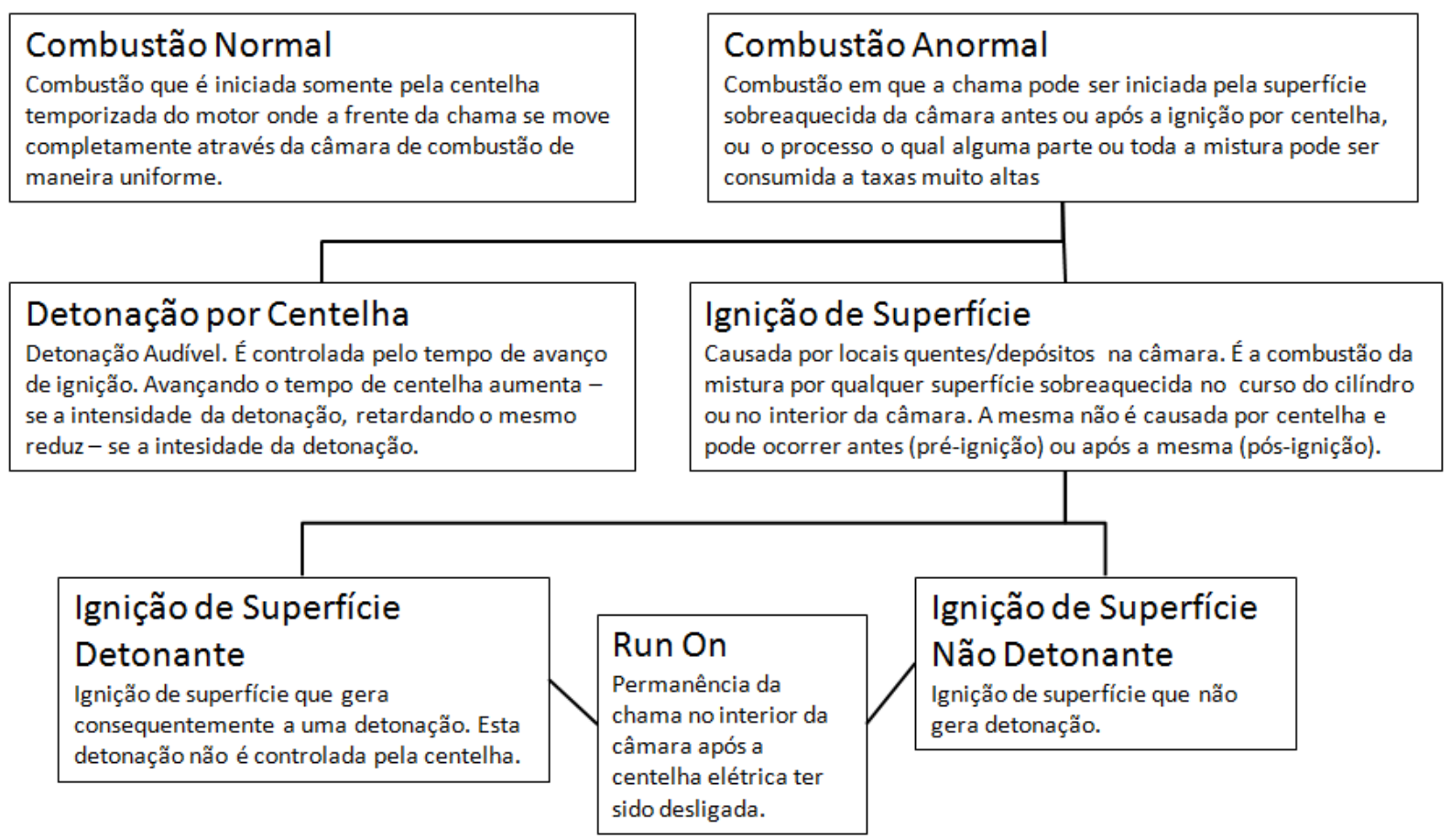

Fonte: Adaptado de (HEYWOOD, 1988).

\subsubsection{Ignição de superfície: efeitos}

De todos os fenômenos de ignição de superfície possíveis, o que causa mais dano é a pré ignição. Qualquer processo que avance a combustão do tempo em que há o máximo torque, causará grande rejeição térmica dada às crescentes pressões dos gases queimados e às temperaturas resultantes. Grandes rejeições térmicas causam altas temperaturas, que por sua vez, podem adiantar o ponto de pré ignição, fato que pode ocorrer até que haja falha em algum componente crítico ao funcionamento do motor. Todas as partes que podem causar pré ignição são aquelas que não estão na temperatura normal de trabalho ou abaixo da mesma ou onde depósitos se acumulam e provêem isolação térmica. Alguns exemplos são velas, válvulas de exaustão e pontos metálicos ásperos como bordas na cabeça do pistão.

A pré ignição é um fenômeno muito mais térmico do que mecânico, pois sua manifestação se dá por um aumento significativo de temperatura sem muitas vibrações mecânicas, como no caso de detonação. Isto pode ser evidenciado pela fusão de velas ou pistões decorrentes de tal fenômeno. Quando a pré ignição é muito intensa, o sobreaquecimento rapidamente é transferido às paredes da câmara de combustão e desta maneira, sobreaquecendo rapidamente a cabeça do cilindro e o pistão. Sob estas condições, a detonação 
não é estável: o sobreaquecimento aumenta a necessidade de octano do motor (torque), o que por sua vez aumenta a intensidade da pré ignição. Esta passa a ser cada vez mais intensa, e se não controlada pode levar a danos permanentes ao motor em minutos. Pulsos de pressões extremamente altos de até 180atm podem ocorrer na região dos gases residuais, em frequências de 5 a $10 \mathrm{kHz}$.

\subsubsection{Detonação: efeitos}

A detonação primeiramente ocorre sob condições de borboleta totalmente aberta (pedal do acelerador pisado até o fim do curso). Por isso, há uma preocupação direta com relação ao desempenho do motor e também à eficiência do mesmo, pois é um limitante de temperatura, pressão e, consequentemente, do torque. Devido a estes fatores, a detonação limita a taxa de compressão aplicada à mistura.

Segundo (HEYWOOD, 1988), a variação de pressão dentro do cilindro durante a detonação indica em detalhes o que realmente ocorre. A Figura 13 mostra a variação de pressão no cilindro em três ciclos individuais: combustão normal, detonação fraca e detonação forte, respectivamente. Quando a detonação ocorre, flutuações de alta frequência são observadas na pressão em que as amplitudes decaem com o tempo.

Figura 13 - Pressão do cilindro em função do ângulo de ignição 4000rpm, pedal totalmente pressionado, deslocamento de $381 \mathrm{~cm}^{3}$ por cilindro

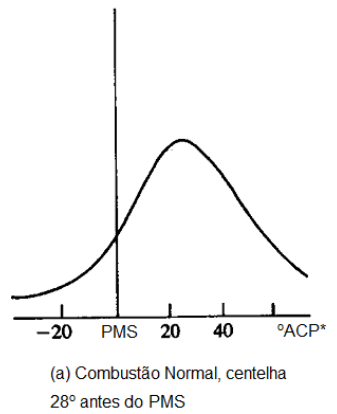

$28^{\circ}$ antes do PMS

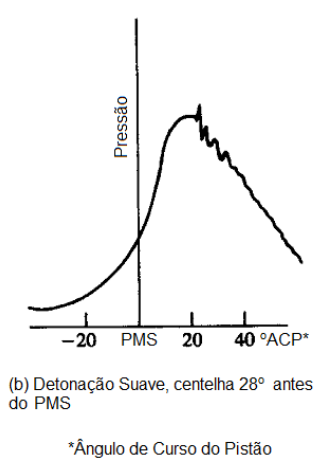

*Ângulo de Curso do Pistão

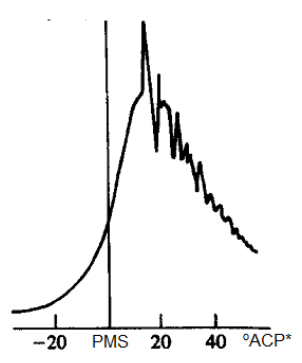

(c) Detonação Intensa, centelha $32^{\circ}$ antes do PMS

Fonte: (HEYWOOD, 1988).

A Figura 13a e a Figura 13b possuem as mesmas condições de operação e o mesmo avanço de ignição. Cerca de um terço dos ciclos deste motor, nestas condições, não apresentou indícios de detonação e desenvolveu níveis normais de pressão com pequenas variações, como na Figura 13b. A detonação de severidade variável ocorreu nos demais ciclos. Com uma fraca ocorrência ou um vestígio de detonação, esta ocorre tardiamente no processo de queima e a amplitude das flutuações de pressão é pequena como mostrado na Figura 
13b. Com a detonação intensa, ilustrada com um tempo de centelha mais avançado e escolhendo especificamente um ciclo mais detonante, tal fenômeno ocorre próximo ao PMS no início do processo de combustão e as amplitudes de pressão são muito maiores, como pode-se ver na distinção entre as Figuras 13a, b e c.

Estas flutuações de pressão produzem um ruído metálico agudo popularmente chamado de "bater de pinos" ou knock. Estes são o resultado da liberação espontânea de energia química do gás residual. Isto causa uma onda de choque que é propagada a partir da região dos gases residuais para toda a estrutura da câmara. Tanto a propagação, quanto o reflexo desta nas paredes da câmara, resultam no perfil oscilatório no tempo, como mostrado nas Figuras 13b e c (HEYWOOD, 1988).

O impacto da detonação depende de sua intensidade e de sua duração. Um vestígio de detonação não tem significado no desempenho do motor ou em sua durabilidade. Já uma forte detonação pode levar a sérios danos no motor. Em aplicações automotivas, geralmente é feita uma distinção entre detonação por aceleração e detonação por velocidade constante.

Detonação por aceleração é somente um desconforto, mas devido à sua curta duração é pouco provável de causar danos ao motor.

Detonação por velocidade constante, pode levar a dois tipos de danos no motor. Este é um problema específico de motores de altas velocidades onde o ruído desta detonação é mascarado por outros ruídos do motor, não sendo então facilmente percebido ao ouvido humano. Fortes detonações em velocidade constante podem facilmente levar à:

1. pré ignição, se houver significantes depósitos em componentes críticos da câmara de combustão;

2. detonação por centelha Runaway Knock - ocorre cada vez mais cedo, por isso, cada vez mais intensa. Isto rapidamente leva a danos severos no motor;

3. corrosão gradual das regiões na câmara de combustão, mesmo se um Runaway Knock não ocorrer.

O motor pode ser danificado pela detonação de maneiras diferentes: afrouxamento e/ou rompimento dos anéis do pistão, falhas na junta do cabeçote, corrosão da cabeça do pistão e sua coroa, aparição de buracos e derretimento do pistão.

\subsubsection{Prevenções à combustão anormal}

A ignição de superfície é um problema que pode ser resolvido por um projeto apropriado do motor, combustível e lubrificante utilizados. Em contraste, a detonação é inerente ao desempenho do motor e é um limitante de eficiência tendo em vista que a 
compressão máxima é limitada para dado combustível devido à existência do fenômeno (HEYWOOD, 1988).

O arrefecimento durante o funcionamento das válvulas de exaustão e o consumo reduzido de óleo geralmente previnem a ocorrência de pré ignição. Colocar a válvula de exaustão entre a vela e a região do gás residual evita o contato tanto com o gás de queima próximo à vela, assim como com o gás residual. Há formas para o interior da câmara de combustão que podem minimizar a probabilidade de pré ignição, como: vela apropriada para a faixa de temperaturas de trabalho da câmara, remoção de pontos ásperos, bordas arredondadas e válvulas de exaustão bem arrefecidas (HEYWOOD, 1988).

Como já mencionado, a detonação é um limitante de desempenho do motor e é inerente ao projeto do mesmo. Para se evitar ou reduzir a probabilidade de ocorrência do fenômeno, é recomendável trabalhar com combustíveis tolerantes a altas taxas de compressão e com bom sistema de arrefecimento do motor. Outras técnicas para tratar o fenômeno de detonação estão detalhadas no tópico a seguir.

\subsubsection{Formas de tratamento do fenômeno de detonação}

Muitos métodos de detecção e caracterização têm sido usados. O ouvido humano é um surpreendente detector de detonação e é comumente utilizado na determinação de octano do motor (a qualidade de combustível que o motor deve ter para evitar a detonação). Os detectores de detonação usados para os sistemas de controle normalmente respondem à aceleração da vibração causada no bloco do motor pelas ondas de pressão (HEYWOOD, 1988). O transdutor piezolétrico é um dispositivo muito utilizado para esta finalidade. Geralmente, o sinal deste transdutor é obtido por filtros passa-faixa de forma que as flutuações causadas pela detonação são enaltecidas (HEYWOOD, 1988). Este tipo de sensor está descrito em mais detalhes na seção 3.6.

Um acelerômetro montado no bloco do motor (sensor de detonação), vide Figura 14, pode dar indicações relativas à severidade da detonação, dado que este esteja na mesma localização em todos os testes. A medição mais precisa de severidade de detonação é através da amplitude máxima das oscilações de pressão que ocorrem em combustões de detonação.

Devido a tais flutuações serem o resultado do fenômeno de propagação das ondas de choque, a localização do transdutor em relação ao local de detonação do gás residual e à forma da câmara de combustão afetará a magnitude da amplitude máxima dos picos de pressão. 
Figura 14 - Exemplo de fixação do sensor de detonação no bloco do motor

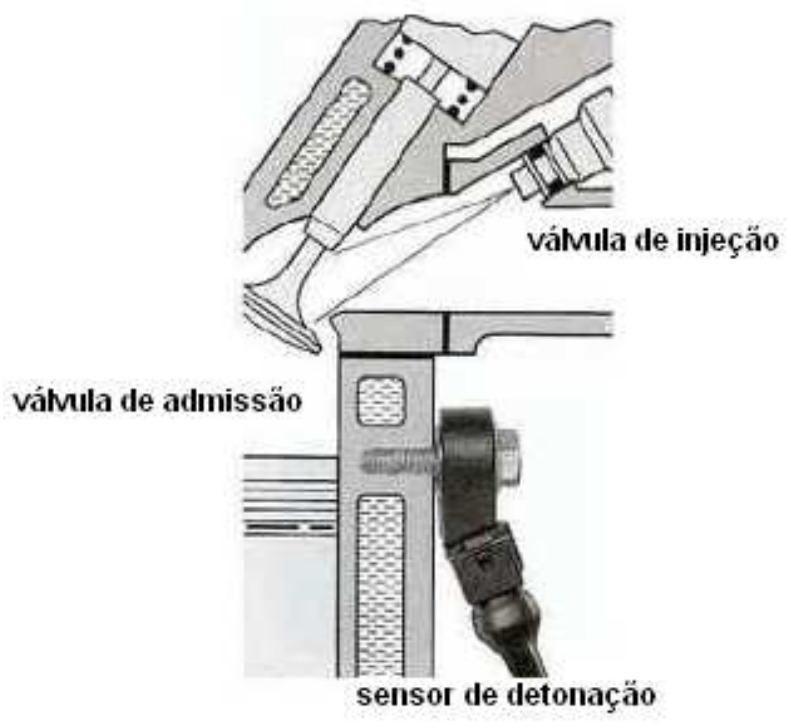

Fonte: Autor.

Figura 15 - Intensidade da detonação (amplitude máxima do filtro passa faixa) em cem ciclos individuais

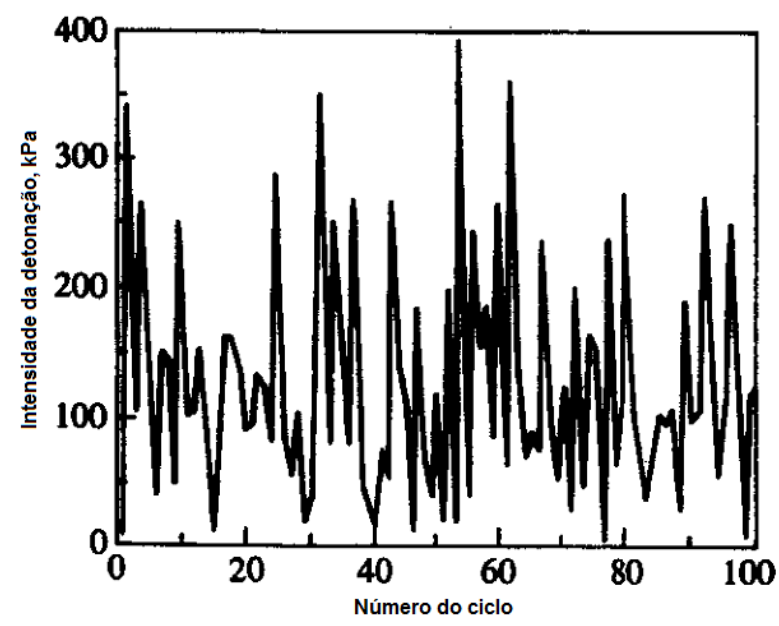

Fonte: Adaptado de (HEYWOOD, 1988).

A amplitude das flutuações de pressão é uma medição útil da intensidade da detonação por que esta depende da quantidade de gás residual que explode espontaneamente. O uso da medição de severidade da detonação mostra que há uma grande variação do comportamento da detonação de ciclo para ciclo. A Figura 15, mostra a intensidade da 
detonação em cem ciclos consecutivos de um dado cilindro de um motor V8 multicilindros, com 2400 rpm e pedal totalmente acionado. Os parâmetros são fixos para todos os ciclos.

A intensidade da detonação varia aleatoriamente de um ciclo não detonante para um ciclo com detonação intensa. A variação de cilindro a cilindro é também substancial devido às variações nas taxas de compressão, composição da mistura, taxa de queima e arrefecimento da câmara de combustão. Um ou mais cilindros podem não apresentar detonação enquanto os demais podem estar com fortes detonações.

Ainda de acordo com (HEYWOOD, 1988), é afirmado que o fenômeno de detonação produz um estado não uniforme dentro dos cilindros. Dado que os detalhes do processo de detonação em cada ciclo e em cada cilindro são diferentes, uma definição fundamental da intensidade da detonação ou sua severidade é realmente difícil.

Para se obter uma medida mais precisa do que ocorre de fato em termos de pressão por conta da detonação no interior do cilindro, há a possibilidade de se utilizar transdutores de pressão localizados no interior da câmara de combustão, o que é mais utilizado em veículos topo de linha. Os componentes de baixa frequência oriundos de ciclos normais de combustão são eliminados e é feita a média da taxa dos picos de pressão em vários ciclos em que há flutuações de pressão seguidas de detonação.

\subsection{Número de octanagem do combustível}

Conforme definido em (PENIDO, 1991), o combustível é classificado segundo o seu poder antidetonante, em número de octano $(N O)$, também chamado octanagem. Quanto maior for o "NO"mais antidetonante será o combustível e, portanto, maior será a sua capacidade de suportar as altas taxas de compressão sem sofrer a explosão. Com isto, pode-se elevar a taxa de compressão, obtendo um aumento na potência.

\subsubsection{Definições}

Os combustíveis como gasolina e álcool possuem entres outros elementos o isoctano $\left(\mathrm{C}_{8} \mathrm{H}_{18}\right)$ e o heptano $\left(\mathrm{C}_{7} H_{16}\right)$. O número de octanagem representa o percentual de isoctano nestes combustíveis. O isoctano possui o valor $(N O=100)$ por possuir poder antidetonante elevado, enquanto que o heptano, que tem um baixo poder antidetonante, é classificado como $(N O=0)$.

Um combustível com o $N O=84$ representa uma mistura de $84 \%$ de isoctano e $16 \%$ de heptano.

Existem combustíveis com $N O>100$ e $N O<0$. O $N O$ de um combustível pode ser também aumentado, por intermédio da adição de outros combustíveis com grande 
poder antidetonante, entre eles podemos citar o álcool etílico, metílico, aditivos etc.

\subsubsection{Taxas de compressão e tipos de combustíveis}

Como mostrado no tópico anterior, diferentes tipos de combustíveis apresentam diferentes níveis de octanagem e, por esta razão, suportam diferentes níveis de pressão. A Figura 16 mostra a relação de dados para os combustíveis gasolina e álcool:

Figura 16 - Características dos combustíveis gasolina e álcool

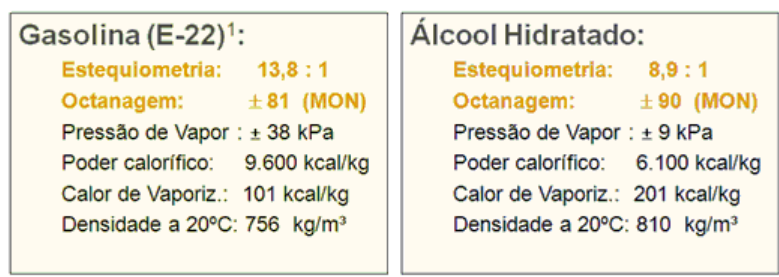

${ }^{1} E 22=$ Gasolina com $22 \%$ de volume de etanol anidro

Fonte: Autor.

A Figura 17 exemplifica como seria representada a curva de torque por avanço de ignição para os combustíveis gasolina e álcool, mas o mesmo pode ser entendido entre combustíveis do mesmo tipo só que um com baixo $N O$ e outro com alto $N O$, os quais seriam representados nas curvas que seguem com o texto "Taxa Alta" e "Taxa Baixa". A partir desta, serão identificados alguns pontos que viabilizarão a justificativa da utilização de tal curva para identificar o tipo de combustível que está sendo utilizado no motor.

Figura 17 - Curvas do torque em função do ângulo de ignição para álcool e gasolina

Requisito de Ignição, com RPM=Cte

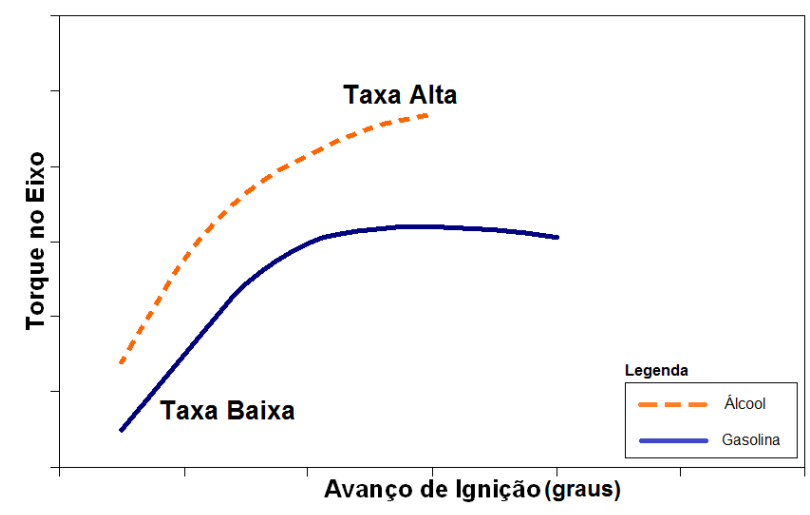

Fonte: Autor. 
Como ilustrado na Figura 18, a taxa de octanagem influencia o máximo avanço possível antes de acontecer detonação. Tendo em mão estas informações, é possível saber o ponto máximo de avanço para cada combustível.

Figura 18 - Indicação de diferentes pontos de detonação em combustíveis diferentes

Requisito de Ignição, com RPM=Cte

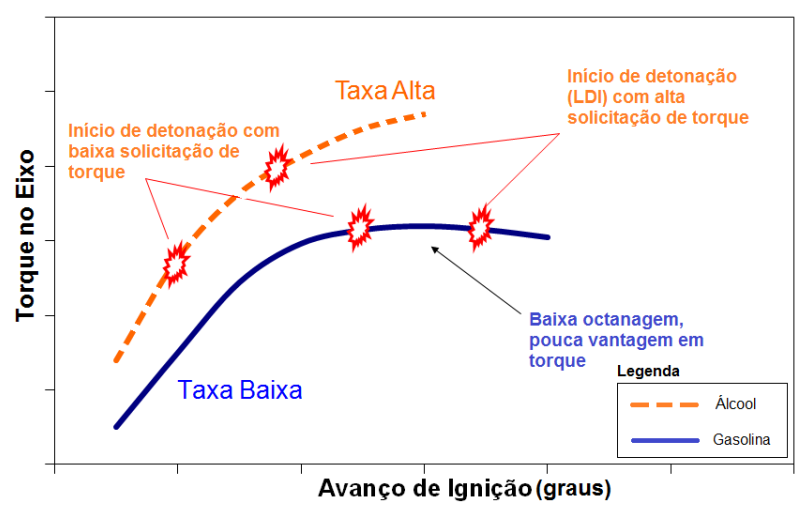

Fonte: Autor.

A Figura 19 destaca a importância do sensor de detonação para que seja possível explorar o máximo de excursão da curva Torque x Ignição. Sem o mesmo, deve-se fazer uma calibração "conservadora"para o ponto de trabalho máximo de avanço.

Figura 19 - Torque em função do avanço de ignição sem utilizar o sensor de detonação

\section{Requisito de Ignição, com RPM=Cte}

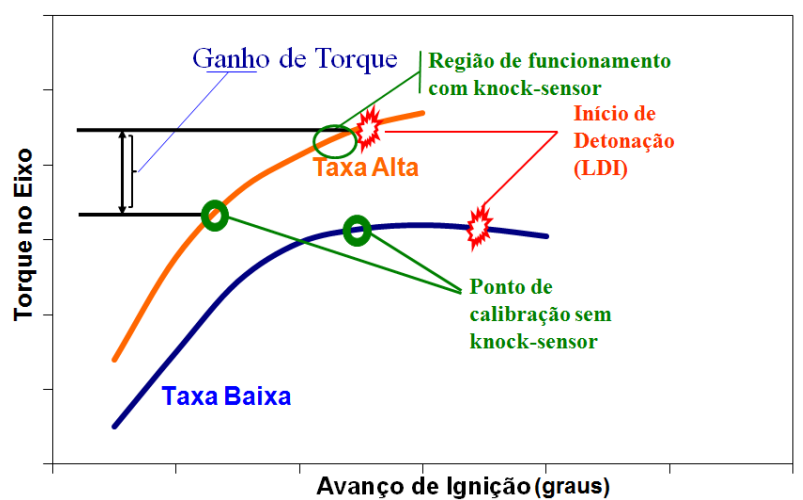

Fonte: Autor.

E finalmente, na Figura 20, assim como na Figura 19 é mostrada a eficiência que é conseguida em termos de torque com a utilização do sensor de detonação. A utilização do sensor possibilita avançar continuamente o ponto de ignição às condições que seriam 
mais próximas das condições que ocasionariam detonação. E no caso de ocorrência do fenômeno, o sensor irá detectar a vibração oriunda do mesmo e mandar um sinal à $E C U$ para ser tratado.

Figura 20 - Melhoria do aproveitamento da curva de torque em função do avanço com o sensor de detonação

Requisito de Ignição, com RPM=Cte

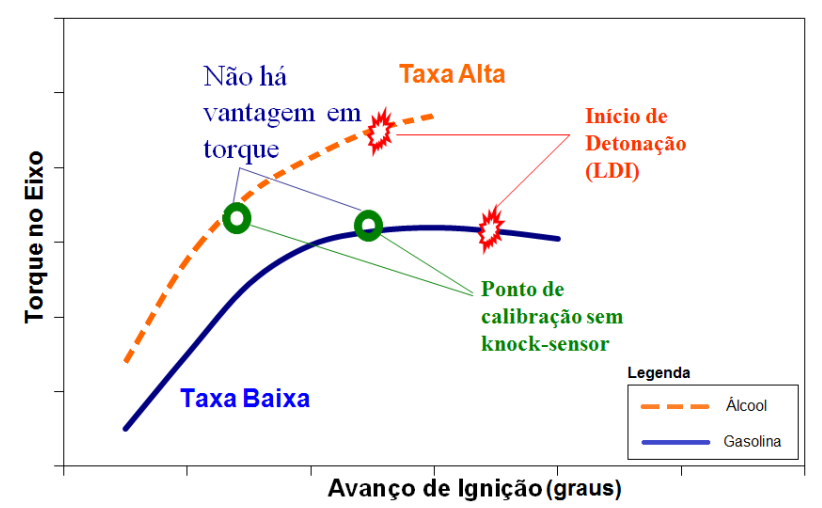

Fonte: Autor.

Como visto nos parágrafos acima, os combustíveis a álcool e à gasolina possuem curvas "Torque x Ignição"diferentes. Por isso, se fosse esperado o torque típico do álcool em um motor funcionando à gasolina, o mesmo não seria obtido, pois o avanço contínuo não proporcionaria os valores esperados de torque. Como exemplo de efeito, a rotação demandada não seria entregue ao usuário. Ao passo que, se fosse aplicado o máximo torque típico de um motor movido a álcool em um motor movido à gasolina, a detonação viria com o avanço muito menor ao comparado à situação em que o combustível adequado estivesse sendo utilizado.

Portanto, por conta destas propriedades dos combustíveis, é possível determinar qual combustível está sendo utilizado através do sensor de detonação e possivelmente sem a necessidade do uso de sensor de combustível. Com tal identificação, seria possível aplicar estratégias de controle mais customizadas ao combustível utilizado.

Além desta aplicação, o sensor de detonação pode ser interpretado de forma mais gradativa do que em algumas abordagens existentes que são praticamente "binárias"(FURREY, 1980; BOSCH, 2006).

Dada as descrições do fenômeno de detonação, a importância do mesmo para a garantia de conservação do motor e possibilidade de melhoria de eficiência, abordaremos no próximo tópico o sensor de detonação. 


\subsection{O Sensor de detonação ou knock sensor (KS)}

O sensor de detonação, ou knock sensor, é um sensor piezolétrico, mais especificamente um acelerômetro. De acordo com (FRADEN, 2004), o efeito piezolétrico tem uma aplicação natural na deteç̧ão de vibração e aceleração.

É afirmado em (FRADEN, 2004) que o efeito piezolétrico é dado pela compressão ou tensionamento de um cristal, o que origina uma carga elétrica. Isto se deve à propriedade ferroelétrica, onde um material pode ter seus dipolos invertidos devido um campo magnético externo, que os materiais piezolétricos possuem.

O funcionamento é mostrado na Figura 21, com vista pelo terceiro eixo z. Aplicandose uma força axial no cristal, o mesmo desenvolve carga elétrica devido ao tensionamento mecânico. O tensionamento na direção contrária também desenvolve carga elétrica, porém com polaridade inversa. O sensor é construído em forma de capacitor em que o dielétrico é o cristal de quartzo. As placas metálicas equalizam a carga em toda a superfície das mesmas, no entanto, construções mais complexas permitem determinar o local exato de flexão/compressão do cristal.

Figura 21 - Efeito piezolétrico em um cristal de quartzo

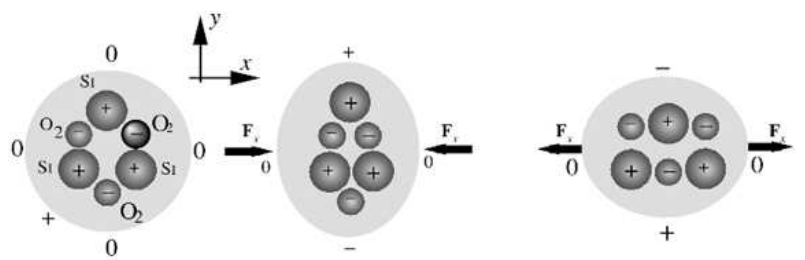

Fonte: (FRADEN, 2004).

A aplicação de tensão elétrica ao material, por sua vez, gera tensionamento mecânico. Vários transdutores piezolétricos são construídos com dois pinos para se aplicar tensão elétrica e dois para se medir a tensão resultante do tensionamento causado. A Figura 22 ilustra a construção de um sensor piezolétrico em forma de capacitor.

Ainda segundo (FRADEN, 2004), as células de cristal no material podem ser consideradas como dipolos elétricos. Em alguns materiais, como o quartzo, estas células são naturalmente orientadas ao longo dos eixos de aplicação mecânica do cristal, dando assim a sensibilidade do material ao tensionamento. Para os materiais cristalinos que não possuem dipolos orientados é necessário que se realize o processo de polarização na construção dos mesmos,(FRADEN, 2004) e (MOHEIMANI; FLEMING, 2006). As duas formas de orientação cristalina são ilustradas na Figura 23. 
Figura 22 - Construção de um sensor piezolétrico

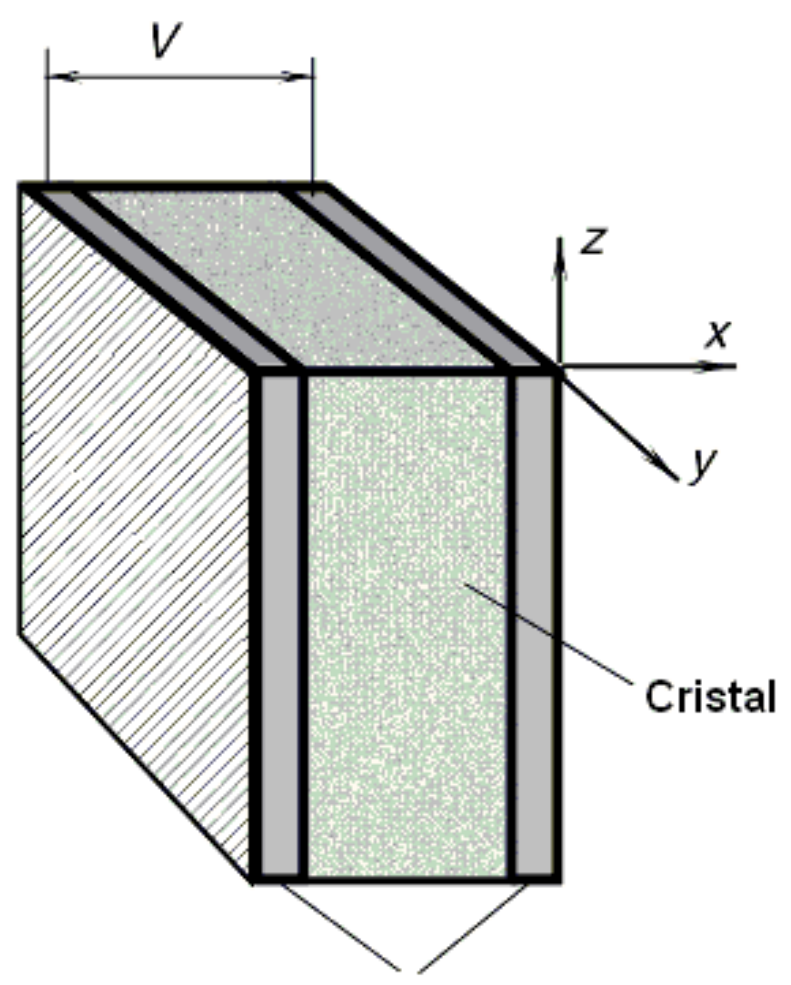

Eletrodos

Fonte: Adaptado de (FRADEN, 2004).

Figura 23 - Estruturas de cristais piezoelétricos
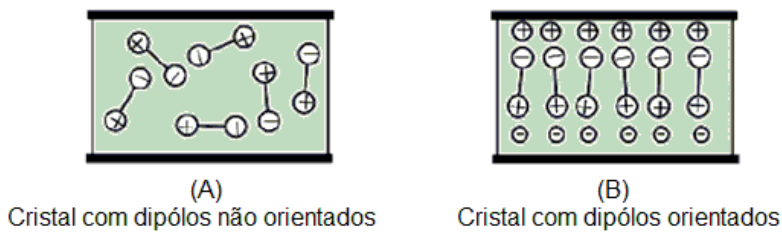

Fonte: Adaptado de (FRADEN, 2004).

De acordo com (JANSHOFF; STEINEM, 2007), o critério para o controle de frequência no projeto de ressonadores é o modo de espessura de corte do cristal, o qual determina a estabilidade da mesma. O tipo de corte do cristal para a construção do sensor leva em consideração os requisitos exigidos pela aplicação do mesmo. Cada corte de um cristal piezolétrico suporta diferentes modos de vibração em que estes são caracterizados por possuírem diferentes velocidades, fases de polarização e acoplamentos piezolétricos, onde este último determina a eficiência de conversão de energia mecânica em elétrica 
(FRADEN, 2004). Os modos são geralmente encomendados em função da velocidade de onda. Portanto, os cristais destinados à detecção do fenômeno de detonação possuem um corte que proporciona um maior tensionamento do material na faixa de frequência em que o fenômeno geralmente ocorre.

Figura 24 - Modos de vibração de sensores piezolétricos

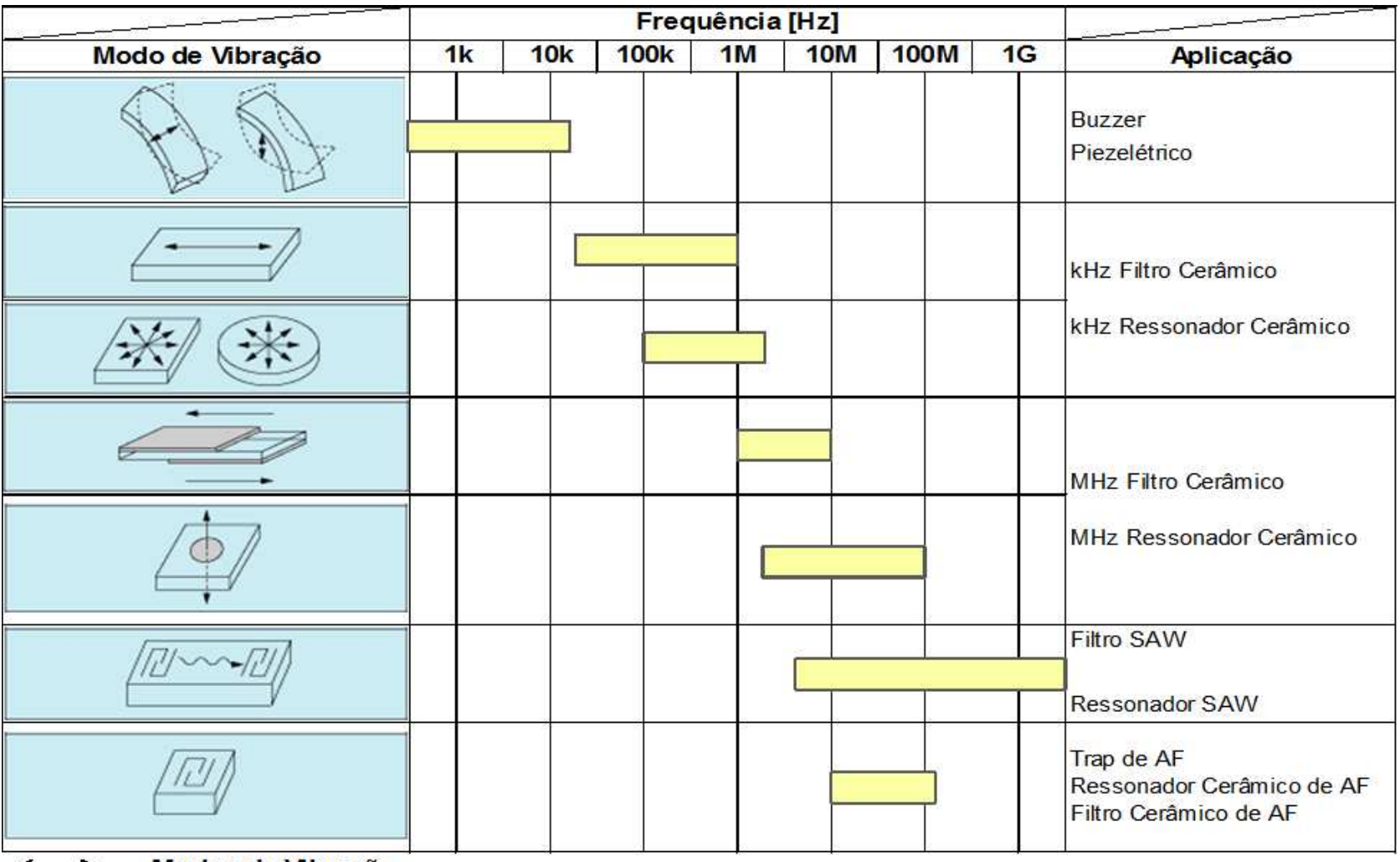

$\longleftrightarrow$ Modos de Vibração

Fonte: Adaptado de (MURATA, 2012).

A Figura 24 mostra os modos de vibração em função da frequência, bem como as aplicações de sensores piezoelétricos (MURATA, 2012).

Segundo (FRADEN, 2004), após o elemento piezo estar preparado, este é instalado em um invólucro, onde seus eletrodos são ligados a terminais elétricos. Este conjunto compõe o sensor.

Estes sensores operam em frequências tão baixas quanto $2 \mathrm{~Hz}$ até dezenas de Hertz, pois eles possuem rejeição de ruído boa, alta linearidade e uma ampla faixa de temperatura operacional (até $120^{\circ} \mathrm{C}$ ). Apesar dos cristais de quartzo serem usados ocasionalmente como elementos sensores, os materiais mais populares são as cerâmicas piezolétricas, como o titanato de bário, zirconita titanato de chumbo (PZT) e metaniobato de chumbo. O cristal é prensado entre o invólucro e a massa, os quais exercem uma força proporcional 
à aceleração sobre ele (Figura 25). A aceleração do invólucro move a massa relativa, a qual exerce uma força sobre o cristal. A saída está diretamente proporcional ao nível de aceleração ou vibração.

Quando ocorre um tensionamento, o estado de equilíbrio dos dipolos é perdido e o material piezolétrico desenvolve uma carga elétrica. Se o tensionamento é mantido por um tempo longo suficiente, as cargas serão novamente neutralizadas pela fuga interna. Assim, um sensor piezolétrico é sensível apenas a um tensionamento variável ao invés de um nível constante do mesmo. Em outras palavras, um sensor piezolétrico é um dispositivo de tensão alternada, em vez de um dispositivo de tensão contínua.

Figura 25 - Esquema básico de um acelerômetro piezolétrico

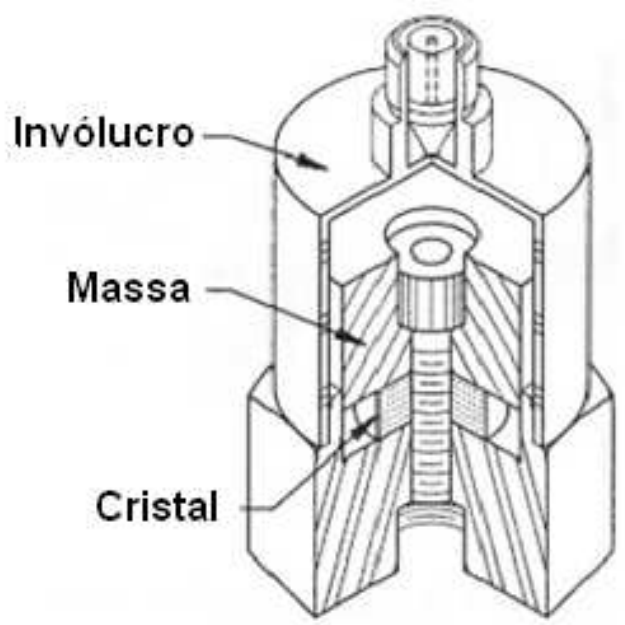

Fonte: Adaptado de (FRADEN, 2004).

As características básicas a serem levadas em consideração para o projeto de uma aplicação utilizando um sensor de detonação estão descritas na seção de anexos. Estas foram retiradas de um manual (datasheet) de um sensor comercial (BOSCH, 2006).

\subsection{Processamento do sinal do sensor de detonação}

Nesta seção, serão apresentados os métodos de processamento de sinais para a caracterização do sinal do sensor de detonação. Inicialmente apresentando a teoria de filtros adaptativos e em seguida uma breve revisão de preditores adaptativos, o qual é o método utilizado neste trabalho. 


\subsubsection{Tópicos dos fundamentos de filtros adaptativos}

Os algoritmos adaptativos utilizados neste trabalho são métodos estocásticos derivados do algoritmo gradiente descendente e do método Newton. Ambos algoritmos fazem parte dos vários métodos de estimação existentes projetados para encontrar iterativamente a melhor solução para reduzir o erro de estimação do sinal de interesse. Tal algoritmo fornece a cada iteração $i$ o vetor de coeficientes $w_{i}$, o qual, quando estável, minimiza o erro de estimação (também chamado de função custo). Neste trabalho, o erro de estimação é avaliado sob o critério da média dos mínimos quadrados (least mean squares criterion), definido por:

$$
J(w)=E|\boldsymbol{d}-\hat{\boldsymbol{d}}|^{2}
$$

na qual $\boldsymbol{d}$ é o valor medido, $E$ denota a operação de valor esperado e $J(w)$ é a função custo. O termo $\hat{d}$ representa a estimativa do valor medido, definido como:

$$
\hat{d}=u w
$$

Dado que $w$ é um vetor coluna e $\boldsymbol{u}$ é um vetor linha, ambos de tamanho $M$ (ou em outras palavras, $w_{M \times 1}$ e $\left.\boldsymbol{u}_{1 \times M}\right)$. As indicações em negrito representam variáveis aleatórias.

Em todo problema de estimação é desejado reduzir a função custo ao mínimo valor possível, de acordo com (SAYED, 2008), pode-se mostrar que $J(w)$ deverá ser minimizado à solução miníma utilizando a seguinte relação:

$$
J_{\min }={\sigma_{d}}^{2}-R_{u d} R_{u}^{-1} R_{d u}
$$

com $R_{\boldsymbol{u} \boldsymbol{d}}=E \boldsymbol{u} \boldsymbol{d}^{*}$ sendo vetor linha, $R_{\boldsymbol{d} \boldsymbol{u}}=E \boldsymbol{d} \boldsymbol{u}^{*}$ vetor coluna representando a variância cruzada da entrada $\boldsymbol{u}$ e saída $\boldsymbol{d}$, e por fim, $R_{\boldsymbol{u}}^{-1}$, uma matriz inversa quadrada da covariância dos valores de entrada. A notação “*” refere-se ao conjugado complexo e $\sigma_{d}^{2}$ é a variância do valor medido.

O valor mínimo da função custo (3.5) é obtido aplicando o vetor de coeficientes ótimos, denotado por $w^{o}$, na definição da função custo (3.3). O coeficiente ótimo $w^{o}$ é a solução do modelo de estimação linear abaixo, também chamado de equações normais:

$$
R_{u} w^{o}=R_{d u}
$$

Caso exista a inversa de $R_{\boldsymbol{u}}$, o vetor de coeficientes ótimos pode ser obtido por:

$$
w^{o}=R_{u}^{-1} R_{d u}
$$


Finalmente, o vetor de coeficientes ótimos pode ser obtido, de forma aproximada, utilizando o algoritmo gradiente descendente definido como:

$$
w_{i}=w_{i-1}+\mu\left[R_{d u}-R_{u} w_{i-1}\right]
$$

na qual $\mu$ é o tamanho do passo. O termo "aproximado" foi utilizado pois o gradiente descendente só converge para $w^{o}$ quando $i \rightarrow \infty$. A velocidade de convergência de tal algoritmo, tanto de $w_{i}$ para $w^{o}$ ou $J(w)$ para $J_{\text {min }}$, é dependente dos modos de convergência do gradiente descendente definidos por:

$$
\text { Modo de convergência }{ }_{g d^{1}}=1-\mu \lambda_{k}
$$

${ }^{1} \mathrm{gd}=$ gradiente descendente

na qual, $k>0$ e $k \in \mathbb{N}$.

Os modos de convergência são os autovalores da matriz de coeficientes, a qual é definida por:

$$
I-\mu R_{u}
$$

Os modos de convergência, determinam o quão rápido ou o quão lento será a convergência do algoritmo. Cada modo de convergência está associado a um dos autovalores de $R_{u}$, como pode ser visto na equação acima. Quanto menor o valor do modo de convergência, mais rápido será a convergência de $w_{i}$ para $w^{o}$ e consequentemente de $J(w)$ para $J_{\text {min }}$, ao passo que quanto maior a magnitude do modo de convergência, mais lenta será tal convergência. O tamanho de passo, $\mu$, está intrinsicamente ligado a velocidade de convergência do algortimo e limitado aos autovalores da matriz $R_{u}$ pois, conforme (SAYED, 2008), $\mu$ deve seguir a seguinte relação para garantia de convergência:

$$
0<\mu<2 / \lambda_{\max }
$$

Uma implicação da existência de (3.11) é que os autovalores de (3.10) estejam dentro do círculo unitário.

O coeficiente $w$ pode ser obtido também através do método de Newton, o qual é uma derivação do algoritmo gradiente descendente, definido da seguinte maneira:

$$
w_{i}=w_{i-1}+\mu\left[\epsilon I+R_{u}\right]^{-1}\left[R_{d u}-R_{u} w_{i-1}\right]
$$

em que $\epsilon$ é um valor positivo pequeno para "pequenos ajustes". 
O método de newton, ao contrário do gradiente descendente, independe dos valores de $R_{u}$ para convergência do erro $\tilde{w}$ para zero, sendo $\tilde{w}=w^{o}-w$ e depende somente do valor do tamanho de passo, $\mu$. Conforme mostrado em (SAYED, 2008), se a condição:

$$
0<\mu<2
$$

for satisfeita, a convergência $\tilde{w} \rightarrow 0$ é garantida para este algoritmo, mas novamente sob a premissa de que $i \rightarrow \infty$. O algoritmo de Newton, difere também do gradiente descendente no número de modos de convergência, em que, ao contrário deste último, o método de Newton possui apenas um modo de convergência, o qual é dependente do tamanho de passo e é definido por:

$$
\text { Modo de convergência } m^{2}=1-\mu \lambda_{k}
$$

${ }^{2} \mathrm{mn}=$ método de newton

Devido o método de newton chegar mais rápido ao valor ótimo de $w$, o erro de estimação mínimo também é atingido de forma mais rápida.

A representação do algoritmo gradiente descendente pode ser verificada na Figura 26.

Figura 26 - Representação do algoritmo gradiente descendente

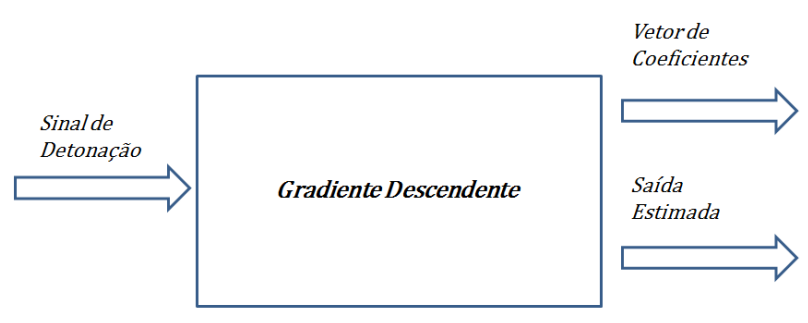

Fonte: Autor.

Em aplicações reais, raramente a estatística dos sinais de interesse é conhecida, como o algoritmo gradiente descendente requer (em razão de $R_{\boldsymbol{d} u}$ e $R_{\boldsymbol{u}}$ ). Portanto, a solução mostrada em (3.6) não é possível de ser alcançada na prática. Assim, alguns algoritmos estocásticos foram criados tendo como base o algoritmo gradiente descendente. Tais algoritmos são concebidos sob aproximações estocásticas de $R_{\boldsymbol{d} u}$ e $R_{\boldsymbol{u}}$ para contornar o desconhecimento das estatísticas do sinal. Estas aproximações são dadas por: 


$$
\begin{gathered}
\hat{R}_{d u} \approx d(i) u_{i}, \mathrm{e} \\
\hat{R}_{u} \approx u_{i}^{*} u_{i}
\end{gathered}
$$

na qual $u_{i}$ representa uma coleção das $M$ realizações anteriores ao instante $i$ de $u(i)$, sendo $u_{i}=\{u(i-1), u(i-2), u(i-3), \ldots u(i-M+1)\}$.

As aproximações acima geram os algoritmos utilizados neste trabalho, os quais são:

A: Algoritmo da média dos mínimos quadrados ou Least mean square algorithm (LMS)

O qual é baseado no algoritmo gradiente descendente (3.8). Após aplicação das aproximações estocásticas definidas em (3.15), o algoritmo a seguir é obtido:

$$
w_{i}=w_{i-1}+\mu u_{i}^{*}\left(d(i)-u_{i} w_{i-1}\right)
$$

O LMS herda as características do gradiente descendente como a alta depêndencia dos valores de entrada para convergência (ou rápida convergência). No entanto, este algoritmo é simples computacionalmente e possui simples viabilidade de implantação computacional.

\section{B: Algoritmo da média dos mínimos quadrados normalizado ou Norma- lized least mean square algorithm (NLMS)}

Este algoritmo é concebido aplicando (3.15) no método de Newton (3.12), com algumas manipulações algébricas, como pode ser conferido em (SAYED, 2008), chega-se a:

$$
w_{i}=w_{i-1}+\mu \frac{u_{i}}{\left\|u_{i}\right\|^{2}}\left(d(i)-u_{i} w_{i-1}\right) .
$$

Assim como o LMS herda as características do gradiente descendente, o NLMS herda as caracteríticas do método de Newton em que uma delas é de rápido rastreamento do sinal a ser estimado, justificado por sua definição em que o modo de convergência é dependente somente do tamanho de passo.

Todas as derivações acima podem ser encontradas em (SAYED, 2008).

\subsubsection{Predição adaptativa}

Quando se tem um sinal de banda estreita, $s(i)$, embutido em um sinal de banda larga, $\boldsymbol{v}$ (ruído branco por exemplo), sendo $i$ a iteração ou realização temporal, preditores adaptativos podem ser utilizados para separá-los (DINIZ, 2008). Um preditor adaptativo 
(PA) é composto de uma estrutura de filtragem, geralmente um filtro de resposta finita ao impulso ou finite impulse response (FIR) transversal, assim como um algoritmo de aprendizagem. No instante $i$, o filtro FIR é representado por sua resposta ao impulso (truncada) capturada no vetor coluna $w_{i}$.

Para separar $s(i)$ de $\boldsymbol{v}(i)$, o PA "tenta" predizer como será o sinal referência, representado por $\boldsymbol{u}(i)$, através de uma combinação linear das amostras anteriores, i.e.:,

$$
\hat{\boldsymbol{u}}(i)=\boldsymbol{u}_{i-1} w_{i-1},
$$

na qual,

$\hat{\boldsymbol{u}}(i)=$ valor estimado de $\boldsymbol{u}$ na iteração $i$ via combinação linear de amostras passadas, representadas por:

$$
\boldsymbol{u}_{i-1}=\left[\begin{array}{lll}
\boldsymbol{u}(i-1) & \ldots & \boldsymbol{u}(i-M+1)
\end{array}\right]
$$

o qual é o vetor regressor linha e $\mathbf{w}_{i-1}$ é a resposta ao impulso do filtro preditor no instante $i-1$.

O vetor $\mathbf{w}_{i-1}$ é projetado para minimizar o erro de predição:

$$
\boldsymbol{e}(i)=\boldsymbol{u}(i)-\hat{\boldsymbol{u}}(i)
$$

O preditor ótimo, $w^{o}$, pode ser encontrado das equações normais (3.6) (LOPES et al., 2010):

$$
R_{u, i} w^{o}=R_{d u, i}
$$

em que $R_{\boldsymbol{u}} \triangleq \mathbf{E} \boldsymbol{u}^{*} \boldsymbol{u}$ e $R_{\boldsymbol{d} \boldsymbol{u}}^{*} \triangleq \mathbf{E} \boldsymbol{u}^{*} \boldsymbol{u}$ são as estatísticas do sinal, como mostrado na seção anterior. No caso de predição, temos que $\boldsymbol{d} \leftarrow u(i)$ e $\boldsymbol{u} \leftarrow u_{i-1}$.

\subsubsection{Estimador de Potência}

É um algoritmo utilizado para fornecer a potência instântanea ou a potência total do sinal aplicado ao mesmo. Como visto na Figura 15, devido ao fato do sinal de detonação apresentar amplitudes diferentes na ocorrência e ausência do fenômeno, este algoritmo pode ser útil para sua detecção, pois os diferentes perfis de amplitude possuem diferentes valores de potência associados. Conforme mostrado em (HAYKIN; VEEN, 1999), a definição de potência instântanea do sinal $p(i)$, para cada instante $i$, é dada por:

$$
p(i)=x(i)^{2}
$$


na qual $x(i)$ é o sinal que se deseja saber a potência instântanea.

Também de acordo com (HAYKIN; VEEN, 1999), a definição de potência total, com período fundamental $N$ é dada por:

$$
P=\frac{1}{N} \sum_{i=0}^{N-1} x(i)^{2}
$$

O estimador de potência é um algoritmo que permite uma seleção ponderada de cada uma das potências acima, a instantânea e a total. A seleção é feita através de fatores ponderadores, $\alpha$ e $\beta$, como definido abaixo:

$$
y(i)=\alpha y(i-1)+\beta x(i)^{2}
$$

Com o modelo dado, vemos que se $\alpha$ for muito maior que $\beta$, o comportamento preponderante mostrado nas realizações de $y$ será o da potência total desenvolvida pelo sinal aplicado, $x(i)$. Ao passo que se a regra for de que $\beta$ seja muito maior que $\alpha$, a resposta preponderante em $y$ será a potência instântanea do sinal.

Para garantir que sempre somente um dos valores de potência acima seja escolhido com maior peso, assim como garantir a estabilidade do algoritmo, os fatores $\alpha$ e $\beta$ devem seguir as seguintes regras, respectivamente:

$$
\begin{gathered}
\alpha=1-\beta \mathrm{e} \\
|\alpha|<1
\end{gathered}
$$




\section{Metodologia}

Neste capítulo, estão contidas as seções que estabelecem o problema a ser resolvido, o método proposto para sua solução e os métodos de teste escolhidos.

\subsection{Afirmação do problema}

O sinal de detonação possui a forma indicada na Figura 27. Como se pode ver, este possui forma similar a uma senóide amortecida aleatoriamente, a qual é uma componente altamente correlacionada. Note também que a não ocorrência de detonação remete à aparência de um ruído branco.

Figura 27 - Sinal real de detonação

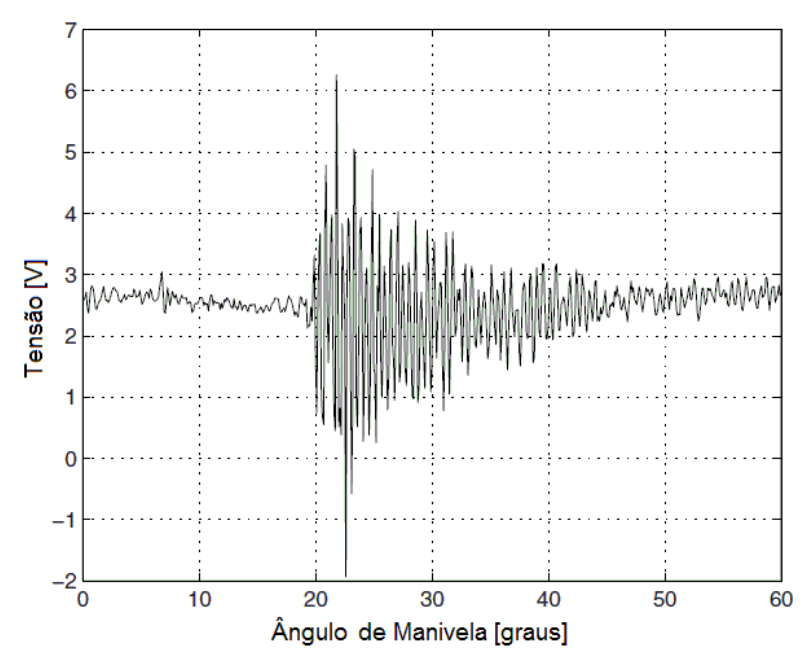

Fonte: (STOTSKY, 2007a).

A geração de detonação depende de vários fatores como explicado anteriormente, o que torna sua ocorrência não determinística e não estacionária. Portanto, o acontecimento de uma detonação é algo aleatório (STOTSKY, 2007a; STOTSKY, 2007b), mas a probabilidade de ocorrência pode ser aumentada com alguns procedimentos, os quais serão mencionados a seguir.

Na prática, o sinal de detonação pode ocorrer avançando o ângulo de ignição, ação que pode ser interpretada como uma solicitação de torque, conforme explicado na seção 3.4.1. Esta é uma situação característica de corridas ou provas de arrancadas nos quais altos níveis de torque são solicitados. A detonação também pode ocorrer com combustível 
de má qualidade ou em laboratório, onde neste último é possível adiantar a ignição de seu ponto normal de operação (STOTSKY, 2007a; STOTSKY, 2007b; HEYWOOD, 1988).

Ruídos associados, característica correlacionada somada a não estacionariedade do sinal, criam a problemática a qual dificulta a caracterização da detonação. Para a resolução deste problema, duas etapas são propostas e seus respectivos requisitos:

1. Modelar o sinal real de detonação para avaliação de possíveis algoritmos de tratamento

O modelo de simulação deve estar apto a oferecer diferentes comportamentos de um sinal simulado de detonação.

Os tipos de geração devem permitir um ambiente flexível de testes onde os comportamentos devem ser possíveis de serem escolhidos de acordo com o teste que se deseja fazer.

A geração do sinal deve permitir aleatoriedade de ocorrência do fenômeno.

2. Escolha do algoritmo de tratamento baseado nos requisitos de sinais O algoritmo para tratar tal sinal deve estar apto a indicar a diferença entre detonação e não detonação, assim como indicar os diferentes tipos de detonação em termos de suas várias amplitudes e comprimentos possíveis.

O modelo apresentado neste trabalho, epecificamente na seção 4.2.1 é baseado no desenvolvimento apresentado em (URLAUB; BOHME, 2005), porém com direcionamento voltado a testes de robustez de algoritmos de tratamento de sinais, dado que o mesmo fornece diversos perfis de detonação em uma única simulação.

\subsection{Resolução do problema proposto}

Nesta seção serão mostrados os passos tomados para solucionar o problema estabelecido na seção anterior. Tal resolução terá três etapas:

1. Proposta de um modelo do sinal de detonação para simulações

2. Demonstração da eficiência dos algoritmos adaptativos na detecção do fenômeno

3. Simulação com os algoritmos propostos e resultados

Os dois primeiros itens serão apresentados neste capítulo e o terceiro em um capítulo a parte. 


\subsubsection{Modelamento do sinal de detonação}

Primeiramente, o sinal do sensor de detonação é modelado na ausência do evento de detonação. Este é caracterizado por um ruído branco de baixa amplitude como visto na Figura 27, o que a partir deste ponto é chamado de ruído de fundo. Portanto, sempre que o termo ruído de fundo for utilizado está sendo mencionado o sinal do sensor de detonação sem a ocorrência do fenômeno.

Para atender às características do sinal descritas na seção 4.1, uma senóide amortecida pode ser adicionada ao ruído de fundo. A forma de onda resultante apresentará um perfil próximo ao sinal real de detonação. Portanto, tem-se que:

sinal do sensor de detonação $(\boldsymbol{u})=$ ruído de fundo + senóide amortecida (na ocorrência de detonação)

na qual,

senóide amortecida será representada por, $s=\left[\begin{array}{llll}s(1) & s(2) & \ldots & s(l)\end{array}\right]$ e

ruído de fundo será representado por, $\boldsymbol{v}=\left[\begin{array}{llll}\boldsymbol{v}(1) & \boldsymbol{v}(2) & \ldots & \boldsymbol{v}(q)\end{array}\right]$

sendo,

$$
\boldsymbol{s}(n)=\gamma\left(\sin \left(\frac{2 \pi}{F n}\right) \exp ^{-\tau n}\right), n=1,2,3, \ldots l
$$

na qual,

$\gamma=$ amplitude máxima desejada para o evento de detonação,

$F=$ fator de Frequência (conforme $N$ cresce, frequência senoidal tende a 0 ),

$\tau=$ fator de amortecimento (pequeno, fracionário e maior do que 0. Conforme $\tau$ cresce, $\exp ^{-\tau i}$ tende a ser constante,

$l=$ tamanho máximo (em número de pontos no gráfico, ou iterações) da componente amortecida $s$,

e para o ruído de fundo,

$\boldsymbol{v}(i)=$ realização de ruído branco com distribuição gaussiana (gerado pela função randn do Matlab®) e,

$\sigma_{\boldsymbol{v}}^{2}=$ variância do ruído branco,

$q=$ comprimento máximo do ruído de fundo,

no qual $i$ é um indexador de iteração. 
Note que $s$ está em negrito, representando assim uma variável aleatória, devido a ocorrência do fenômeno ser aleatória. Outro detalhe é que o comprimento do ruído de fundo representa o comprimento do sinal do sensor de detonação, $\boldsymbol{u}$. Além disso, antes das somas de $s$ ao sinal $\boldsymbol{u}, \boldsymbol{u}=\boldsymbol{v}$.

Portanto, se for desejado avaliar várias "ocorrências" de detonação em apenas um experimento (uma simulação geradora de um gráfico), é necessário fazer a soma 4.1 várias vezes e em momentos distintos (iterações distintas), para assim representar diferentes ocorrências do fenômeno. Por conta disto, a senóide amortecida, a qual representa a ocorrência de detonação, deve ser menor do que o sinal simulado total do sensor de detonação, $\boldsymbol{u}$, para que assim seja possível fazer múltiplas somas a este. Por isso, o sinal do sensor é modelado por blocos, onde cada bloco inicialmente possui tamanho idêntico ao tamanho da componente amortecida, $l$. A soma do tamanho dos blocos é igual ao comprimento total do sinal do sensor de detonação, q, que por sua vez é igual ao tamanho do ruído de fundo gerado.

Conforme mencionado, cada bloco possui o tamanho $l$ (número de pontos no gráfico ou iterações) o qual é respectivo ao número de realizações que a senóide amortecida possui, ao passo que o sinal simulado resultante do sensor de detonação possui número de iterações (ou pontos no gráfico) múltiplo do valor de iterações de cada bloco (ou da senóide amortecida), representado por $q$.

$$
q=l b, b=1,2,3, \ldots
$$

na qual

$$
\begin{gathered}
q=\text { tamanho do sinal simulado do sensor de detonação } \\
\text { ruído de fundo } \\
l=\text { tamanho do sinal amortecido }(\mathbf{s}) \\
b=\text { número de blocos }
\end{gathered}
$$

O valor de iterações do sinal simulado do sensor depende de quantas vezes é desejado observar uma possível ocorrência de detonação. Por exemplo, se o número de iterações de uma senóide amortecida for de 500 ( ou $l=500$ ), cada bloco terá 500 iterações pois deverá comportar uma possível ocorrência deste sinal. Caso seja desejado observar 3 possíveis ocorrências do fenômeno, o sinal simulado resultante do sensor será de 1500 (ou $q=1500$ ) iterações, pois 3 blocos seriam interpretados como o sinal vindo do sensor. A Figura 28 mostra como o sinal simulado do sensor é composto.

Para permitir flexibilidade nos testes, a geração do sinal do sensor possui algumas opções de atribuições do sinal amortecido ao ruído branco inicial de cada bloco. Estas atribuições devem seguir uma hierarquia estabelecida no programa como descrito na Tabela 1.

O gerador de sinais possui a opção de selecionar qual tipo de geração é necessária. 
Figura 28 - Sinal simulado do sensor de detonação representado como uma divisão de blocos

\begin{tabular}{|l|l|l|l|l|l|}
\hline Bloco 1 & Bloco 2 & Bloco 3 & Bloco 4 & $\cdots$ & Bloco b \\
\hline
\end{tabular}

Fonte: Autor.

Tabela 1 - Opções de geração de detonação

\begin{tabular}{|c|c|c|}
\hline Prioridade & Regra & Opção $\mathbf{N}^{o}$ \\
\hline $\begin{array}{l}1 \text { - Mandató- } \\
\text { rio (precondi- } \\
\text { ção as outras }\end{array}$ & $\begin{array}{l}\text { Pula um bloco e verifica se um sinal amortecido } \\
\text { pode ser adicionado no próximo bloco }\end{array}$ & $\begin{array}{l}\text { Não aplicável } \\
\text { sempre funcio- } \\
\text { nando }\end{array}$ \\
\hline 2 & $\begin{array}{l}\text { Gera detonação por bloco fixo, frequência fixa, fator } \\
\text { de amortecimento fixo e amplitude aleatória }\end{array}$ & 1 \\
\hline 2 & $\begin{array}{l}\text { Gera detonação por bloco aleatório, frequência fixa, } \\
\text { fator de amortecimento fixo e amplitude aleatória }\end{array}$ & 2 \\
\hline 2 & $\begin{array}{l}\text { Gera detonação por bloco fixo, frequência fixa, fator } \\
\text { de amortecimento aleatório e amplitude aleatória }\end{array}$ & 3 \\
\hline 2 & $\begin{array}{l}\text { Gera detonação por bloco aleatório, frequência fixa, } \\
\text { fator de amortecimento aleatório e amplitude alea- } \\
\text { tória }\end{array}$ & 4 \\
\hline 2 & $\begin{array}{l}\text { Gera detonação por bloco aleatório, frequência ale- } \\
\text { atória, fator de amortecimento fixo e amplitude ale- } \\
\text { atória }\end{array}$ & 5 \\
\hline 2 & $\begin{array}{l}\text { Gera detonação por bloco fixo, frequência aleatória, } \\
\text { fator de amortecimento fixo e amplitude aleatória }\end{array}$ & 6 \\
\hline 2 & $\begin{array}{l}\text { Gera detonação por bloco aleatório, frequência alea- } \\
\text { tória, fator de amortecimento aleatório e amplitude } \\
\text { aleatória }\end{array}$ & 7 \\
\hline
\end{tabular}

Observando a Tabela 1, é possível perceber que 3 parâmetros são configuráveis para permitir um ambiente de testes flexível:

1. Sinal de detonação com amplitude aleatória;

2. Sinal de detonação com amplitude aleatória e fator de amortecimento aleatório;

3. Sinal de detonação com amplitude aleatória, fator de amortecimento aleatório e frequência aleatória;

Modelados da seguinte forma, respectivamente: 
1. $\left[\begin{array}{lll}\boldsymbol{u}(k l) & \ldots & \boldsymbol{u}(k l+l-1)\end{array}\right]=\left[\begin{array}{lll}\boldsymbol{v}(k l) & \ldots & \boldsymbol{v}(k l+l-1)\end{array}\right]+$

$$
\varsigma(q-k l+l) s
$$

na qual,

$$
k=1,2, \ldots(b-1) \mathrm{e},
$$

$$
\varsigma(h)= \begin{cases}1, & h \geq 0 \\ 0, & h<0\end{cases}
$$

2. $\left[\begin{array}{lll}\boldsymbol{u}(k l) & \ldots & \boldsymbol{u}(k l+l-1)\end{array}\right]=\left[\begin{array}{lll}\boldsymbol{v}(k l) & \ldots & \boldsymbol{v}(k l+l-1)\end{array}\right]+$

$$
\varsigma(q-k l+l) \nu \gamma\left(\sin \left(\frac{2 \pi}{N i}\right) \exp ^{\varrho i}\right) ;
$$

3. $\left[\begin{array}{lll}\boldsymbol{u}(k l) & \ldots & \boldsymbol{u}(k l+l-1)\end{array}\right]=\left[\begin{array}{lll}\boldsymbol{v}(k l) & \ldots & \boldsymbol{v}(k l+l-1)\end{array}\right]+$

$$
\varsigma(q-k l+l) \nu \gamma\left(\sin \left(\frac{2 \pi}{N \vartheta i}\right) \exp ^{\varrho i}\right) ;
$$

nos quais,

$\varrho, \vartheta$ e $\nu$ são números aleatórios distintos com distribuição uniforme entre 0 e 1.

Há dois tipos de atribuições do sinal de detonação:

1. Atribuição por bloco;

2. Atribuição por bloco aleatório;

Estes são atribuídos da seguinte maneira:

Atribuição $1=$

$$
\begin{cases}\text { Se o restante de } \frac{k}{2}=0 ; & \boldsymbol{u}=\boldsymbol{v}+\boldsymbol{s}\left(-\frac{I(k)-1}{2}\right) \\ \text { Se o restante de } \frac{k}{2} \neq 0 ; & \boldsymbol{u}=\boldsymbol{v}\end{cases}
$$

Atribuição $2=$

$$
\begin{cases}\text { Se o restante de } \frac{k}{2}=-1 ; & \boldsymbol{u}=\boldsymbol{v}+\boldsymbol{s}\left(-\frac{I(k)-1}{2}\right) \\ \text { Se o restante de } \frac{k}{2} \neq 0 ; & \boldsymbol{u}=\boldsymbol{v}\end{cases}
$$


no qual,

$$
I(k)=\left\{\begin{array}{l}
1, k=(\varrho-\vartheta)>0 \\
-1, k=(\varrho-\vartheta)<0
\end{array}\right.
$$

O gerador de sinais oferece uma combinação de todos os cenários acima, permitindo um ambiente de testes flexível. Tais combinações geram os sinais mostrados na Figura 29 e descritos na Tabela 1. 
Figura 29 - Opções de geração de detonação ao sinal simulado do sensor

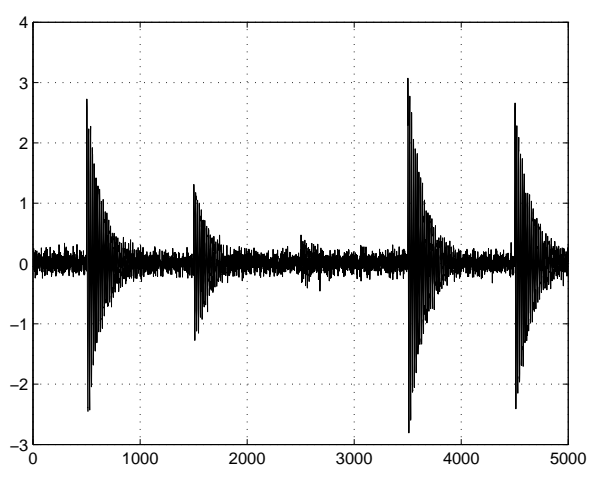

Opção 1

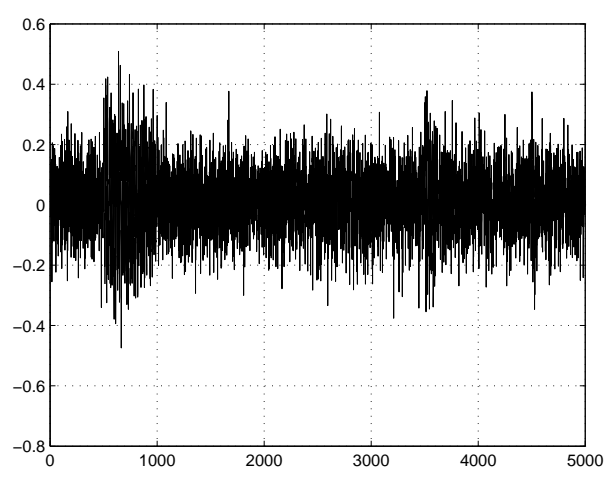

Opção 3

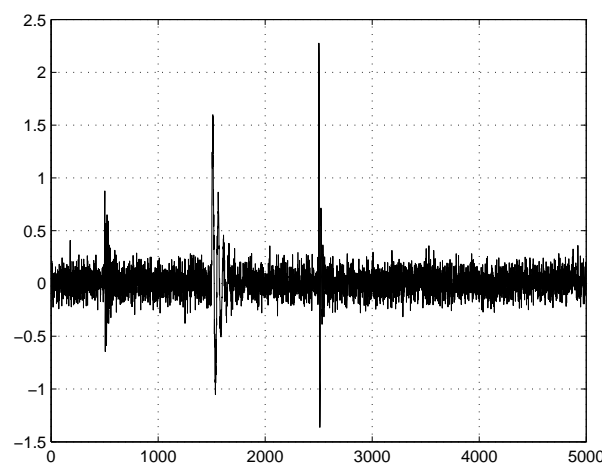

Opção 5

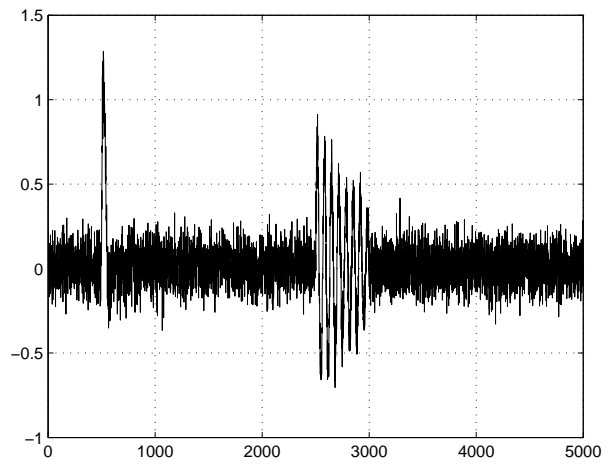

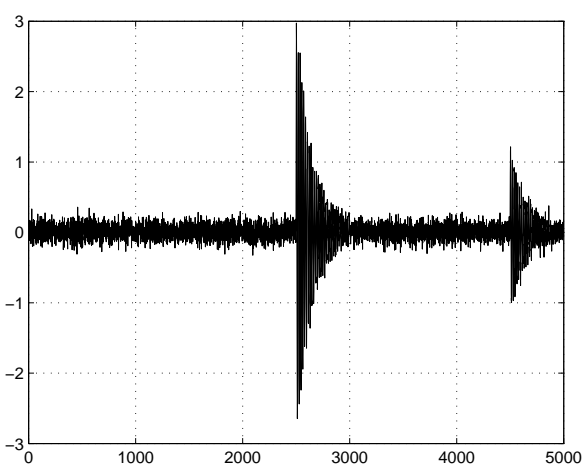

Opção 2

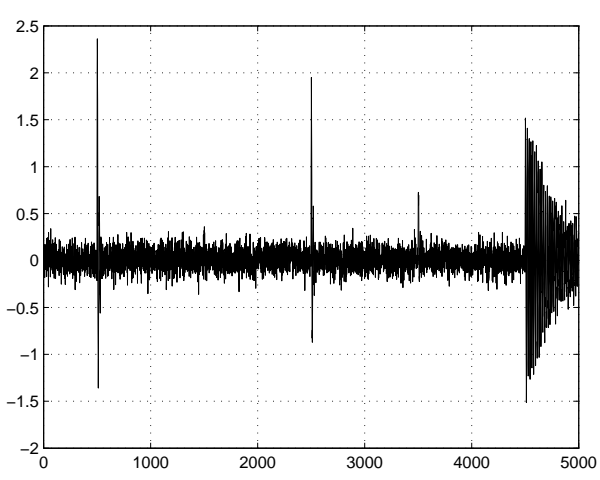

Opção 4

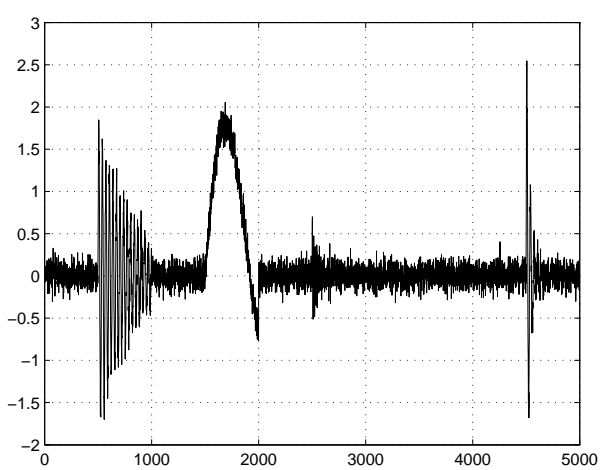

Opção 6

Fonte: Autor.

Opção 7 


\subsubsection{Escolha e aplicação dos algoritmos de tratamento de sinais}

\section{Filtros adaptativos}

Na seção 3.7, foram apresentados os algoritmos propostos para a resolução do problema apresentado previamente na seção 4.1. A aplicação dos filtros adaptativos deve ser justificada tanto por sua maior complexidade computacional frente aos estimadores de potência como também da motivação de sua escolha. A utilização de filtros adaptativos justifica-se pela configuração PA, conforme descrito na seção 3.7.

Considerando o modelo de sinal da seção 4.2.1, wo pode ser calculado como segue:

$$
w^{o}=R_{u}^{-1} R_{d u}
$$

E também conforme visto na seção 3.4.6, pode-se ter duas formas de operação para os algoritmos propostos: (a) operação normal e (b) detonação:

- (a) Operação Normal: $\boldsymbol{u}(i)=\boldsymbol{v}(i)$.

Neste modo de operação, dado que $\boldsymbol{v}(i)$ é ruído branco e $\boldsymbol{u}(i)$ é o sinal resultante do sensor,

$R_{\boldsymbol{u}}=\mathbf{E} \boldsymbol{u}^{*} \boldsymbol{u}=\sigma_{\boldsymbol{v}}^{2} I \mathrm{e}$

$R_{\boldsymbol{d} \boldsymbol{u}}=\mathbf{E} \boldsymbol{u}(i) \boldsymbol{u}_{i-1}^{*}=0$

Por isso, $w_{i}^{o}=0_{M \times 1}$, i.e., é numericamente zero.

- (b) Detonação: $\boldsymbol{u}(i)=s(i)+\boldsymbol{v}(i)$.

Neste modo de operação, a oscilação vista no sensor por conta de detonação pode ser vista como uma parte correlacionada embutida no sinal resultante, de forma que,

$$
\begin{aligned}
R_{\boldsymbol{u}} & = \\
\mathbf{E} \boldsymbol{u}^{*} \boldsymbol{u} & = \\
\left(s_{i-1}+\boldsymbol{v}_{i-1}\right)^{*}\left(s_{i-1}+\boldsymbol{v}_{i-1}\right) & = \\
s_{i-1}^{*} s_{i-1}+\sigma_{\boldsymbol{v}}^{2} I & \\
R_{\boldsymbol{d} \boldsymbol{u}} & = \\
\mathbf{E} \boldsymbol{u}(i) \boldsymbol{u}_{i-1}^{*} & = \\
(s(i)+\boldsymbol{v}(i))\left(s_{i-1}+\boldsymbol{v}_{i-1}\right)^{*} & = \\
s(i) s_{i-1}{ }^{*} &
\end{aligned}
$$

com,

$$
s_{i-1}=\left[\begin{array}{lll}
s(i-1) & \ldots & s(i-M)
\end{array}\right]
$$


sendo o regressor e,

$$
\boldsymbol{v}_{i-1}=\left[\begin{array}{lll}
\boldsymbol{v}(i-1) & \ldots & \boldsymbol{v}(i-M)
\end{array}\right]
$$

Para encontrar o vetor de coeficientes $w_{i}$ em (4.5) com algumas manipulações chegase a:

$$
w^{o}=R_{u}^{-1} R_{d u}
$$

equação que requer uma inversão da matriz $R_{u}$. Aplicando o lema de inversão de matriz (SAYED, 2008; LOPES et al., 2010), em $R_{\boldsymbol{u}}$, tem-se:

$$
\begin{array}{r}
R_{\boldsymbol{u}}{ }^{-1}= \\
\frac{1}{\sigma_{\boldsymbol{v}}^{2}} I-\frac{1}{\sigma_{\boldsymbol{v}}^{2}} s_{i-1}{ }^{*}\left(1+s_{i-1} \frac{1}{\sigma_{\boldsymbol{v}} s_{i-1}{ }^{*}}\right)^{-1} s_{i-1} \frac{1}{\sigma_{\boldsymbol{v}}^{2}}= \\
\frac{1}{\sigma_{\boldsymbol{v}}^{2}} I-\frac{1}{\sigma_{\boldsymbol{v}}^{2}} s_{i-1} *\left(\frac{1}{\sigma_{\boldsymbol{v}}^{2}+s_{i-1} s_{i-1}}\right) s_{i-1} .
\end{array}
$$

Empregando este resultado em (4.7), como feito anteriormente em (LOPES et al., 2010) e utilizando (4.6), implica que:

$$
\begin{aligned}
{\left[\frac{1}{\sigma_{v}^{2}} I-\frac{1}{\sigma_{\boldsymbol{v}}^{2}} s_{i-1} *\right.} & \left.\left(\frac{1}{w^{o}+s_{i-1} s_{i-1}}\right) s_{i-1}\right] s(i) s_{i-1}{ }^{*}= \\
\frac{s_{i-1} s_{i-1}{ }^{*}}{\sigma_{\boldsymbol{v}}^{2}}\left(1-\frac{s_{i-1} s_{i-1}{ }^{*}}{\sigma_{\boldsymbol{v}}^{2}-s_{i-1} s_{i-1}}\right) &
\end{aligned}
$$

Sabendo que $s_{i-1} s_{i-1}{ }^{*}=c$ na qual $c$, é uma constante, finalmente tem-se que:

$$
w^{o}=\frac{s(i) s_{i-1}^{*}}{\sigma_{\boldsymbol{v}}^{2}}\left(1-\frac{c}{\sigma_{\boldsymbol{v}}^{2}-c}\right) .
$$

E de forma iterativa (4.10) pode ser expressada da seguinte maneira, $w_{i}^{o}=R_{\boldsymbol{u}}{ }^{-1} R_{\boldsymbol{d} u}=$ $\frac{s(i) s_{i-1}^{*}}{\sigma_{\boldsymbol{v}}^{2}}\left(1-\frac{c}{\sigma_{\boldsymbol{v}}^{2}-c}\right) \neq 0$, isto é, $w_{i}^{o}$ é numericamente diferente de zero.

Esta propriedade pode ser explorada eficientemente para detectar o fenômeno de detonação. Para isso, pode-se estabelecer um certo limiar, THR, em que se deve verificar as componentes do preditor ótimo $w_{i}^{o}$ a cada iteração $i$ e compará-las a tal limiar. Tendo $\left[w_{i}^{o}\right]_{n}$ como a n-ésima componente do vetor $w_{i}^{o}$, se $\left[w_{i}^{o}\right]_{n} \geq(T H R)$, uma detonação aconteceu. Ao passo que, se $\left[w_{i}^{o}\right]_{n}<(T H R>0)$ o motor é declarado 
estar em operação normal de funcionamento. A entrada de $\left[w_{i}^{o}\right]_{n}$ escolhida para tal comparação, ou mesmo para melhor caracterizar o fenômeno é com $n=1$, devido à primeira entrada de $w_{i}^{o}$ tender a ser a maior dentre todas as componentes $n$ em virtude da correlação de $s(i)$ consigo mesmo (PAPOULIS; PILLAI, 2004). A determinação do limiar THR não faz parte do escopo deste trabalho.

O próximo passo é o de projetar de forma eficiente $w_{i}^{o}$. Tal projeto é complexo devido os parâmetros do sinal $s(i)$ não serem conhecidos a priori, conforme visto na seção 3.7.1. De maneira alternativa, as equações normais podem ser solucionadas de forma aproximada com os algoritmos adaptativos (seção 3.7) (SAYED, 2008).

Para uma estimativa inicial $w_{-1}$, o mesmo pode ser atualizado (otimizado) de maneira adaptativa como:

$$
w_{i}=w_{i-1}+\mu p_{i}
$$

com $p_{i}$ sendo um vetor de atualização direcional. Note que a equação (4.11) é a base para o algoritmo gradiente descendente mostrado na seção 3.7. Se $p_{i}$ for escolhido seguindo a regra estocástica do algoritmo gradiente descendente, os algoritmos $L M S$ e NLMS podem ser obtidos conforme mostrado na seção 3.7 e (SAYED, 2008).

Ambos os algoritmos foram testados com sucesso, conforme será mostrado a seguir. Se $\mu$ for escolhido corretamente, após algumas iteracões $w_{i}$ será estatisticamente próximo de $w_{i}^{o}$. Se um certo limiar, $T H R$, for cautelosamente escolhido, os algoritmos adaptativos mostrados podem ser indicadores da ocorrência de detonacão como mencionado anteriormente. A única diferença é que os testes são conduzidos com $w_{i}$, ao invés de (por ser desconhecido, como comentado) $w_{i}^{o}$. Uma vez que o pico de detonação foi detectado, o tempo de decaimento ao ruído de fundo THR pode ser tomado como uma forma indireta de se medir o comprimento do sinal de detonação ou sua duração.

\section{Estimador de Potência}

Observando o algoritmo definido em (3.20) e dado que a potência instântanea de um sinal tem muitas variações (3.18), para tornar o estimador de potência útil para a caracterização da detonação (onde o ruído de fundo já é algo indesejado), o termo respectivo à potência total do sinal deve possuir peso maior. Para se obter tal comportamento, foi escolhido $\alpha=0.99$.

Conforme definido em (OPPENHEIM; R., 1999), devido à energia do ruído branco $\boldsymbol{v}$, ser uma constante e definida por:

$$
E_{v}=\sigma_{v}^{2}
$$


se a amplitude do sinal de detonação for próxima à amplitude do ruído branco, a energia de ambos será próxima e, com isto, a ocorrência do fenômeno não será indicada de forma clara o que o torna inviável para a detecção neste cenário.

\subsubsection{Método de teste dos algoritmos}

Os algoritmos mostrados até esta seção serão testados de forma individual e combinada para se estabelecer a melhor forma de se caracterizar o fenômeno. As Figuras 30 e 31 mostram tais combinações.

Figura 30 - Combinação do algoritmo $L M S$ com o estimador de potência

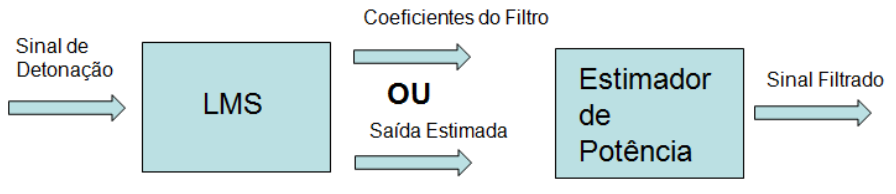

Fonte: Autor.

Figura 31 - Combinação do algoritmo $N L M S$ com o estimador de potência

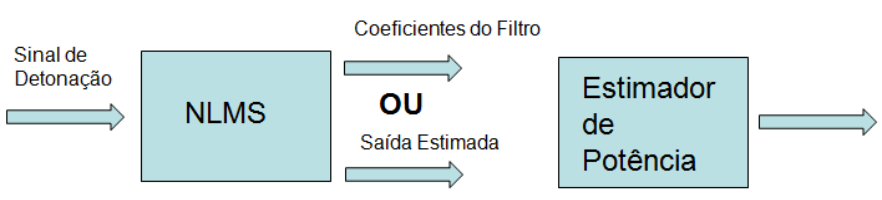

Fonte: Autor.

Para os testes há quatro casos a serem considerados:

\section{Caso normal de ocorrência de detonação}

Este item pode ser considerado como os casos em que a ocorrência do fenômeno é visivelmente perceptível. Isto ocorre quando o pico devido à detonação é muito maior do que os picos devidos ao ruído branco.

O ambiente de simulação escolhido para os resultados deste cenário foi o respectivo à opção 4 mostrada na seção 4.2.1. Esta opção foi escolhida dentre as possíveis por apresentar frequência fixa, a qual é interpretada como sendo a típica de detonação e aleatoriedade necessária nos outros parâmetros (decaimento, ocorrência e amplitude). 
O cenário crítico é o cenário respectivo à opção 1, porém com detonações de alta amplitude. A denominação foi dada devido a este cenário apresentar maior correlação em seu total devido a soma de componente amortecida em todos os blocos em que a atribuição é possível, fato que ocasionou um dos algoritmos propostos apresentar tendência a divergir, sendo testado em tal cenário.

\section{Detonação e ruído branco com amplitudes próximas}

Já o terceiro caso pode ser considerado para as ocorrências de detonação de baixa intensidade, em que o respectivo pico seria muito próximo aos picos decorrentes do ruído branco. Este cenário é o respectivo à opção 4, porém com detonações de baixa amplitude.

\section{Sinal obtido de uma detonação real}

É o cenário real de ocorrência do fenômeno. Para tal teste, o sinal real foi coletado de um veículo VW Pólo 2.0 Litros em um dinamômetro de rolo inercial. Para causar a detonação, os seguintes procedimentos são realizados:

a) O ângulo de ignição é adiantado do ponto nominal de calibração da $E C U$ para causar a detonação. Isto é feito por uma unidade de controle desenvolvida pelo grupo de estudos de eletrônica automotiva resultante de uma cooperação entre EPUSP e FATEC Santo André, por isso, a descrição da mesma está fora do escopo deste trabalho e foi feita em (PEREIRA, 2013).

b) Carro parado posicionado no dinamômetro de rolo.

c) Ligar o carro.

d) Iniciar aceleração com a primeira marcha engatada.

e) Esperar o veículo desenvolver no máximo $10 \mathrm{~km} / \mathrm{h}$ nas marchas iniciais, por exemplo:

$1^{a}$ marcha: Acelerar até $10 \mathrm{~km} / \mathrm{h}$

$2^{a}$ marcha: Acelerar até $25 \mathrm{~km} / \mathrm{h}$

$3^{a}$ marcha: Acelerar até $35 \mathrm{~km} / \mathrm{h}$

$4^{a}$ marcha: Acelerar até $45 \mathrm{~km} / \mathrm{h}$

$5^{a}$ marcha: Acelerar até $55 \mathrm{~km} / \mathrm{h}$

Durante todo o experimento, o pedal do acelerador é totalmente acionado. Isto gera uma maior solicitação de torque para o motor via $E C U$, em razão de que a rotação do motor está baixa assim como a velocidade desenvolvida pelo rolo para a marcha selecionada. Isto faz com que a pressão no interior da câmara aumente e, por consequência, a temperatura. 
f) Coletar o sinal proveniente do sensor de detonação com um osciloscópio. Na ocorrência do fenômeno, detectada de forma auditiva e visual no aparelho, a imagem do osciloscópio é parada e exportada para planilhas eletrônicas.

É assumido que os algoritmos aqui apresentados são utilizados após uma filtragem analógica passa-faixa, ou após o estágio de seleção de faixa de frequência ótima para detecção do fenômeno conforme mostrado em (STOTSKY, 2007a).

Dados os métodos apresentados, as simulações com os algoritmos foram realizadas no programa $M A T L A B^{\circledR}$ e os resultados apresentados no capítulo que segue. 


\section{Resultados e análises}

\subsection{Desempenho individual dos algoritmos propostos}

Neste capítulo, serão apresentados os resultados obtidos com as simulações descritas no capítulo 4. Na primeira seção, os resultados individuais de cada algoritmo são mostrados e em seguida os resultados provenientes da combinação dos mesmos. Na segunda seção, os desempenhos individuais e combinados são comparados. Por fim, na terceira seção, os algoritmos propostos são comparados com métodos existentes para tratamento do sinal do fenômeno. Para cada experimento, uma Tabela com os parâmetros para observação de $w_{i}$ e $\hat{\boldsymbol{d}}$, para o melhor desempenho, é mostrada.

Os gráficos são dados em amplitude em função de iterações e não em função de graus de avanço de ignição, pois são provenientes de simulações. O mesmo vale para as formas de onda do sinal real, na qual a obtenção foi feita a partir de exportação do sinal obtido em osciloscópio sem observação ou controle do avanço de ignição aplicado.

\subsubsection{Cenário 1: caso normal de ocorrência de detonação}

Tabela 2 - Cenário 1 - Configurações para o $L M S$

\begin{tabular}{|l|l|l|}
\hline Algoritmo & Parâmetros & $\begin{array}{l}\text { SNR do Sinal } \\
\text { Aplicado [db] }\end{array}$ \\
\hline $\boldsymbol{L M S}\left(w_{i}\right)$ & $\mu=0.15$ e $M=2$ & 18.8643 \\
\hline $\boldsymbol{L} \boldsymbol{M} \boldsymbol{S}(\hat{\boldsymbol{d}})$ & $\mu=0.1$ e $M=4$ & 18.8643 \\
\hline
\end{tabular}

\section{1. $L M S$}

A convergência do $L M S$ na configuração de preditor adaptativo se mostrou muito sensível ao tamanho de passo $\mu$, dependendo da ordem $M$ escolhida.

Tendo $\mu=0.15$, o desempenho de caracterização oferecido por tal filtro mostrouse razoável, sob certos limites, com algumas escolhas específicas da ordem do filtro. Com $M=2$, o filtro mostrou o melhor desempenho em termos de estabilidade e caracterização do fenômeno, isto é, as ocorrências são claramente visíveis e distintas do ruído de fundo, assim como o decaimento ao mesmo. Com valores de ordem maiores que este, sob o mesmo $\mu$, o filtro mostrou tendência em divergir, pois, como mostrado em (SAYED, 2008), sob condições não estacionárias, o tamanho de passo $\mu$ deve seguir a seguinte relação para 
estabilidade e convergência em sentido médio quadrático (mean square stability):

$$
\sum_{k=1}^{M} \frac{\lambda_{k} \mu}{2-\lambda_{k} \mu}<1
$$

para valores reais e,

$$
\frac{1}{2} \sum_{k=1}^{M} \frac{\lambda_{k} \mu}{1-\lambda_{k} \mu}<1
$$

para valores complexos. Assumindo que $\lambda_{k}$ seja a componente da diagonal de $R_{\boldsymbol{u}}$, implica que $\lambda_{k}=\sigma_{u}^{2}$, então, substituindo em (5.1 e 5.2):

$$
M \sigma_{u}^{2} \mu<1-\sigma_{u}^{2} \mu \text { (real) e } M \sigma_{u}^{2} \mu<2-2 \sigma_{u}^{2} \mu \text { (complexo) }
$$

Logo,

$$
\mu<\frac{2}{(M+2) \sigma_{u}^{2}}
$$

para valores reais e,

$$
\mu<\frac{2}{(M+1) \sigma_{u}^{2}}
$$

para valores complexos. As equações (5.3 e 5.4) mostram que quanto maior a ordem $M$, menor deverá ser o tamanho de passo $\mu$, o que pôde ser comprovado neste experimento, pois mantendo $\mu$ fixo e aumentando-se a ordem do filtro, o mesmo divergiu a partir de $M=6$.

As realizações do vetor de coeficientes $w_{i}$ no tempo, mostraram a melhor forma de caracterização do fenômeno como mostrado na seção 4.2.2. Quando não há ocorrência de detonação os valores das componentes do vetor são próximos de 0 , ao passo que na ocorrência de detonação os coeficientes adquirem valores significativamente maiores que 0 .

Além destes resultados, o algoritmo mostrou em sua saída estimada $\boldsymbol{d}$, ou $\hat{\boldsymbol{d}}$, uma ação de remoção de ruído ou denoising, onde é possível perceber de forma mais clara o amortecimento no sinal do sensor devido à detonação. 
Figura 32 - Cenário 1 individual - Evolução dos coeficientes $w_{i}$ e saída do estimador de potência

Realizações de $\mathrm{W}_{\mathrm{i}}$ no Decorrer do Tempo, $\mu=0.15$ Ordem $=2$ para o LMS

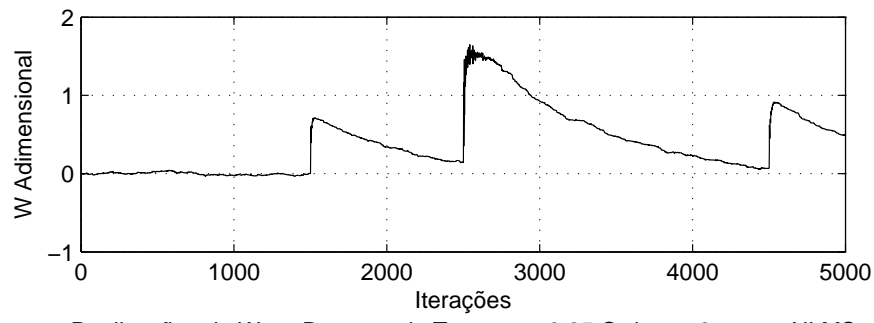

Realizações de $\mathrm{W}_{\mathrm{i}}$ no Decorrer do Tempo, $\mu=0.25$ Ordem $=2$ para o NLMS
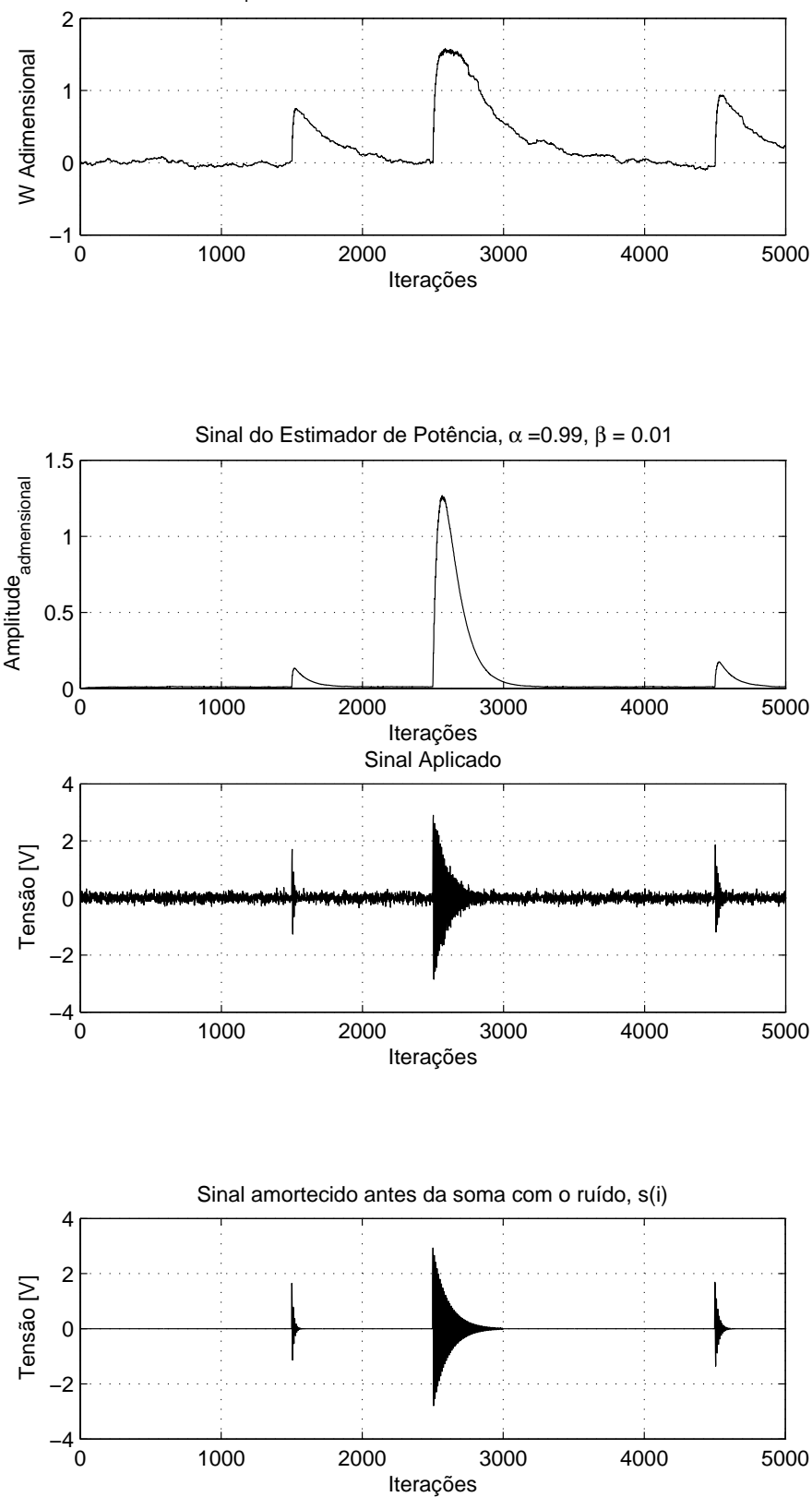

Fonte: Autor. 
Com a configuração inicial, $\mu=0.15$ e $M=2$, o filtro atenuou a $S N R$ do sinal de entrada para $14.5 d b$ na saída estimada deste algoritmo, porém removendo boa parte do ruído. A ação de remoção do ruído de fundo foi melhorada com o aumento do valor de $M$ e diminuição do valor de $\mu$, obedecendo ao estabelecido em (5.3 e 5.4), na qual com $M=4$ e $\mu=0.1$ foi obtida a melhor relação sinal ruído. Nesta configuração, a saída apresentou uma $S N R=21 d b$ contra os $18 d b$ do sinal de entrada. As formas de onda podem ser verificadas na Figura 33. Observando o vetor de coeficientes com os valores da configuração para remoção de ruído, foi verificada maior lentidão do filtro, devido à redução do tamanho de passo e aumento da ordem do mesmo.

\section{NLMS}

Tabela 3 - Cenário 1 - Configurações para o $N L M S$

\begin{tabular}{|l|l|l|}
\hline Algoritmo & Parâmetros & $\begin{array}{l}\text { SNR do Sinal } \\
\text { Aplicado [db] }\end{array}$ \\
\hline NLMS $\left(w_{i}\right)$ & $\begin{array}{l}\mu=0.25, M=2 \\
\text { e } \epsilon=0.651\end{array}$ & 18.8643 \\
\hline NLMS $(\hat{\boldsymbol{d}})$ & $\begin{array}{l}\mu=1.1, M=5 \text { e } \\
\epsilon=0.651\end{array}$ & 18.8643 \\
\hline
\end{tabular}

Foi observado que quanto maior o tamanho de passo, mais veloz o algoritmo se comportava, porém com nível de variações diretamente proporcional. Inicialmente, o NLMS foi testado com $\mu=0.15$.

Prosseguindo com os experimentos em busca de melhor desempenho, alterou-se os valores dos parâmetros do algoritmo para diversos valores. No entanto, com $\mu$ maior que 0.25 as variações tornaram-se excessivas, assim como valores de $M$ maiores que 2 . Portanto, o melhor desempenho obtido foi com $\mu=0.25$ e $M=2$, enquanto que para utilização de remoção de ruídos ou denoiser, a melhor configuração foi $\mu=1.1$ e $M=5$, configuração que rendeu uma $S N R$ de $32.23 d b$ na saída estimada do $N L M S$, um ganho de mais de $10 d b$ em relação ao sinal de entrada.

\section{Estimador de potência}

Apresentou excelente caracterização do fenômeno, mostrando em sua saída apenas o entorno do sinal e fazendo com que o ruído branco fosse representado por valores próximos de zero. O desempenho para o cenário 1 pode ser visto na Figura 32. 
Figura 33 - Cenário 1 individual - Ação de denoising e evolução dos valores estimados $\hat{\boldsymbol{d}}$, saída do estimador de potência

Saída Estimada a partir dos $\mathrm{W}_{\mathrm{i}}$ Econtrados $\mu=0.1$ Ordem $=4$ para o LMS

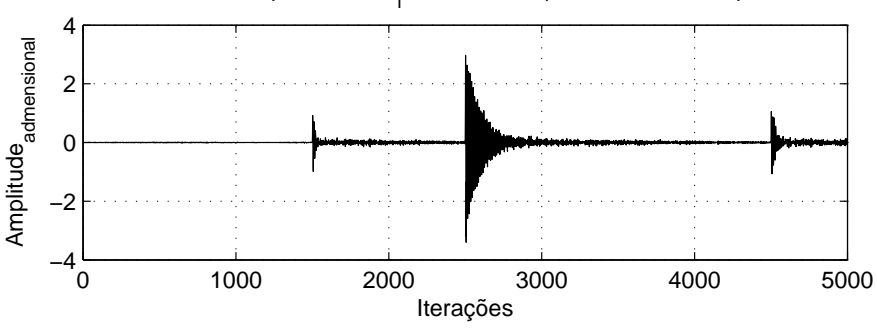

Saída Estimada a partir dos W.s Econtrados $\mu=1.1$ Ordem $=5$ para o NLMS
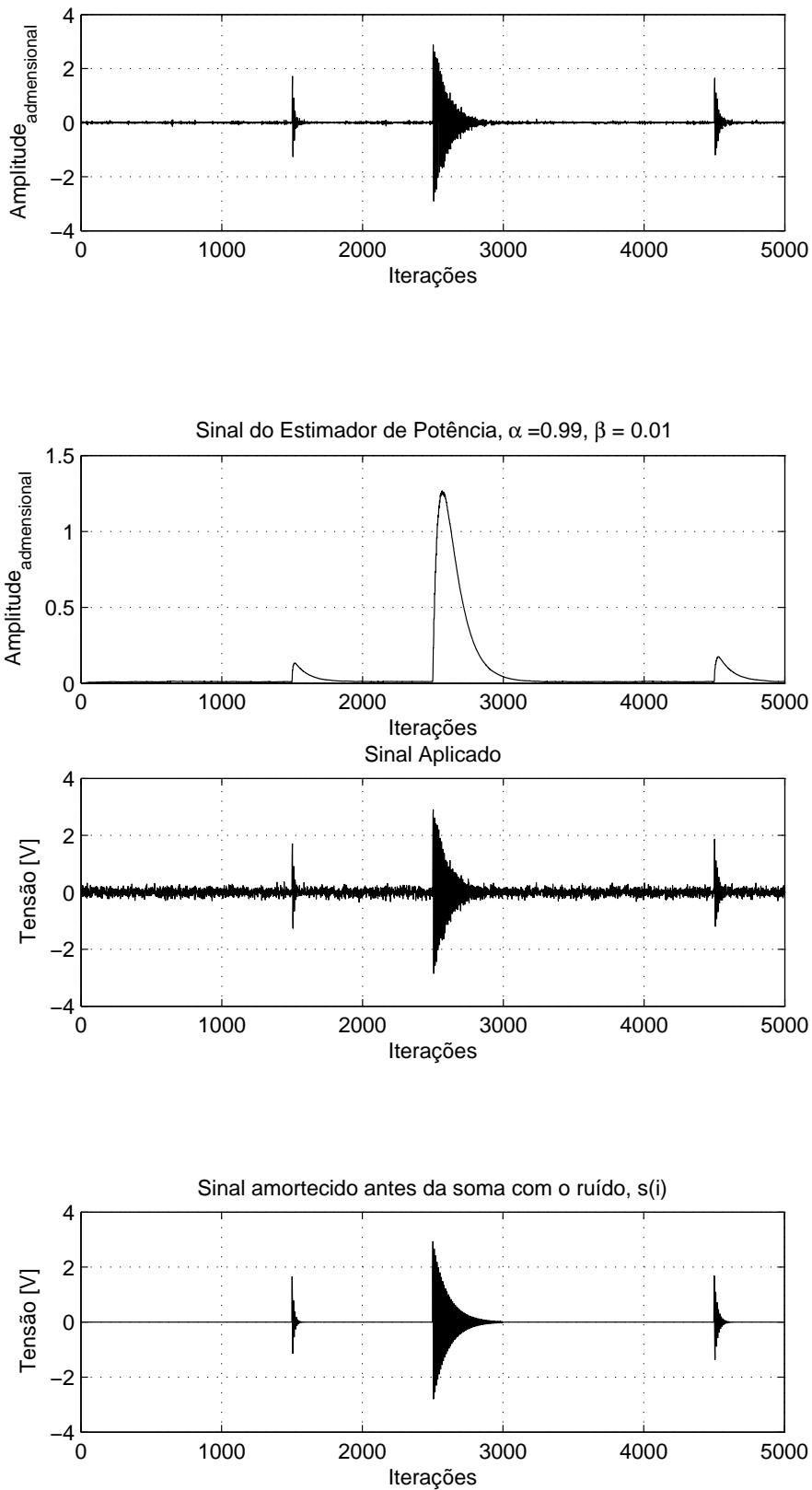

Fonte: Autor. 


\subsubsection{Cenário 2: caso crítico de detecção do fenômeno}

1. $L M S$

Tabela 4 - Cenário 2 - Configurações para o $L M S$

\begin{tabular}{|l|l|l|}
\hline Algoritmo & Parâmetros & $\begin{array}{l}\text { SNR do Sinal } \\
\text { Aplicado [db] }\end{array}$ \\
\hline $\boldsymbol{L M S}\left(w_{i}\right)$ & $\begin{array}{l}\mu=0.001 \text { e } M= \\
4\end{array}$ & 19.2451 \\
\hline $\boldsymbol{L M S}(\hat{\boldsymbol{d}})$ & $\mu=0.1$ e $M=4$ & 19.2451 \\
\hline
\end{tabular}

Neste cenário o algoritmo mostrou tendência à divergência. Para que este não divergisse foi necessário utilizar valores muito baixos de $\mu$ se comparado ao experimento anterior, valores maiores que $M=4$, com $\mu=0.001$, causavam divergências no filtro. Mesmo obedecendo as relações (5.3 e 5.4), não foi possível extrair melhor desempenho deste filtro, valores maiores de $\mu$ trouxeram maiores variações para os coeficientes do filtro. No entanto, a ação de denoising do filtro foi satisfatória e apresentou uma de $S N R$ para $22 d b$, ganho de quase $3 d b$ com relação à entrada.O desempenho desenvolido pelo LMS neste cenário pode ser observado na Figura 34.

2. NLMS

Tabela 5 - Cenário 2 - Configurações para o NLMS

\begin{tabular}{|l|l|l|}
\hline Algoritmo & Parâmetros & $\begin{array}{l}\text { SNR do Sinal } \\
\text { Aplicado [db] }\end{array}$ \\
\hline NLMS $\left(w_{i}\right)$ & $\begin{array}{l}\mu=0.32, M=10 \\
\text { e } \epsilon=0.3\end{array}$ & 19.2451 \\
\hline NLMS $(\hat{\boldsymbol{d}})$ & $\begin{array}{l}\mu=0.049, M= \\
15 \text { e } \epsilon=0.7\end{array}$ & 19.2451 \\
\hline
\end{tabular}

Este algoritmo apresentou um desempenho robusto se comparado ao LMS. A ordem necessária para uma boa caracterização do fenômeno somente foi possível com $M=10$ e $\mu=0.3$. Valores inferiores de $\mu$ mostraram um desepenho de rastreamento do sinal lento (capacidade de acompanhar as variações do sinal de entrada) e valores superiores de $M$ não mostraram fidelidade na relação de grandeza entre os picos (neste caso, os picos são crescentes a cada ocorrência).

A caracterização do fenômeno foi possível nos coeficientes de $w_{i}$. No entanto, cada indicação de ocorrência não decaiu de forma exponencial como o sinal aplicado. A configuração aplicada no cenário 1 não apresentou êxito para caracterizar o fenômeno no cenário 2 , pois os picos representados nos coeficientes apresentaram variações e amplitudes próximas. O desempenho de remoção do ruído apresentou atenuação da $S N R$ para $17 d b$, com $M=15$ e $\mu=0.049$, a qual foi a melhor configuração obtida. 
O termo $\epsilon$ foi significante para melhorar o desempenho deste algoritmo. Para se observar $w_{i}$, o melhor $\epsilon$ foi igual a 0.3 , ao passo que para a ação de denoising o melhor $\epsilon$ foi igual a 0.7. A forma como este parâmetro foi empregado serve como um ajuste fino, na qual um valor pequeno faz com que $\mu$ seja maior (como pode ser visto em (3.17)), fazendo então com que o desempenho de rastreamento do filtro seja mais rápido, o que é desejável quando a aplicação requer a utilização de $w_{i}$. Um valor menor de $\mu$, ocasionado por um $\epsilon$ maior, provê uma estimativa mais estável de $\hat{d}$ por tornar o filtro mais lento e gerar coeficientes com menos variações em $w_{i}$. Além disso, valores menores de $\mu$ possibilitam o aumento da ordem de $M$ em obediência a (5.3 e 5.4), fazendo assim com que a banda de bloqueio do filtro aumente, removendo assim mais eficientemente o ruído aditivo de banda larga, $v(i)$, do sinal de entrada, apresentando esta remoção na saída estimada do filtro. Resultados similares de aumento da $S N R$ e melhora da estimativa do sinal de banda estreita, com aumento da ordem, foram obtidos em (KOSHITA et al., 2011; LOPES et al., 2009).

3. Estimador de potência

Apresentou excelente caraterização do fenômeno, apresentando em sua saída apenas o entorno do sinal e fazendo com que o ruído branco fosse representado por zero. No entanto, novamente deixou a desejar na fidelidade de indicação de amplitude o que pode ser observado na amplitude dos 3 últimos picos.

O desempenho para o cenário 2 pode ser visto nas Figuras 34 e 35. 
Figura 34 - Cenário 2 individual - Evolução dos coeficientes $w_{i}$ e saída do estimador de potência

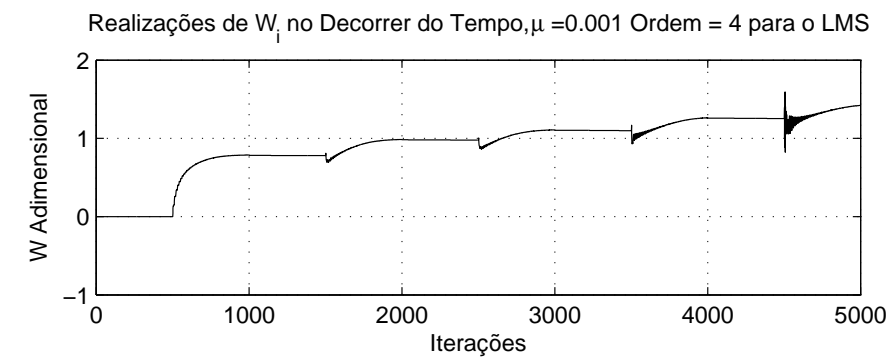

Realizações de $\mathrm{W}_{\mathrm{i}}$ no Decorrer do Tempo, $\mu=0.32$ Ordem $=10$ para o NLMS
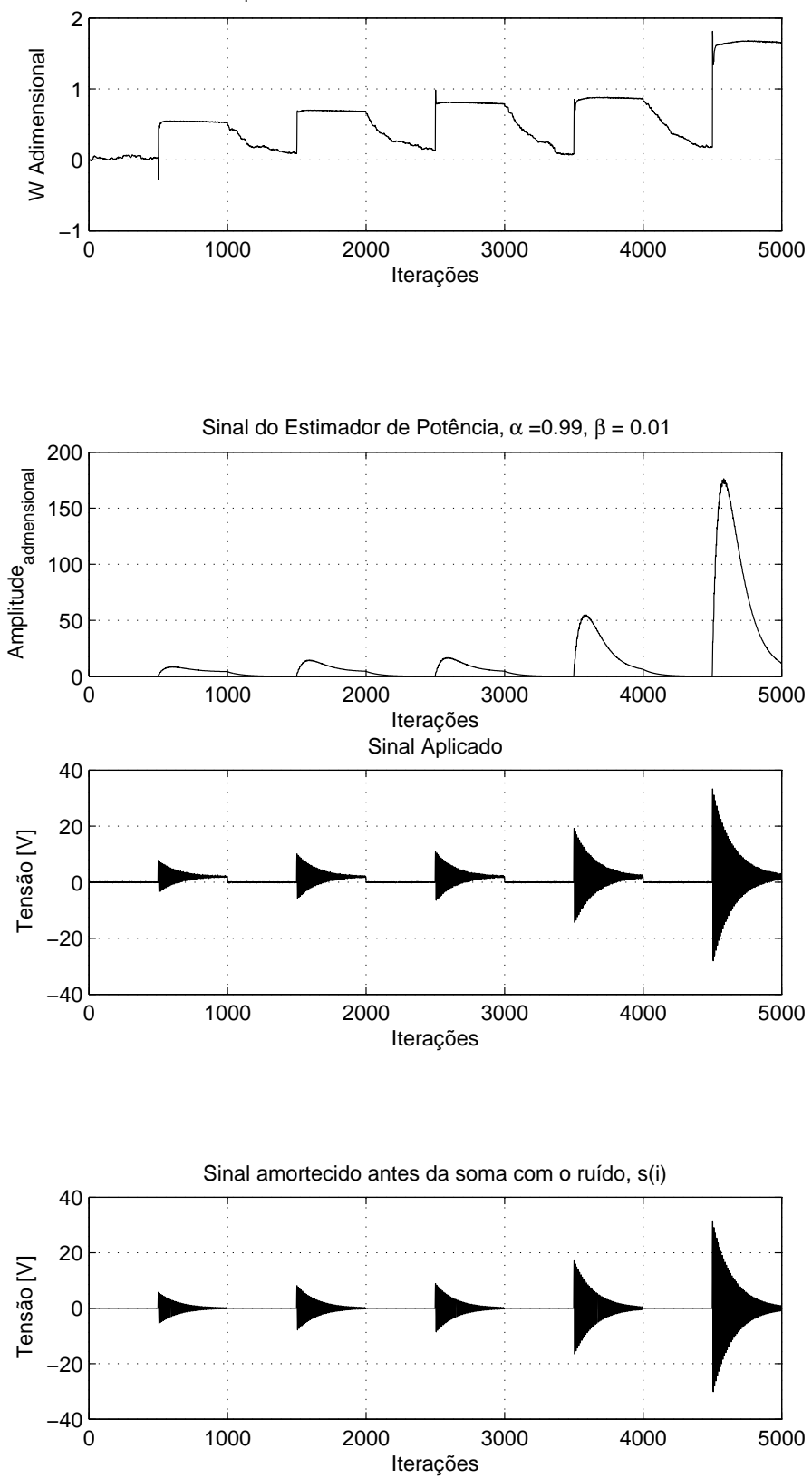

Fonte: Autor. 
Figura 35 - Cenário 2 individual - Ação de denoising e evolução dos valores estimados $\hat{\boldsymbol{d}}$, saída do estimador de potência
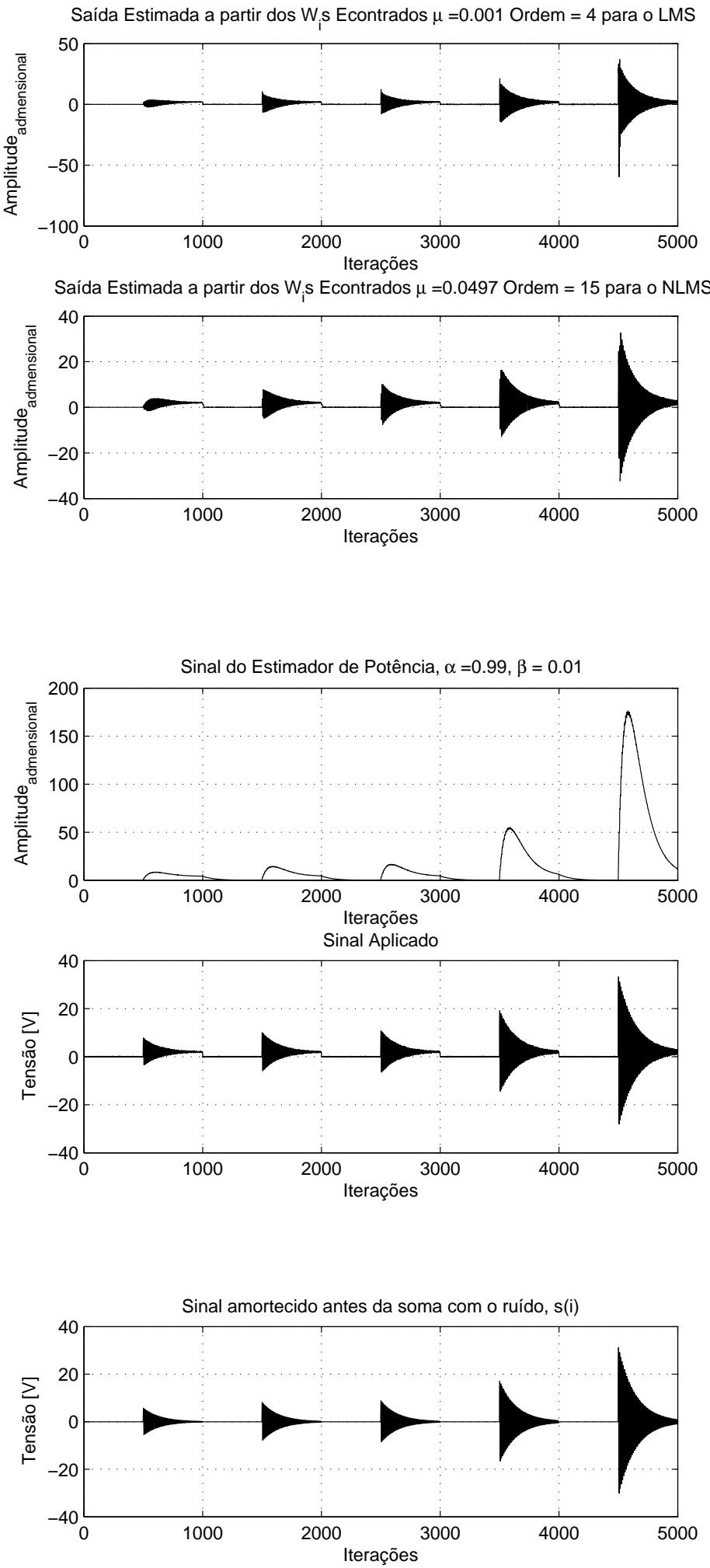

Fonte: Autor. 


\subsubsection{Cenário 3: detonação e ruído branco com amplitudes próximas}

1. $L M S$

Tabela 6 - Cenário 3 - Configurações para o $L M S$

\begin{tabular}{|l|l|l|}
\hline Algoritmo & Parâmetros & $\begin{array}{l}\text { SNR do Sinal } \\
\text { Aplicado [db] }\end{array}$ \\
\hline $\boldsymbol{L M S}\left(w_{i}\right)$ & $\mu=0.7$ e $M=1$ & 1.1154 \\
\hline $\boldsymbol{L M S}(\hat{\boldsymbol{d}})$ & $\mu=0.5$ e $M=15$ & 1.1154 \\
\hline
\end{tabular}

Neste cenário, foi possível aumentar o valor de $\mu$ para 0.7 e obter um desempenho de rastreamento mais rápido para observação de $w_{i}$, no entanto, valores menores praticados no cenário 1 também foram bem sucedidos mas não tão fiéis em caracterização. Muitas variações foram percebidas no vetor de coeficientes $w_{i}$ para este cenário de baixa $S N R$. A ação de denoising exigiu um grande aumento na ordem do filtro para $M=15$. Tal aumento justifica-se pelo fato de implicar em um maior estreitamento na banda de transição do filtro, fazendo assim com que o sinal altamente degradado (baixa $S N R$ ) seja recuperado, devido a remoção do ruído branco, possibilitada pelo alto valor da ordem utilizada do filtro. Tal configuração resultou em um ganho de cinco vezes de $S N R$. O sinal obtido na saída estimada do filtro, apresentou uma $S N R$ de $5.5239 \mathrm{db}$.

\section{NLMS}

Tabela 7 - Cenário 3 - Configurações para o NLMS

\begin{tabular}{|l|l|l|}
\hline Algoritmo & Parâmetros & $\begin{array}{l}\text { SNR do Sinal } \\
\text { Aplicado [db] }\end{array}$ \\
\hline $\boldsymbol{N L M S ( w _ { i } )}$ & $\begin{array}{l}\mu=0.2, M=1 \text { e } \\
\epsilon=0.2\end{array}$ & 1.1154 \\
\hline $\boldsymbol{N L M S}(\hat{\boldsymbol{d}})$ & $\begin{array}{l}\mu=0.5, M=15 \\
\text { e } \epsilon=0.8\end{array}$ & 1.1154 \\
\hline
\end{tabular}

Para este cenário a melhor caracterização do fenômeno, observada nos coeficientes de $w_{i}$, foi obtida com $\mu=0.2$ e $M=1$, no entanto, valores menores praticados no cenário 1 também foram bem sucedidos mas com desempenho lento de rastreamento do sinal. A ação de denoising, assim como no $L M S$, exigiu alta ordem do filtro e apresentou bom desempenho com a mesma configuração aplicada ao $L M S$. Para o $N L M S$ a $S N R$ da saída foi de $5.1224 d b$, ganho de quase cinco vezes com relação à entrada do filtro.

3. Estimador de Potência

No cenário experimentado, este algoritmo mostrou o sinal aplicado com variações e uma indicação falsa ao final do experimento por volta da iteração 4500. Devido este filtro não ser sensível à estatística do sinal como os algoritmos adaptativos, este tipo de acontecimento pode ocorrer para quando a intensidade de detonação for muito baixa, ou mesmo quando a amplitude de ambos, ruiído de fundo e detonação, forem próximas. 
Figura 36 - Cenário 3 individual - Desempenho de remoção do ruído dos filtros adaptativos $L M S, N L M S$ e saída do estimador de potência

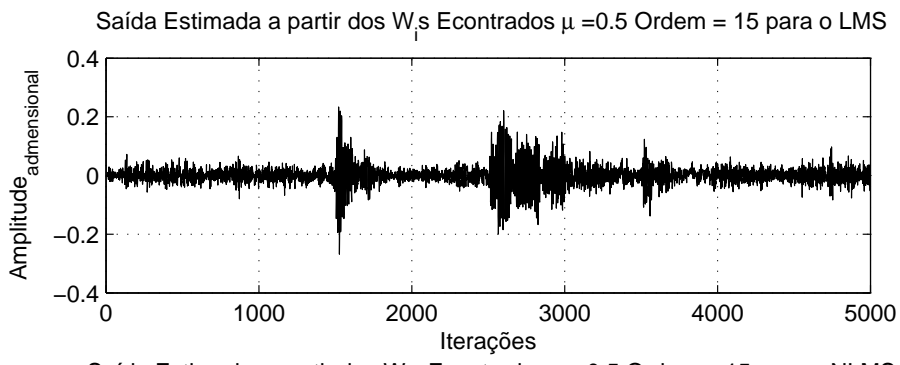

Saída Estimada a partir dos W.s Econtrados $\mu=0.5$ Ordem $=15$ para o NLMS
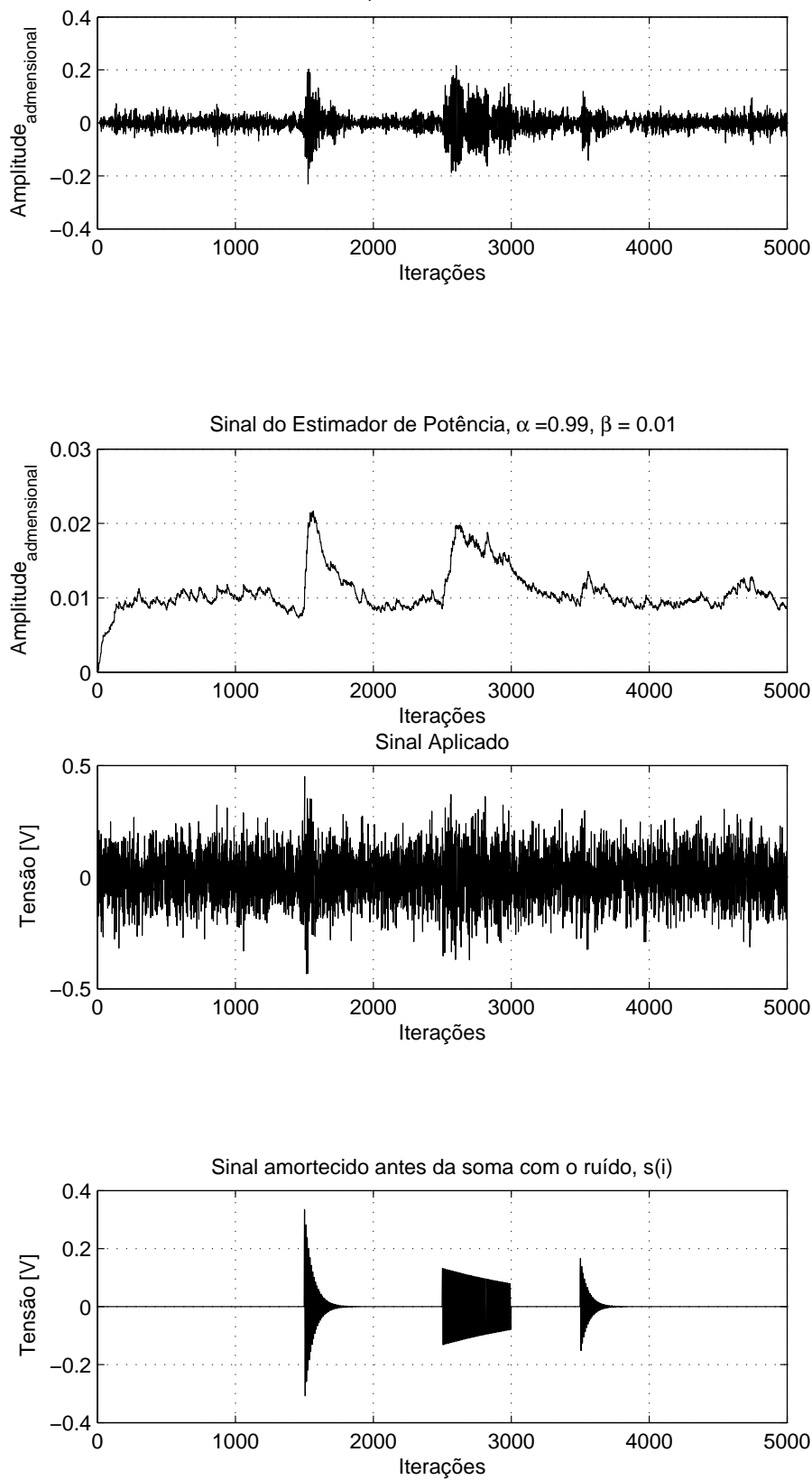

Fonte: Autor. 
Figura 37 - Cenário 3 individual - Evolução dos coeficientes $w_{i}$ e saída do estimador de potência
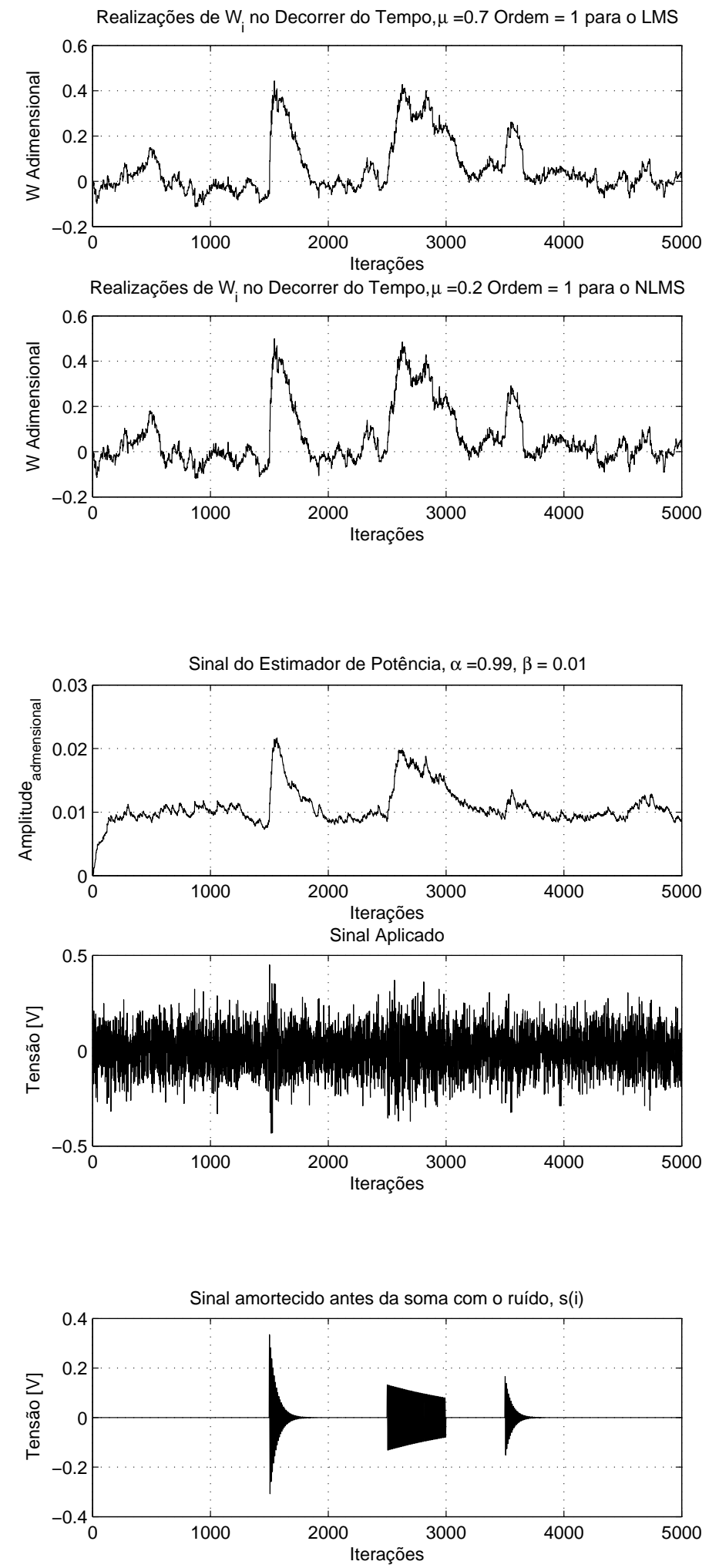

Fonte: Autor. 


\subsubsection{Cenário 4: sinal obtido de uma detonação real}

A aplicação dos sinais reais obtidos com o procedimento mencionado no capítulo 4 mostraram os seguintes resultados:

\section{1. $L M S$}

Este algoritmo divergiu e não apresentou qualquer indicação do fenômeno.

2. NLMS

Tabela 8 - Cenário 4 - Configurações para o NLMS

\begin{tabular}{|l|l|}
\hline Algoritmo & Parâmetros \\
\hline NLMS $\left(w_{i}\right)$ & $\begin{array}{l}\mu=0.25, M=2 \text { e } \\
\epsilon=0.05\end{array}$ \\
\hline NLMS $(\hat{d})$ & $\mu=0.55, M=2$ \\
\hline
\end{tabular}

Este algoritmo apresentou uma indicação pobre do fenômeno nos coeficientes $w_{i}$ e na saída estimada um bom desempenho de remoção do ruído de fundo. A Figura 38 mostra este resultado e sua respectiva configuração.

3. Estimador de potência

Apresentou boa indicação do fenômeno mostrando em sua saída a envoltória do sinal. A Figura 39 mostra esse resultado. 
Figura 38 - Cenário 4 individual - Evolução dos coeficientes $w_{i}$ e saída estimada do NLMS com sinal real de detonação
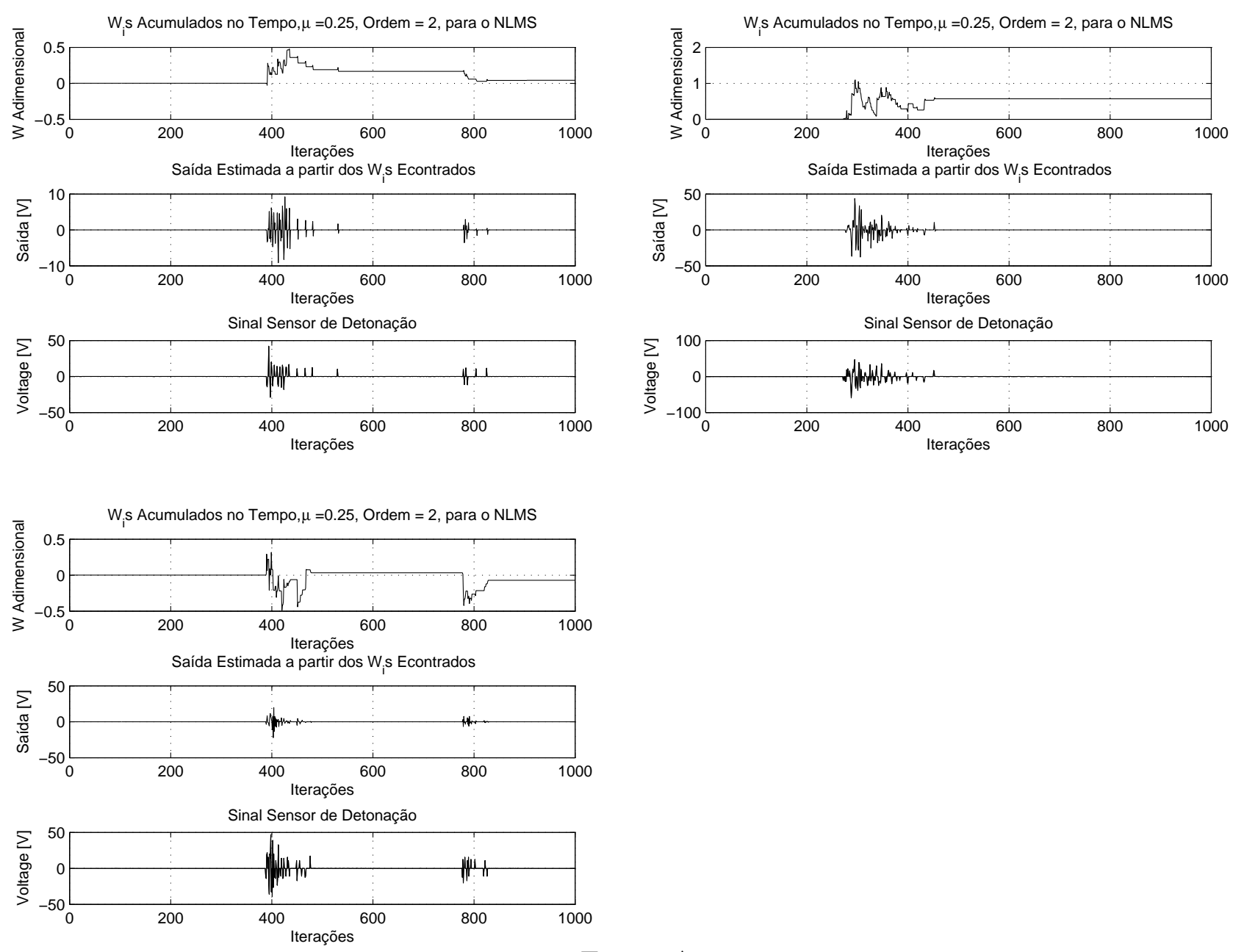

Fonte: Autor. 
Figura 39 - Cenário 4 individual - Saída estimada do estimador de potência com o sinal real de detonação
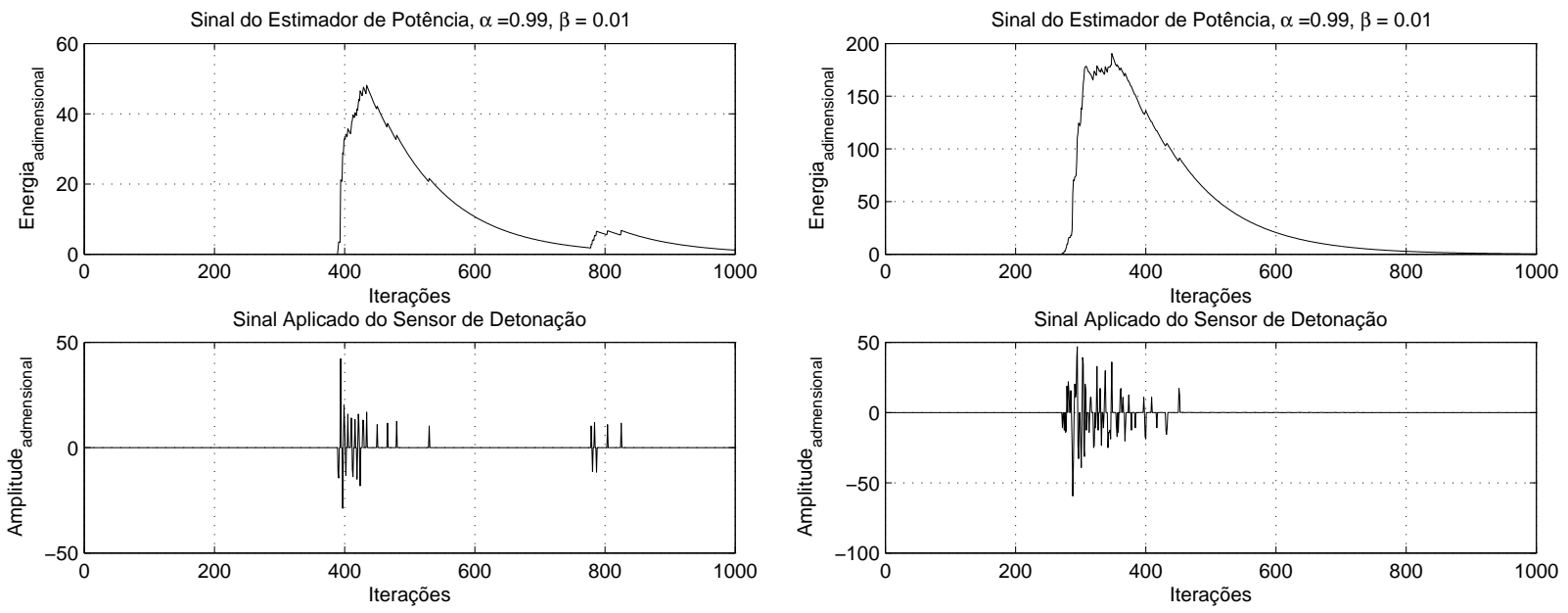

$\mathrm{b}$
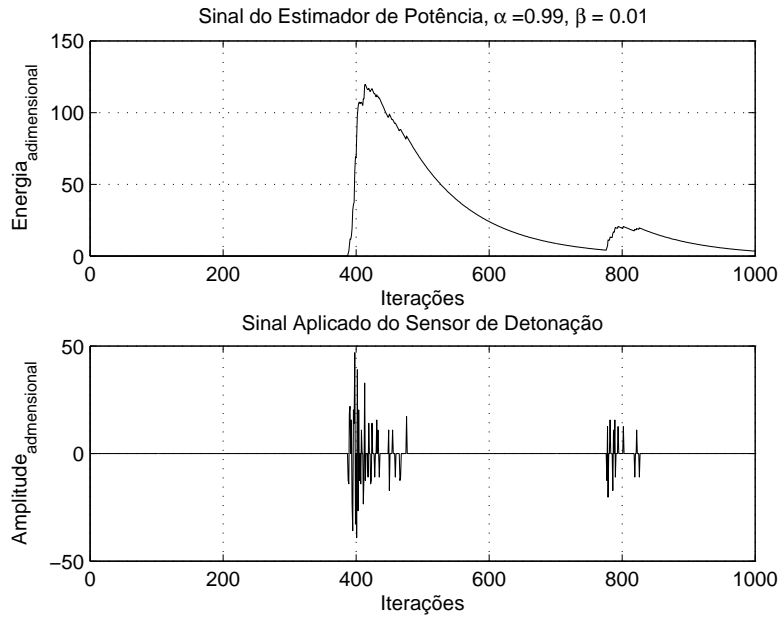

Fonte: Autor.

\subsection{Desempenho combinado dos algoritmos propostos}

Dados os resultados obtidos, otimizações são possíveis de serem realizadas.

Com o resumo feito na Tabela 9 é possível ter uma figura do melhor que pode ser extraído da cada algoritmo para um desempenho superior ao observado até o momento. A característica do $N L M S$ de rápido rastreamento, justificado por sua definição oriunda do método de Newton, poderia ser combinada com a caracterização obtida com o estimador de potência para uma melhor representação do fenômeno. A confiabilidade e simplicidade do $L M S$ combinadas com o estimador de potência poderia resultar numa combinação simples, fácil de se implementar em um sistema embarcado. As propriedades mencionadas dos algoritmos adaptativos estão em (SAYED, 2008). 
Tabela 9 - Tabela comparativa entre os 3 algoritmos propostos

\begin{tabular}{|c|c|c|}
\hline Algoritmo & Vantagem & Desvantagem \\
\hline$N L M S$ & $\begin{array}{l}\text { Bom desempenho de remoção do } \\
\text { ruído de fundo } \hat{d} \text { comparado ao me- } \\
\text { lhor resultado obtido com o estima- } \\
\text { dor de potência. Com altos valo- } \\
\text { res de } \mu \text { o desempenho de rastrea- } \\
\text { mento de } w_{i} \text { caracteriza o fenômeno } \\
\text { de forma satisfatória e rápida, fiel na } \\
\text { representação de picos como denoi- } \\
\text { ser }\end{array}$ & $\begin{array}{l}\text { Altos valores de ordem necessários } \\
\text { para ter desempenho melhor que o } \\
\text { atingido com o } L M S \text { porém, com va- } \\
\text { riações, valores pequenos de } \mu \text { fa- } \\
\text { zem com que detonações com valores } \\
\text { próximos sejam indicadas com am- } \\
\text { plitudes praticamente iguais. }\end{array}$ \\
\hline$L M S$ & $\begin{array}{l}\text { Boa caracterização nos valores de } \\
w_{i} \text {, baixa ordem necessária para } \\
\text { bom desempenho, fiel na represen- } \\
\text { tação de picos como denoiser. }\end{array}$ & $\begin{array}{l}\text { Desempenho ruim de rastreamento, } \\
\text { divergência em possível cenário em } \\
\text { ambiente real. }\end{array}$ \\
\hline $\begin{array}{l}\text { Estimador } \\
\text { de Potência }\end{array}$ & $\begin{array}{l}\text { Melhor caracterização do sinal (com } \\
\text { restrições), simplicidade e veloci- } \\
\text { dade nos cálculos. }\end{array}$ & $\begin{array}{l}\text { Ruído de fundo parcialmente fil- } \\
\text { trado, indicações falsas de ocorrên- } \\
\text { cia do fenômeno, pouca fidelidade na } \\
\text { representação dos picos. }\end{array}$ \\
\hline
\end{tabular}

A caracterização do fenômeno necessita que o ruído de fundo seja minimizado ao menor valor possível e que o comportamento devido à detonação seja enfatizado ao máximo possível. Se a saída de um algoritmo for a entrada de outro, pode-se então obter uma resposta otimizada no final. Os preditores adaptativos apresentam uma característica de remoção do ruído de fundo (quando se tem um sinal de banda estreita embutido em um sinal de banda larga, $u(i)=s(i)+v(i))$, o que é uma propriedade interessante para se usar com o estimador de potência, tendo em vista que o mesmo apresentou um desempenho não tão bom na filtragem de tal ruído. Além destas características, os algoritmos adaptativos fornecem um resposta suavizada em forma de envoltória do sinal de detonação em seu vetor de coeficientes $w_{i}$. Portanto, ambas respostas suavizadas dos algoritmos LMS e NLMS poderiam ser entradas do estimador de potência.

O fator que justifique com maior força o porquê de se utilizar os algoritmos adaptativos como estágio inicial da combinação é o fato destes serem sensíveis à estatística do sinal, conforme mostrado na seção 3.7.1, ao contrário do estimador de potência que é um indicador da potência do sinal. Conforme apresentado anteriormente na seção 5.1, o estimador de potência apresentou desempenho não satisfatório na identificação do sinal no cenário de detonação com amplitude próxima do ruído de fundo por suas potências serem muito próximas. No entanto, a estatística muda drasticamente devido à parte correlacionada decorrente da detonação. O desempenho do estimador de potência também foi aquém do desejado para distinção entre amplitudes.

Os algoritmos são combinados da seguinte maneira: 
$L M S(\hat{\boldsymbol{d}}) \rightarrow(x(i))$ Estimador de Potência $\rightarrow(y(i))$

$L M S\left(w_{i}(1,1)\right) \rightarrow(x(i))$ Estimador de Potência $\rightarrow(y(i))$

$N L M S(\hat{\boldsymbol{d}}) \rightarrow(x(i))$ Estimador de Potência $\rightarrow(y(i))$

$N L M S\left(w_{i}(1,1)\right) \rightarrow(x(i))$ Estimador de Potência $\rightarrow(y(i))$

Note que, devido ao exposto na seção 4.2.2, a primeira posição do vetor $w_{i}$ é a que deverá ser aplicada no estimador de potência.

\subsubsection{Cenário 1 combinado: caso normal de ocorrência de detonação}

1. LMS com Estimador de Potência

Tabela 10 - Cenário 1 combinado - Configurações para o $L M S$

\begin{tabular}{|l|l|}
\hline Algoritmo & Parâmetros \\
\hline $\boldsymbol{L} \boldsymbol{M S}\left(w_{i}\right)$ & $\mu=0.3$ e $M=3$ \\
\hline $\boldsymbol{L} \boldsymbol{M} \boldsymbol{S}(\hat{\boldsymbol{d}})$ & $\mu=1$ e $M=4$ \\
\hline
\end{tabular}

A Figura 40 e 41 representam os experimentos feitos com o cenário típico utilizando o sinal de detonação mostrado na Figura 32. Para a combinação entre o estimador de potência e o $L M S$, utilizando o vetor de coeficientes $w_{i}$, fica claro que a combinação de algoritmos torna a caracterização do fenômeno mais eficiente se compararmos com o desempenho individual. A combinação possibilitou uma alteração na configuração dos parâmetros do $L M S$, na qual o melhor resultado foi obtido com $\mu=0.3$ e $M=3$.

No entanto, a combinação entre estes algoritmos utilizando a saída estimada do $L M S$ praticamente ocultou duas ocorrências do fenômeno de baixa intensidade, mesmo com o aumento de $\mu$ para 1 . Portanto, a melhor configuração para o cenário 1 , entre $L M S$ e estimador de potência é utilizando $w_{i}$. 
Figura 40 - Cenário 1 combinado - Saída do estimador de potência, com $w_{i}$ do $L M S$ sendo a entrada
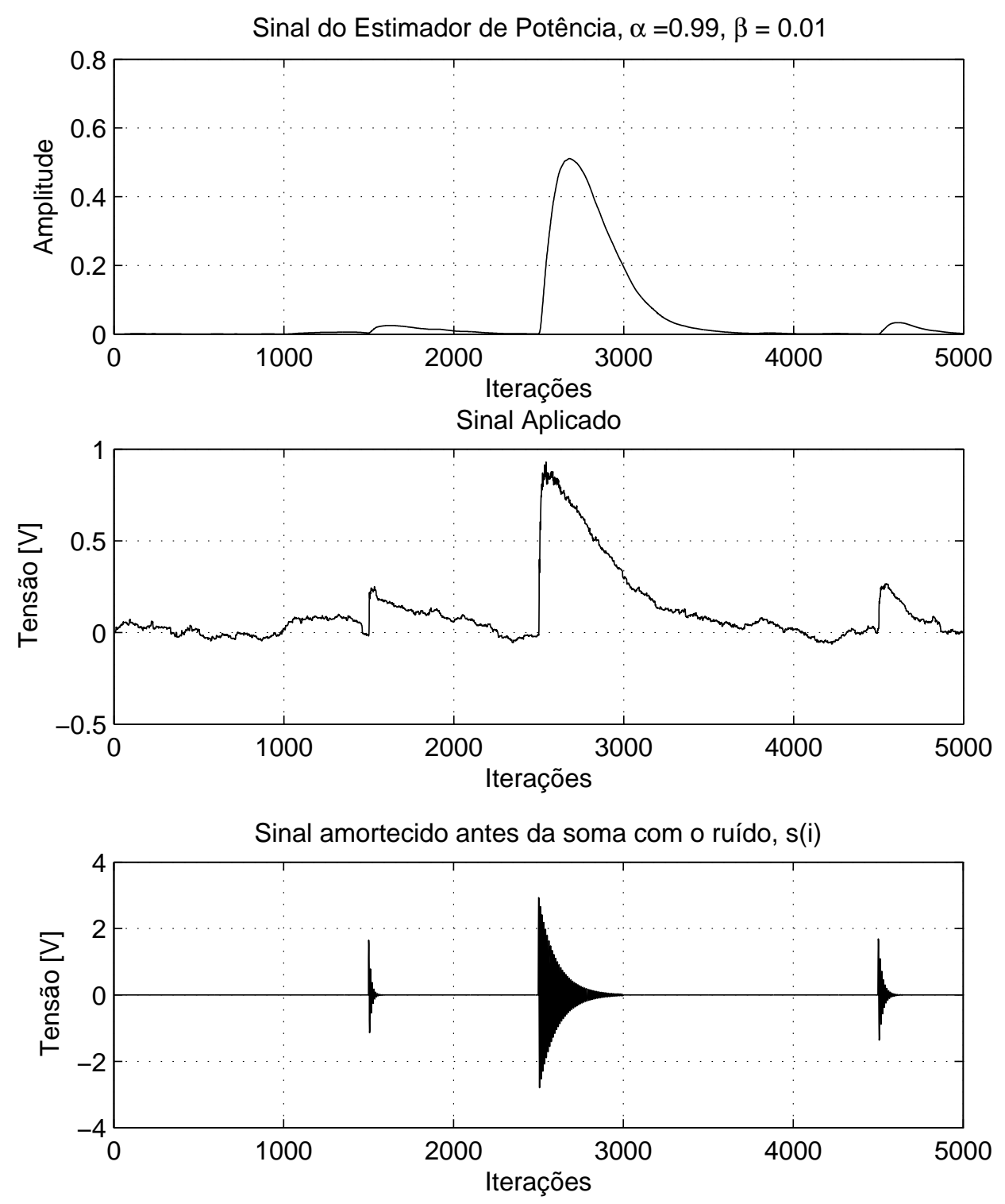

Fonte: Autor 
Figura 41 - Cenário 1 combinado - Saída do estimador de potência, com $\hat{\boldsymbol{d}}$ do $L M S$ sendo a entrada

Sinal do Estimador de Potência, $\alpha=0.99, \beta=0.01$
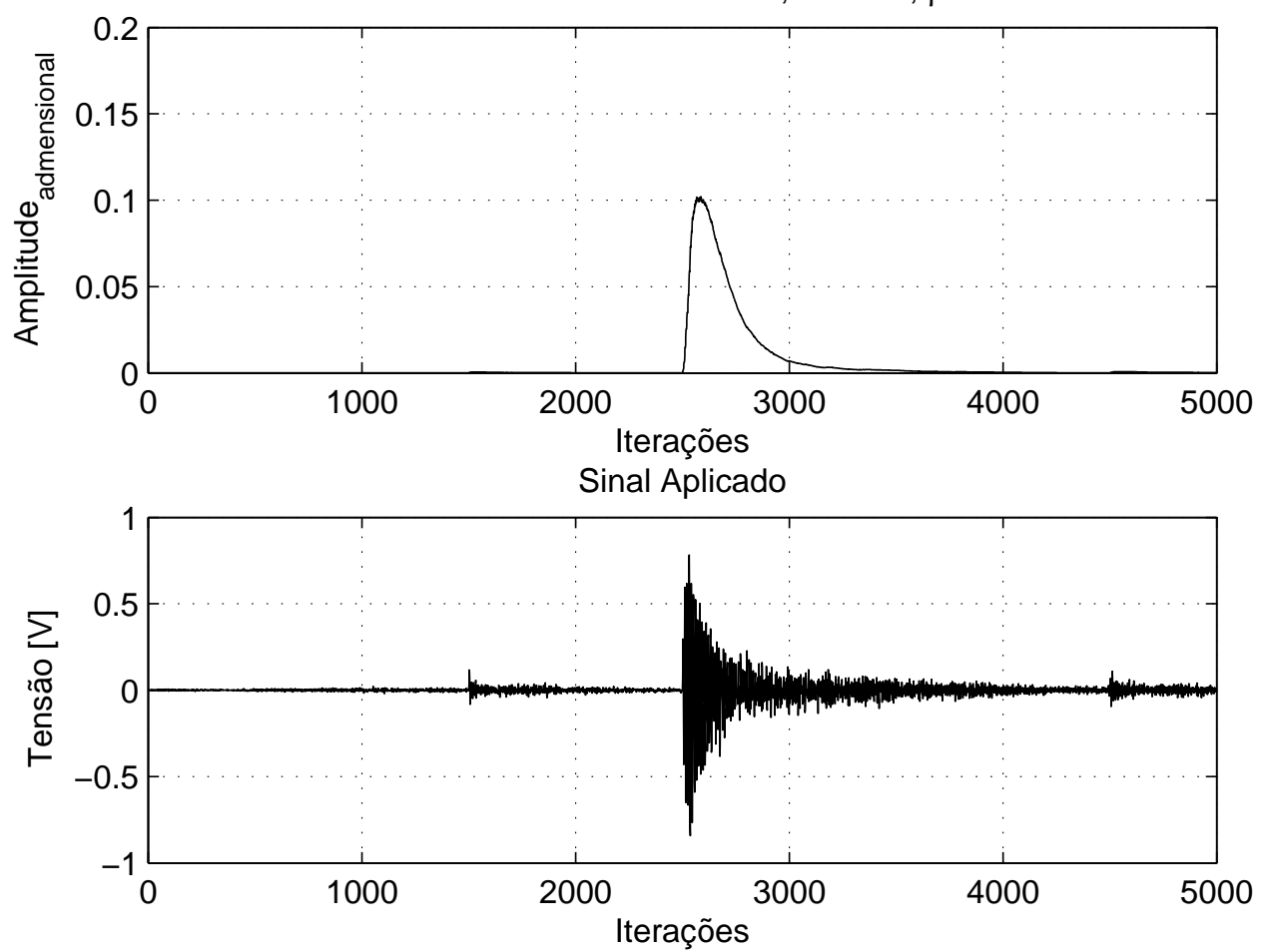

Sinal amortecido antes da soma com o ruído, s(i)

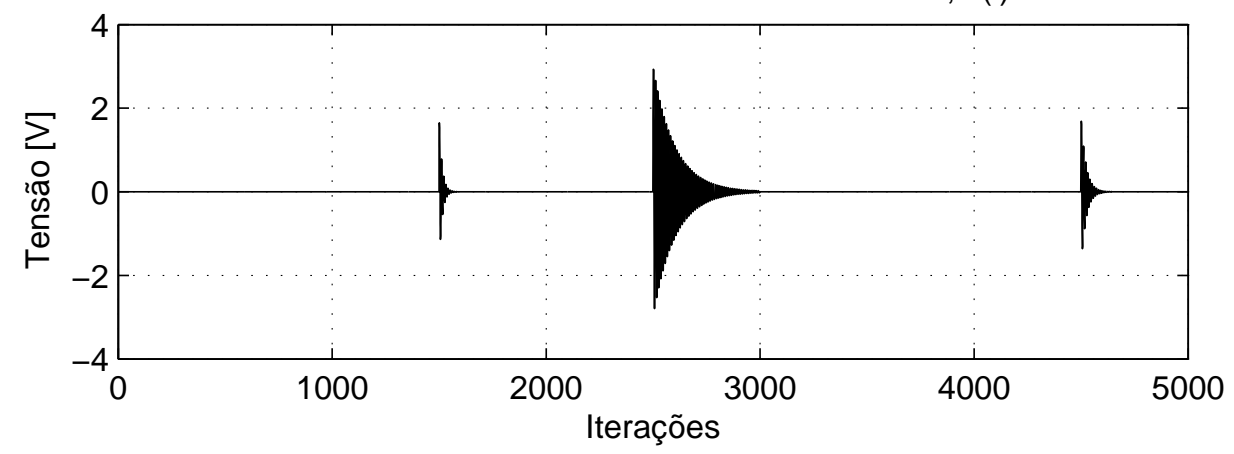

Fonte: Autor.

2. NLMS com estimador de potência

Tabela 11 - Cenário 1 combinado - Configurações para o NLMS

\begin{tabular}{|l|l|}
\hline Algoritmo & Parâmetros \\
\hline $\boldsymbol{N L M S}\left(w_{i}\right)$ & $\begin{array}{l}\mu=0.25, M=2 \mathrm{e} \\
\epsilon=0.651\end{array}$ \\
\hline $\boldsymbol{N L M S}(\hat{d})$ & $\begin{array}{l}\mu=1.1, M=5 \mathrm{e} \\
0.651\end{array}$ \\
\hline
\end{tabular}

A execução com o $N L M S$ foi feita com o valor de $\mu$ que trouxe resultados significativos o que é $\mu=0.25$ e $M=2$. Valores de $\mu=1$ e $M>2$ tiveram bom desempenho 
no quesito de rastreamento do sinal, porém com mais variações.

É possível perceber na Figura 42 que a caracterização utilizando $w_{i}$ do $N L M S$ como a entrada do estimador de potência resultou em uma saída com o sinal de detonação enfatizado de forma suavizada, destacando apenas sua envoltória e também reduzindo o ruído de fundo a praticamente zero, como era o desejado inicialmente. Fazendo uma comparação da resposta mencionada com as obtidas individualmente do $L M S$ e estimador de potência (Figura 32), é possível perceber o quanto a combinação de algoritmos é eficiente. Portanto, a melhor configuração para o cenário 1, entre ambos os algoritmos é utilizando a saída $\hat{\boldsymbol{d}}$ do $N L M S$ aplicada na entrada do estimador de potência.

Figura 42 - Cenário 1 combinado - Saída do estimador de potência, com $w_{i}$ do $N L M S$ sendo a entrada
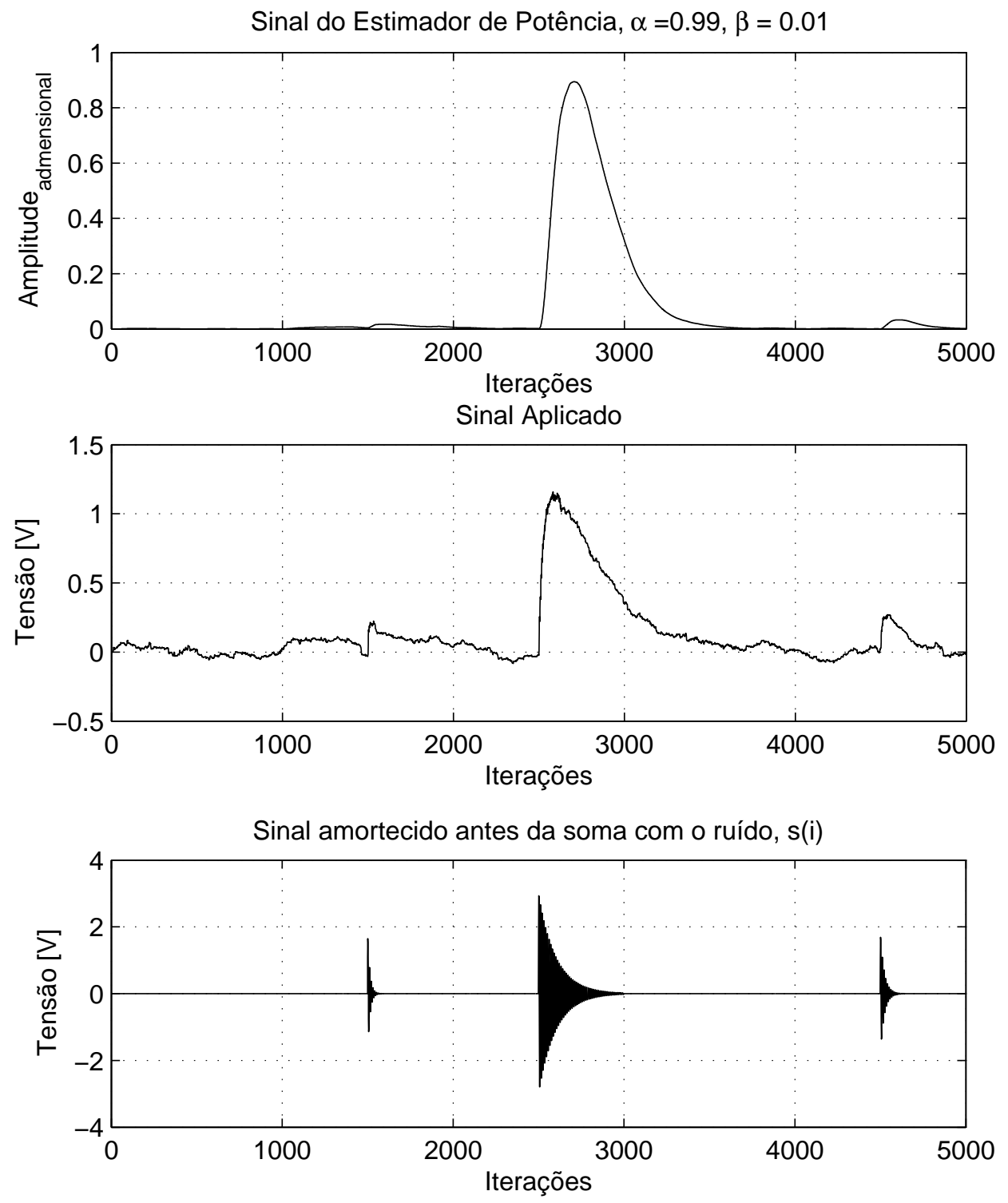

Fonte: Autor 
Figura 43 - Cenário 1 combinado - Saída do estimador de potência, com $\hat{\boldsymbol{d}}$ do $N L M S$ sendo a entrada
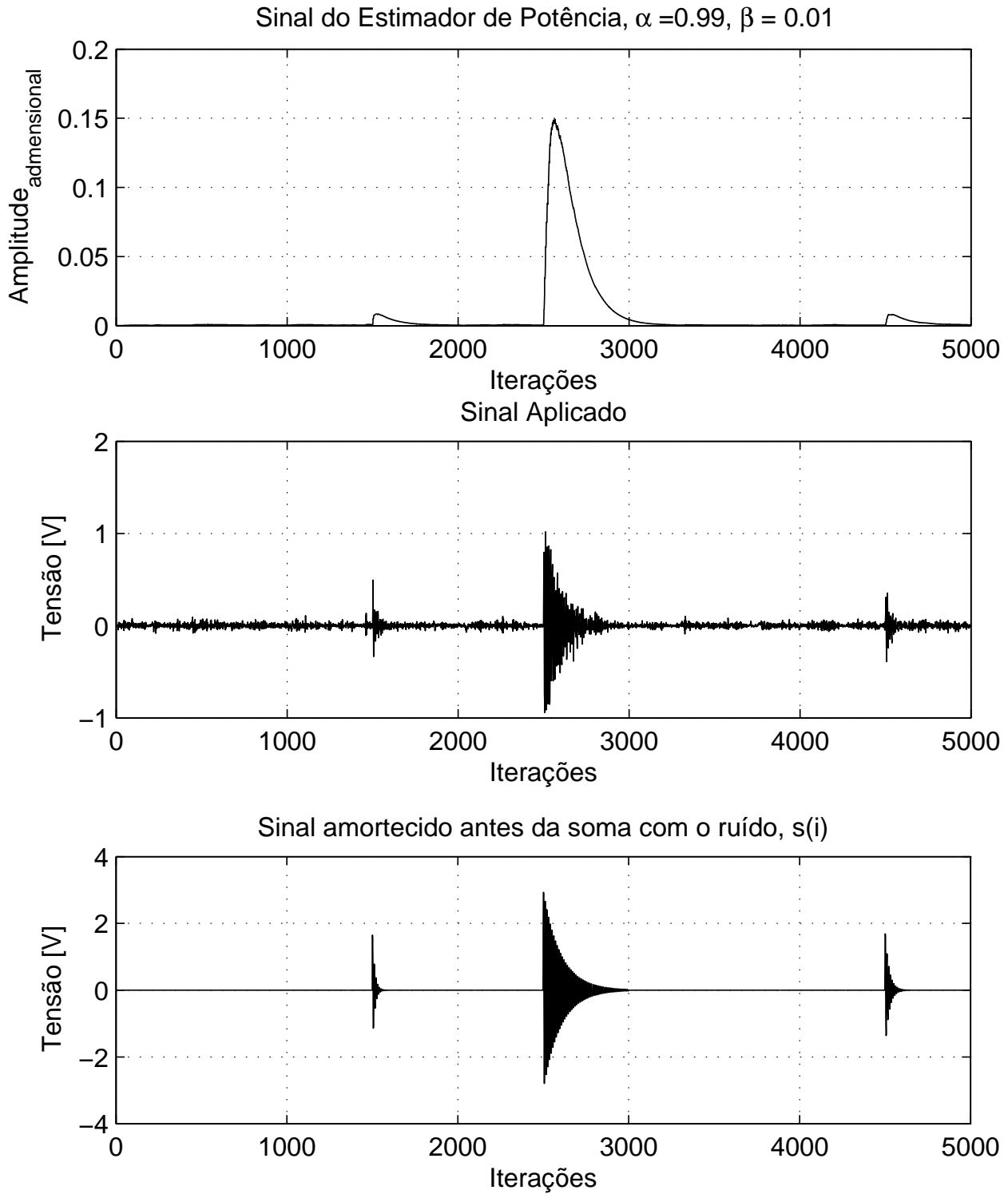

Fonte: Autor.

\subsubsection{Cenário 2: caso crítico de detecção do fenômeno}

1. $L M S$ com estimador de potência

Esta combinação não foi testada devido à divergência encontrada no $L M S$.

2. NLMS com estimador de potência

Neste cenário, os mesmos valores obtidos no experimento individual do NLMS foram utilizados, $\mu=0.32, \epsilon=0.3$ e $M=10$. A combinação entre algoritmos possibilitou uma ligeira redução na ordem para $M=9$ e aumento do passo para $\mu=0.4$, o parâmetro $\epsilon$ ajudou a melhorar ainda mais a resposta observada nos coeficientes com o $\epsilon=0.6$. Notou- 
Tabela 12 - Cenário 2 combinado - Configurações para o NLMS

\begin{tabular}{|l|l|}
\hline Algoritmo & Parâmetros \\
\hline $\boldsymbol{N L M S}\left(w_{i}\right)$ & $\mu=0.4, M=9 \mathrm{e}$ \\
& $\epsilon=0.6$ \\
\hline $\boldsymbol{N L M S}(\hat{\boldsymbol{d}})$ & $\mu=0.1, M=4 \mathrm{e}$ \\
& 0.7 \\
\hline
\end{tabular}

se que a combinação com o estimador de potência apresentou uma suavização eficiente das variações obtidas tanto nos coeficientes como na saída estimada do NLMS.

Figura 44 - Cenário 2 combinado - Saída do estimador de potência, com $w_{i}$ do $N L M S$ sendo a entrada
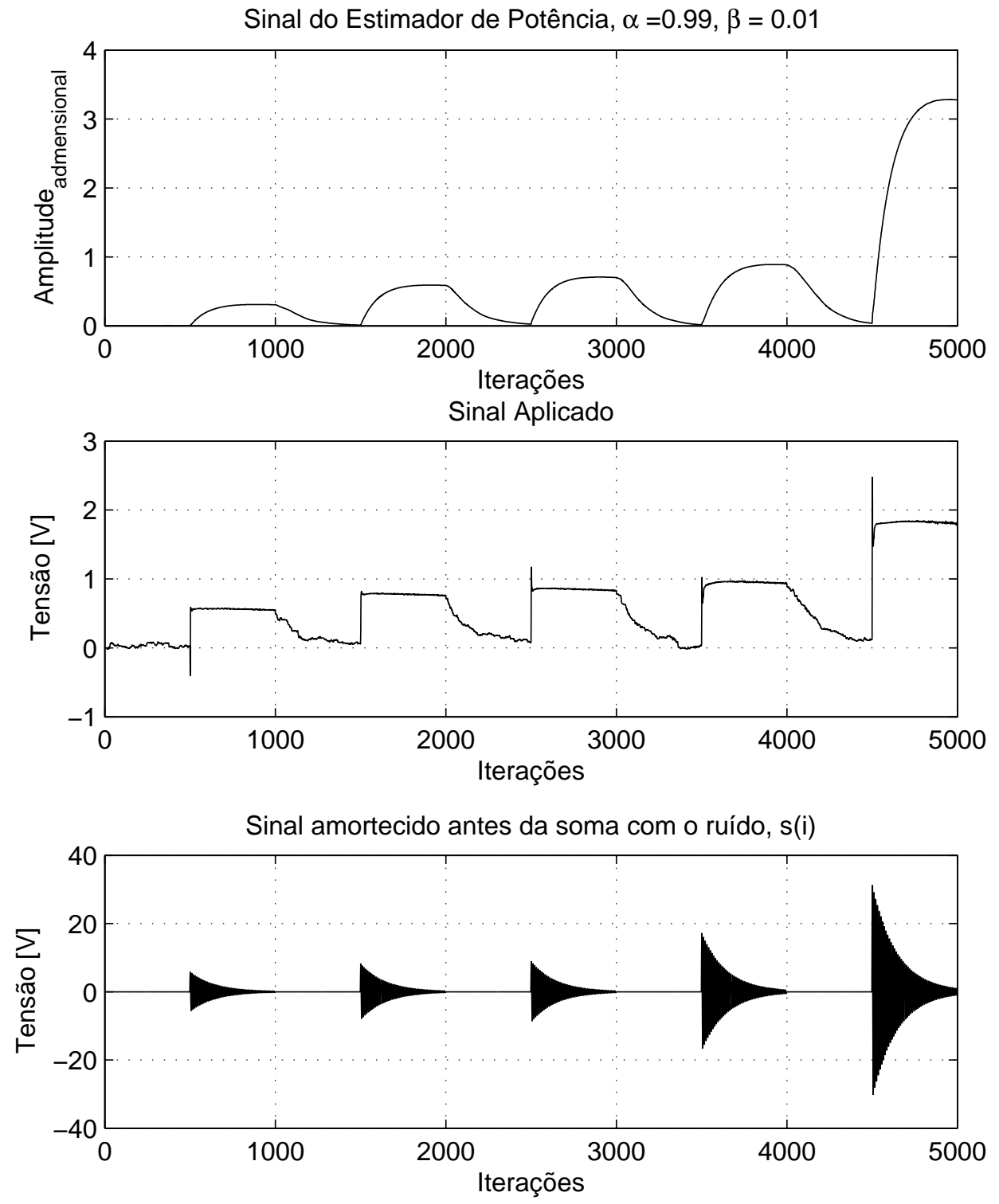

Fonte: Autor. 
Figura 45 - Cenário 2 combinado - Saída do estimador de potência, com $\hat{d}$ do $N L M S$ sendo a entrada
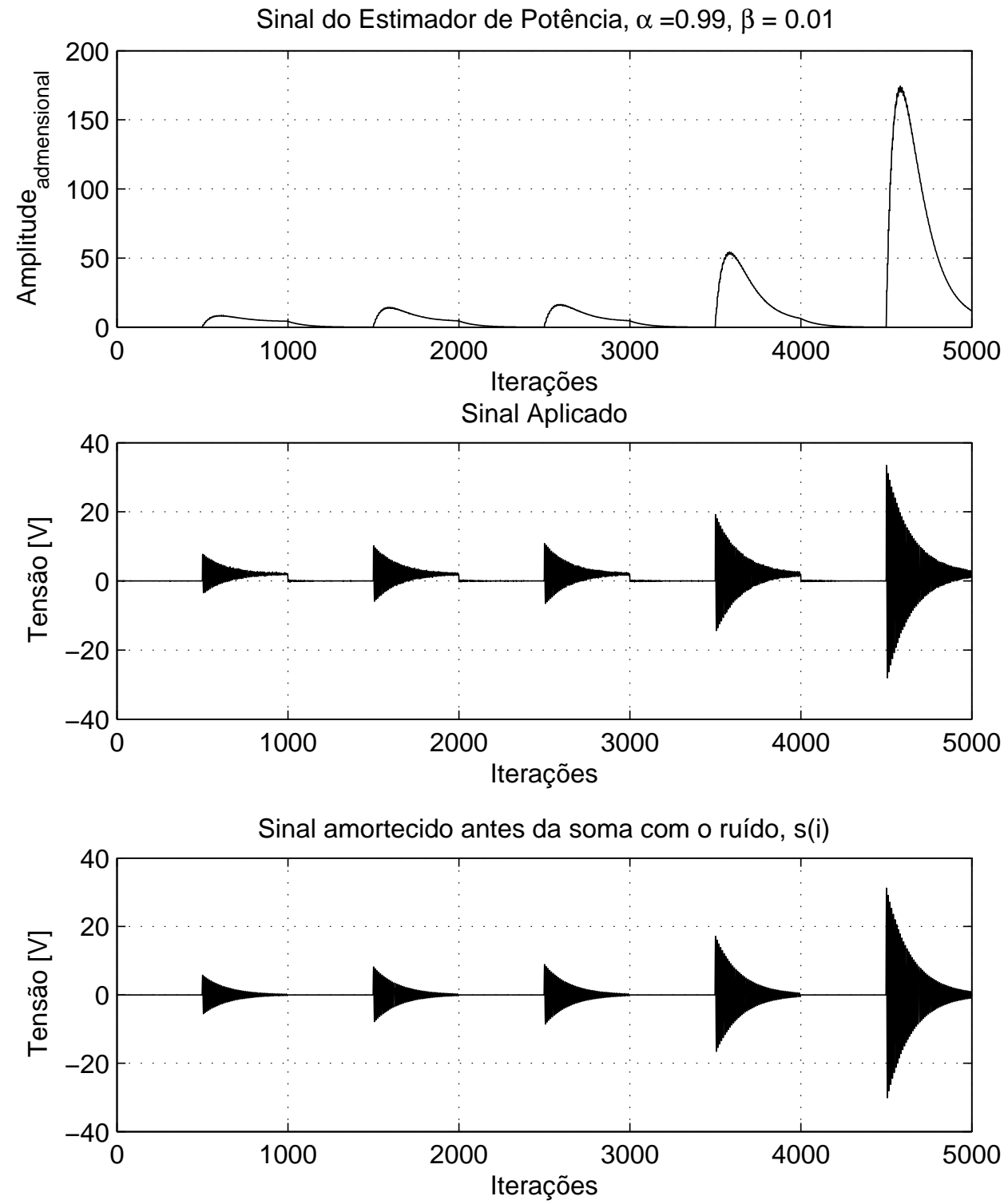

Fonte: Autor.

Aplicando $\hat{\boldsymbol{d}}$ no estimador de potência e com $\mu=0.049$ e $M=15$, todos os níveis de amplitude foram fielmente reproduzidos em forma de envoltória do sinal, obedecendo a ordem de grandeza entre os picos, isto é, se o segundo pico original de detonação fosse pouco menor que o terceiro pico de detonação, a combinação reproduziu essa relação. Valores maiores de $\mu$ e menores de $M$ foram experimentados (i.e.: $\mu=0.1$ e $M=4$ ), o que ocasionou uma redução da $S N R$ obtida na saída do filtro adaptativo, no entanto, resultados similares aos da configuração original ( $\mu=0.049$ e $M=15$ ) foram obtidos na combinação entre algoritmos. Esta observação é importante pois valores menores de ordem e maiores de tamanho de passo facilitam a implementação em sistemas de tempo 
real. Os resultados estão na Figura 45. Para a combinação com o $N L M S$, a resposta mais fiel ao sinal de entrada foi a obtida aplicando-se $\hat{\boldsymbol{d}}$.

\subsubsection{Cenário 3: detonação e ruído branco com amplitudes próximas}

1. $L M S$ com estimador de potência

Tabela 13 - Cenário 3 combinado - Configurações para o LMS

\begin{tabular}{|l|l|}
\hline Algoritmo & Parâmetros \\
\hline $\boldsymbol{L M} \boldsymbol{S}\left(w_{i}\right)$ & $\mu=0.7, M=1$ \\
\hline $\boldsymbol{L M} \boldsymbol{S}(\hat{\boldsymbol{d}})$ & $\mu=0.5$ e $M=15$ \\
\hline
\end{tabular}

Um ruído de maior intensidade foi reproduzido na saída combinada, podendo ser confundido com uma falsa detonação pois o mesmo se deu antes da ocorrência das detonações simuladas.

A combinação neste cenário não possibilitou muita flexibilidade na alteração dos parâmetros para um melhor desempenho, apenas um ligeiro aumento em $\mu$ foi possível sem degradar o desempenho individual do $L M S$, no entanto, sem maiores melhorias na resposta ante à configuração praticada anteriormente na avaliação individual.

Utilizando $\hat{\boldsymbol{d}}$, a combinação com o estimador de potência suavizou as variações obtidas em sua entrada, possibilitando desta forma um aumento do tamanho do passo e, consequentemente, um melhor desempenho de rastreamento, entretanto, o aumento do tamanho de passo ocasionou um aumento de variações na saída da combinação entre algoritmos. Aumentando o passo para $\mu=1$ e a ordem para $M=10$ foi obtida uma degradação severa da $S N R$ na saída do algoritmo adaptativo ( $-63.577 d b)$, no entanto, com melhor caracterização em termos de fidelidade e menos variações na saída do estimador de potência.

Em termos de intensidade de sinal, a combinação utilizando $w_{i}$ apresentou um melhor desempenho, pois os resultados obtidos possuem grandeza em torno de $10^{-2}$ ao passo que os resultados da combinação utilizando $\hat{d}$ apresentaram números de grandeza em torno de $10^{-3}$ Em termos de caracterização, a utilização de $w_{i}$ resultou em uma resposta suavizada na saída mas com uma irregularidade na segunda ocorrência, pouco antes do pico. A utilização de $\hat{\boldsymbol{d}}$ está mais fiel em caracterizar o sinal original mas apresenta muitas variações. O projeto de aplicação destes filtros é quem determinaria quais das duas combinações utilizar, por conta das demandas dos módulos de software que fossem projetados para tratar tal sinal ou mesmo do hardware empregado.

O resultado está apresentado nas Figuras 46 e 47. 
Figura 46 - Cenário 3 combinado - Saída do estimador de potência, com $w_{i}$ do $L M S$ sendo a entrada

Sinal do Estimador de Potência, $\alpha=0.99, \beta=0.01$
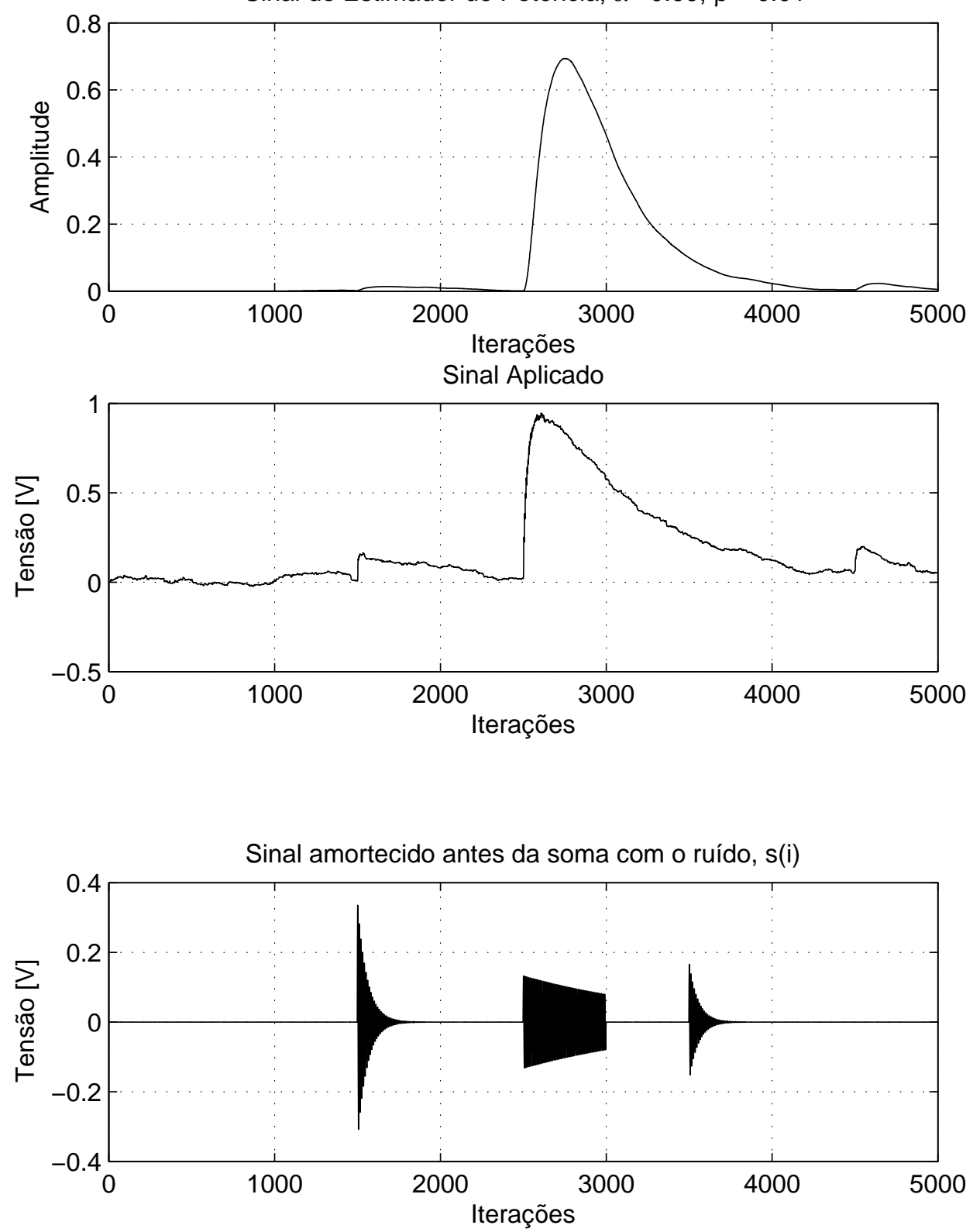

Fonte: Autor. 
Figura 47 - Cenário 3 combinado - Saída do estimador de potência, com $\hat{\boldsymbol{d}}$ do $L M S$ sendo a entrada
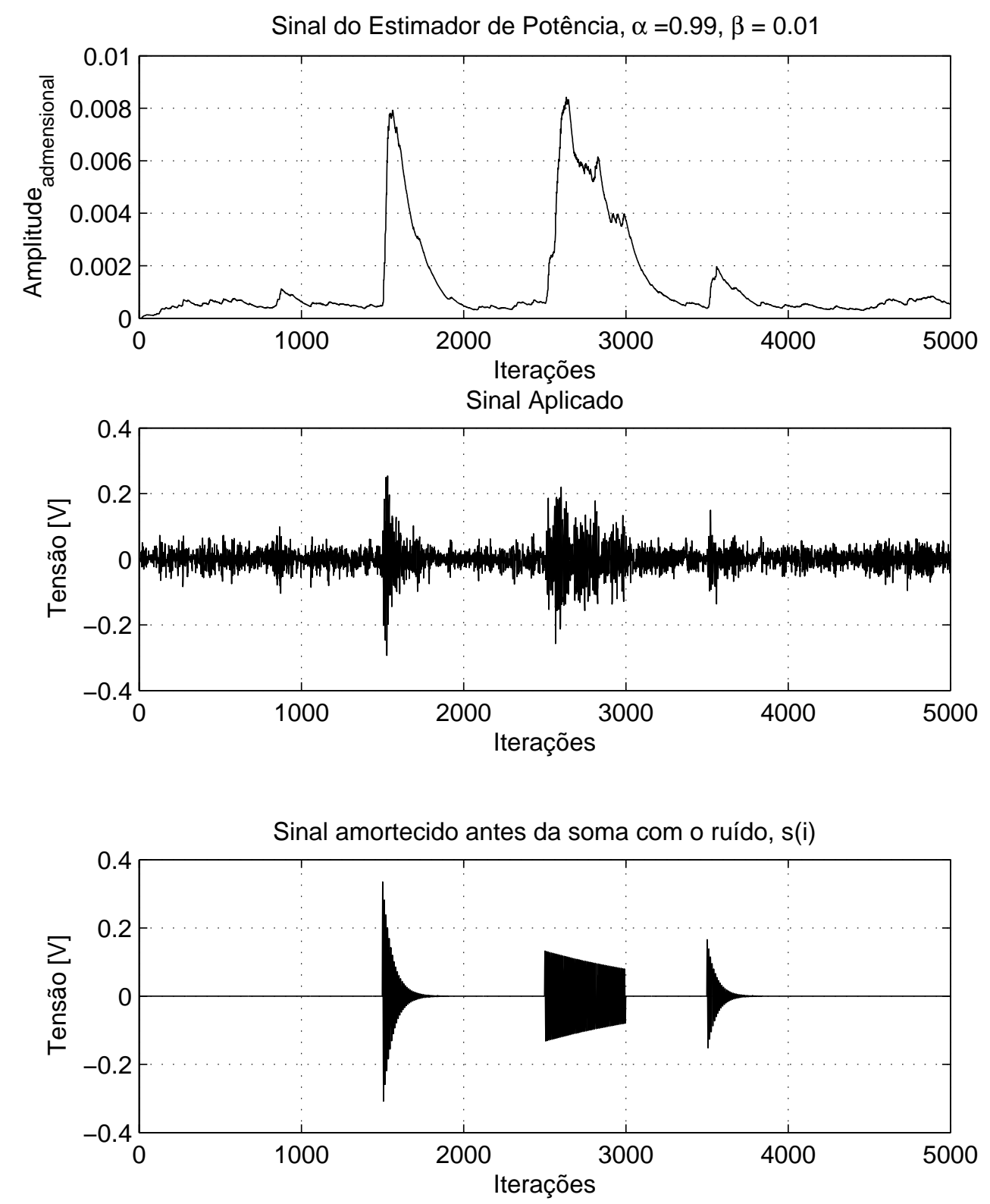

Fonte: Autor.

2. NLMS com Estimador de Potência

Tabela 14 - Cenário 3 combinado - Configurações para o NLMS

\begin{tabular}{|l|l|}
\hline Algoritmo & Parâmetros \\
\hline NLMS $\left(w_{i}\right)$ & $\begin{array}{l}\mu=0.1, M=3 \text { e } \\
\epsilon=0.05\end{array}$ \\
\hline NLMS $(\hat{d})$ & $\mu=1, M=10$ \\
\hline
\end{tabular}

Esta combinação possibilitou um melhor resultado ante ao obtido de maneira indi- 
vidual, pois foi possível mudar os valores de ordem e tamanho de passo. Com $\mu=0.1, M=$ 3 e $\epsilon=0.05$, foi obtido um melhor resultado do que o apresentado com a configuração utilizada na análise individual. A combinação entre algoritmos também possibilitou alteração de parâmetros para a utilização de $\hat{\boldsymbol{d}}$, na qual a configuração $\mu=1$ e $M=10$ proveu um melhor resultado se comparado ao obtido com a configuração praticada na análise individual, mesmo atenuando a $S N R$ de entrada para $-60.21 d b$ na saída do algoritmo adaptativo. O resultado está apresentado nas Figuras 48 e 49.

Figura 48 - Cenário 3 combinado - Saída do estimador de potência, com $w_{i}$ do $N L M S$ sendo a entrada
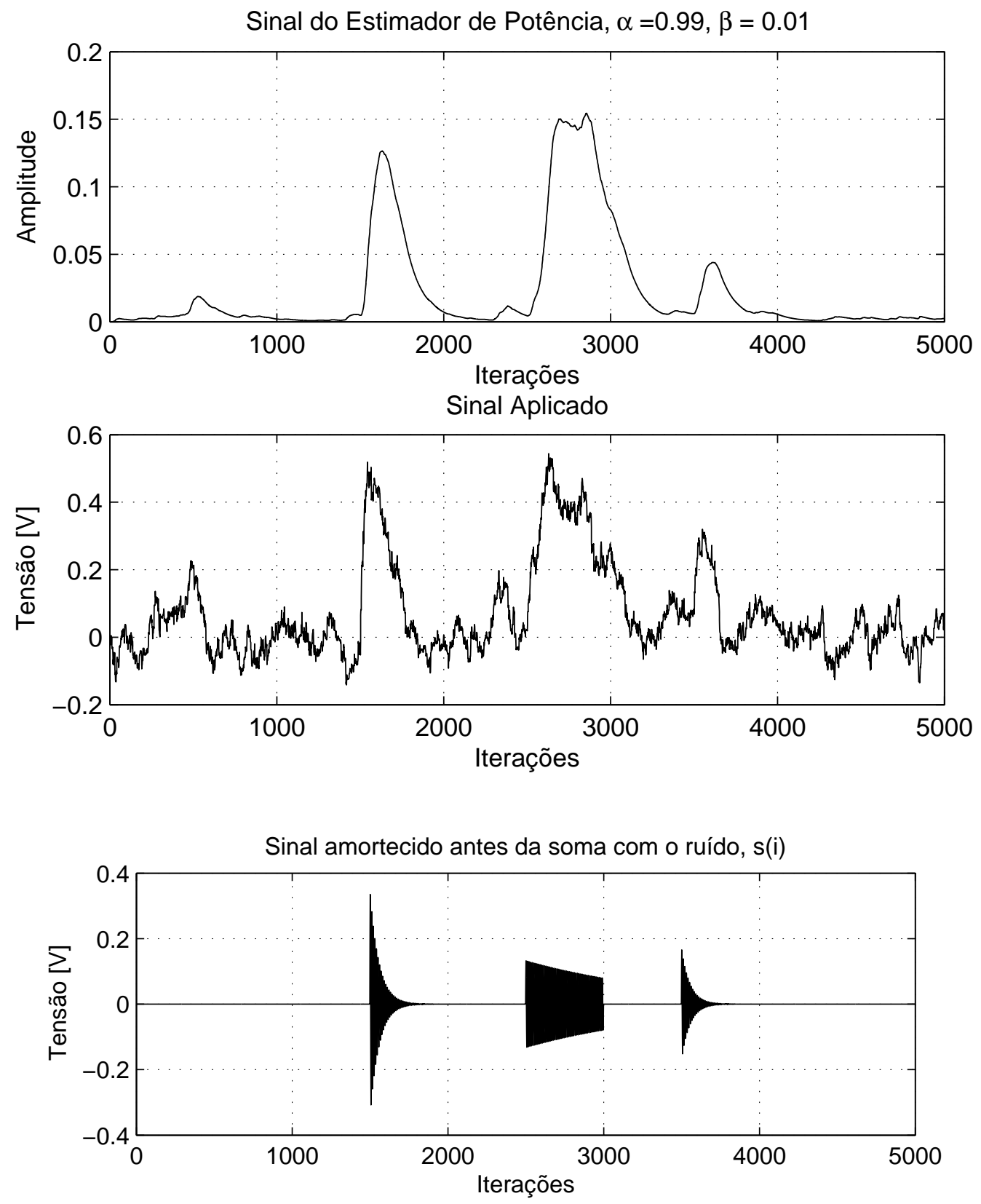

Fonte: Autor. 
Figura 49 - Cenário 3 combinado - Saída do estimador de potência, com $\hat{\boldsymbol{d}}$ do $N L M S$ sendo a entrada
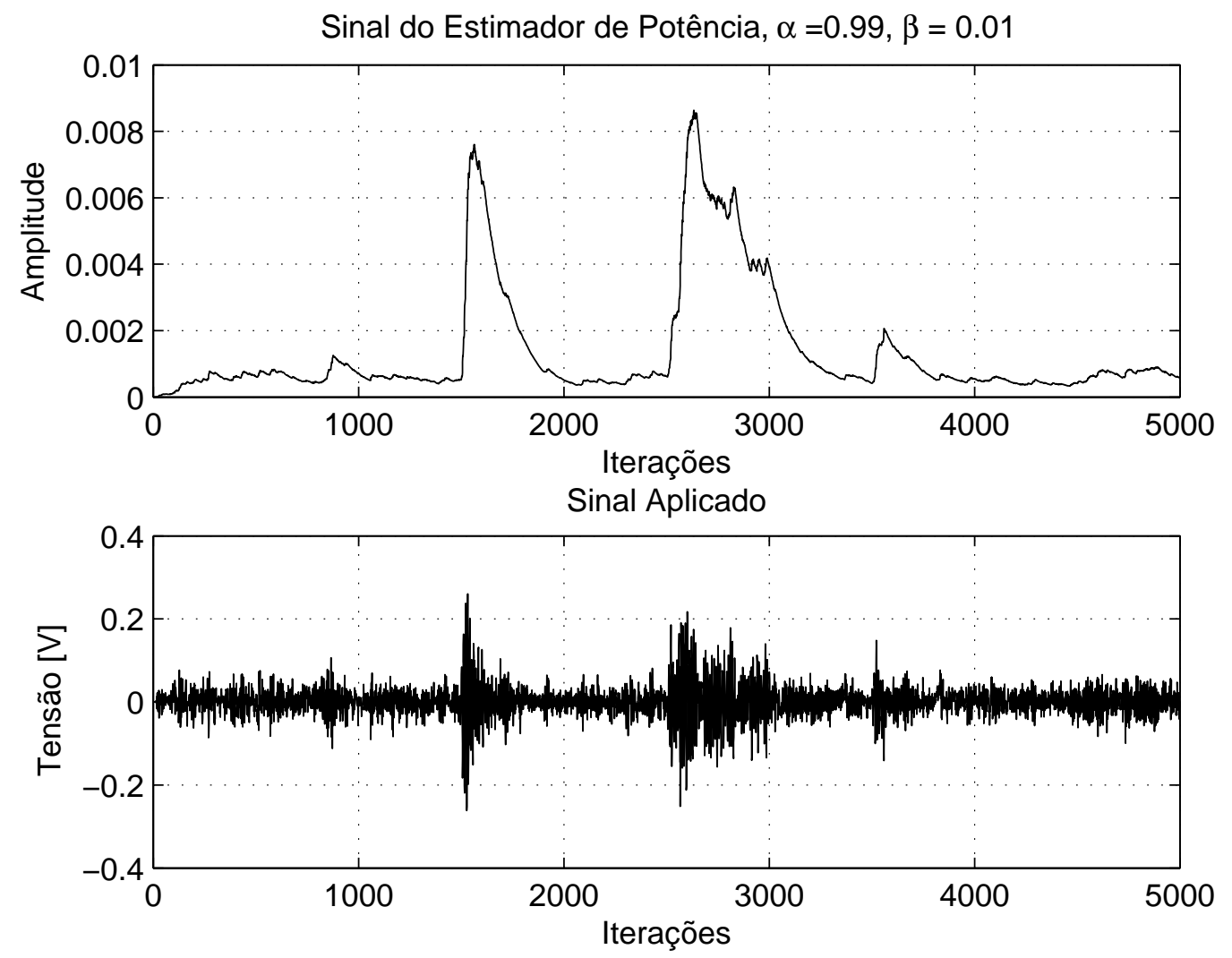

Fonte: Autor. 


\subsubsection{Cenário 4: sinal obtido de uma detonação real}

Tabela 15 - Cenário 4 combinado - Configurações para o NLMS

\begin{tabular}{|l|l|}
\hline Algoritmo & Parâmetros \\
\hline NLMS $\left(w_{i}\right)$ & $\begin{array}{l}\mu=0.25, M=2 \text { e } \\
\epsilon=0.05\end{array}$ \\
\hline NLMS $(\hat{d})$ & $\mu=0.55, M=2$ \\
\hline
\end{tabular}

Para este cenário, devido aos resultados obtidos com cada algoritmo individualmente, a combinação foi feita somente com a saída estimada do NLMS sendo aplicada como entrada no estimador de potência. Os resultados foram semelhantes ao resultado individual do estimador de potência. A Figura 50 mostra os perfis de caracterização obtidos.

Figura 50 - Saída estimada do NLMS sendo a entrada do estimador de potência
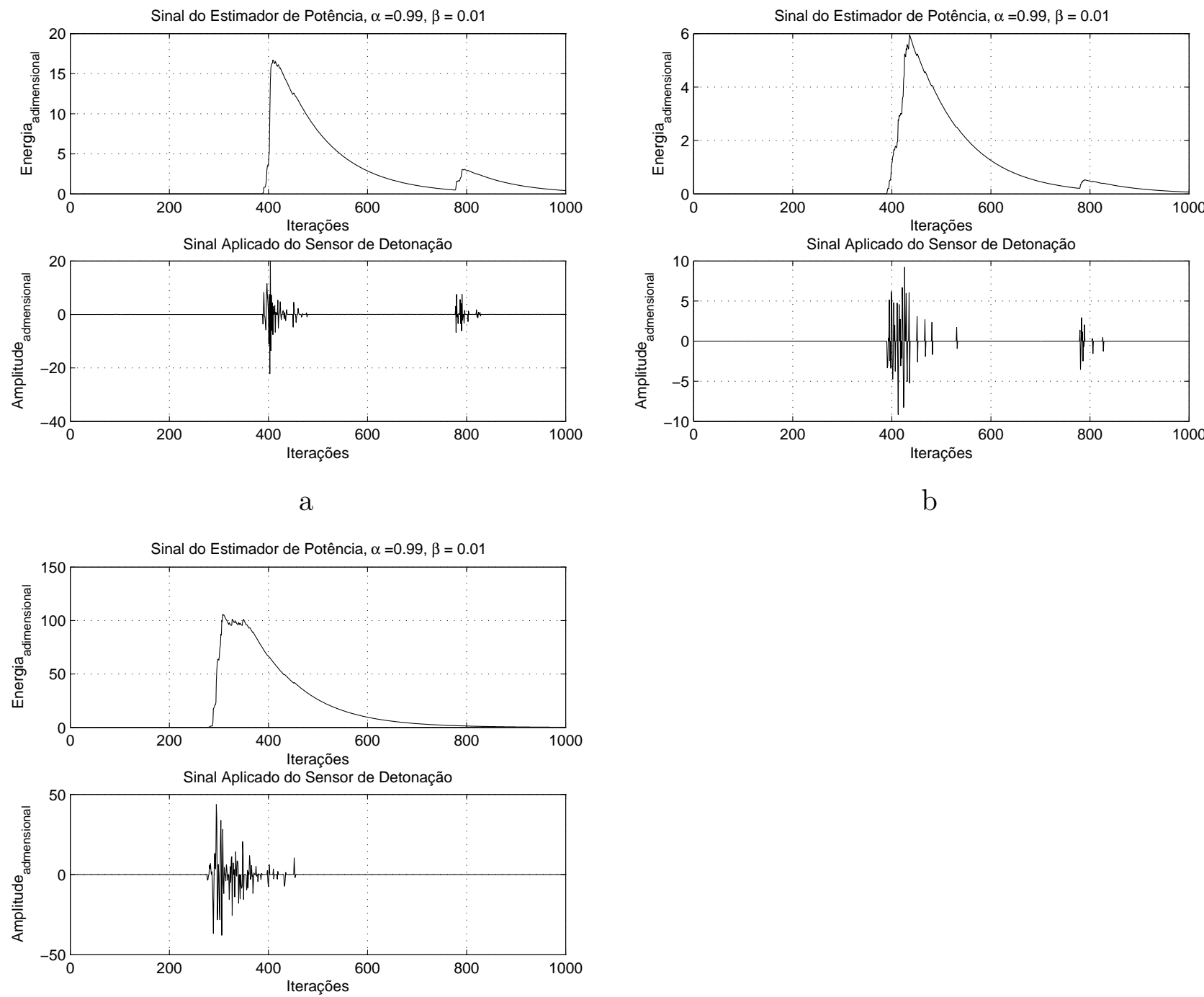


\subsection{Comparação do método proposto com métodos existen- tes}

Muitas técnicas já foram publicadas com o intuito de se tratar o sinal do sensor de detonação. Muitas das publicações focaram seus esforços na utilização do sensor de pressão que é utilizado no interior da câmara de combustão em experimentos laboratoriais. Tal sensor não é muito utilizado na prática devido ao seu elevado custo e inviabilidade de aplicação, apesar de indicar com forma mais precisa a ocorrência do fenômeno, como mostrado na Figura 13.

Dentre estes, alguns trabalhos abordaram a identificação da frequência mais provável de ocorrência do fenômeno de detonação (STOTSKY, 2007a), como mencionado anteriormente, assim como técnicas de filtragem para se extrair o sinal de detonação do sensor de pressão (STOTSKY, 2007a) e também utilização de predição IIR para identificação do sinal de detonação (ETTEFAGH et al., 2008). A seguir, será mostrado em mais detalhes as publicações que foram mais relevantes para o desenvolvimento do método aqui proposto em termos de referência e comparação de desempenho e também uma análise de custo-benefício.

1. Decomposição de fourier, filtragem adaptativa e teste de hipóteses (STOTSKY, 2007a)

Neste trabalho, o autor utilizou a decomposição de Fourier do sinal medido do sensor de pressão. A decomposição apresentada pelo mesmo tem a seguinte forma:

$$
u_{i}=a_{0 i}+\sum_{f=1}^{n}\left(a_{f i} \cos \left(f x_{i}\right)+b_{f i} \sin \left(f x_{i}\right)\right)
$$

na qual $\hat{u}_{i}$ é o valor estimado utilizando a seguinte equação:

$$
\hat{u}_{i}=\varphi_{i}^{T} \theta_{i}
$$

$\operatorname{com} \theta_{i}^{T}$ e $\varphi_{i}^{T}$ :

$$
\begin{gathered}
\theta_{i}^{T}=\left[\begin{array}{ccccc}
a_{0 i} & a_{f 1 i} & b_{f 1 i} & a_{f 2 i} & b_{f 2 i}, \\
\ldots & a_{f n i} & b_{f n i}
\end{array}\right] \\
\\
\varphi_{i}^{T}=\left[\begin{array}{cccc}
1 & \cos \left(f_{1} x_{i}\right) & \sin \left(f_{1} x_{i}\right) & \cos \left(f_{2} x_{i}\right) \\
\sin \left(f_{2} x_{i}\right) & \ldots & \cos \left(f_{n} x_{i}\right) & \sin \left(f_{n} x_{i}\right)
\end{array}\right]
\end{gathered}
$$


$\mathrm{e}$

$$
\begin{gathered}
a_{0}=\frac{1}{M} \sum_{i=1}^{M} u_{i} \\
a_{f}=\frac{2}{M} \sum_{i=1}^{M} u_{i} \cos \left(f x_{i}\right) \\
b_{f}=\frac{2}{M} \sum_{i=1}^{M} u_{i} \sin \left(f x_{i}\right)
\end{gathered}
$$

os quais representam os coeficientes de Fourier. Os termos $f=1 \ldots n, M$ e $i=1 \ldots l$ são as quantidade de frequências envolvidas, tamanho de janela e iteração, respectivamente. Neste trabalho o autor minimiza o erro de estimação com:

$$
\tilde{u}_{i}=\left|u_{i}-\hat{u}_{i}\right|^{2}
$$

Para isto, utiliza o filtro $L M S$, e algumas otimizações, para achar iterativamente os termos do parâmetro $\theta_{i}^{T}$ como pode ser verificado em (STOTSKY, 2007a).

O cálculo do erro serve como identificador dos picos de detonação. O número de frequências incluídas nos modelos (5.6) e (5.7) são acrescidos utilizando o Teste de Variâncias Iguais (STOTSKY, 2007a), onde, uma frequência é acrescentada se a redução do erro for significante estatisticamente com tal inclusão. O procedimento abaixo é feito na sequência:

- Coleção de várias amostras de ciclos detonantes e não detonantes

- A variância de ambos os ciclos é calculada e armazenada

- A seguinte equação é calculada:

$$
t_{f c}=\frac{\bar{A}_{f \operatorname{maxkc}}-\bar{A}_{f \max b c}}{s_{f c}} \sqrt{\frac{n_{k c} n_{b c}}{\left(n_{k c}+F_{f c} n_{b c}\right)}}
$$

com $A_{\text {fmaxkc }}$ sendo a amplitude máxima na frequência $f$ sob a média em um certo número de ciclos detonantes $n_{k c}$ e $\bar{A}_{f m a x b c}$ sendo a amplitude máxima na mesma frequência sob a média em um certo número de ciclos não detonantes, respectivamente. O termo $s_{f l}$ é:

$$
s_{f l}=\sqrt{\frac{\left(n_{k l}-1\right) s_{f k l}^{2}+F_{f l}\left(n_{b l}-1\right) s_{f b l}^{2}}{F_{f l}\left(n_{k l}+n_{f l}-2\right)}} ;
$$

na qual 


$$
s_{f k l}=\sqrt{\frac{1}{\left(n_{k l}-1\right)} \sum_{j=1}^{j=n_{k l}}\left(A_{f \operatorname{maxkl}}-\bar{A}_{f \operatorname{maxkl}}\right)^{2}}
$$

e

$$
s_{f b l}=\sqrt{\frac{1}{\left(n_{b l}-1\right)} \sum_{j=1}^{j=n_{b l}}\left(A_{f \operatorname{maxbl}}-\bar{A}_{f \operatorname{maxbl}}\right)^{2}}
$$

são o desvio padrão para os ciclos detonantes e o ruído de fundo, respectivamente.

Os valores obtidos por (5.14) são testados sob o nível de confiança $\alpha_{f l}$ como segue:

$A$ detonação no motor é detectável quando em certa frequência $f$, no cilindro $l$, com um certo nível de significância $\alpha_{f l}$, se a hipótese nula $H_{0 f l}$ é rejeitada a favor da hipótese alternativa $H_{A f l}: \bar{A}_{\text {maxkl }}>\bar{A}_{\text {fmaxbl }}$.

Portanto, no método recém apresentado, alguns algoritmos podem ser identificados como ferramentas para detectar a ocorrência de detonação:

- Decomposição de Fourier

- Filtragem Adaptativa

- Teste de Hipóteses

- Teste de Igualdade de Variâncias

Como se pode ver, as principais diferenças com este trabalho são:

- O número de métodos utilizados é maior do que os utilizados neste trabalho

- A identificação feita com a decomposição de Fourier juntamente com os filtros adaptativos resultou em um sinal difícil de ser computado para avaliação da ocorrência de detonação por ser muito ruidoso, como pode ser verificado na Figura 51.

2. Modelamento do sinal de detonação e avaliação por mínimos quadrados (Knock Signal Modelling and Evaluation by Least Squares) (URLAUB; BOHME, 2005)

Neste artigo, como mencionado no capítulo anterior, o foco é o de proposta de um modelo de sinal de detonação próximo do sinal real.

Nesta publicação, o autor analisou o comportamento do erro de estimação e covariância entre o sinal modelado e o real. O modelo mostrou um desempenho bom de covariância para baixas rotações enquanto que para altas rotações os resultados não foram tão satisfatórios. O autor propôs um modelo interessante para o sinal de detonação mas não propôs um algoritmo para o tratamento deste sinal.

3. Detecção de detonação baseado na transformada de wavelet (Knock detection based on wavelet transform) (PARK; YANG, 2004) 
Figura 51 - Curva de aprendizado da decomposição de Fourier do sinal de detonação

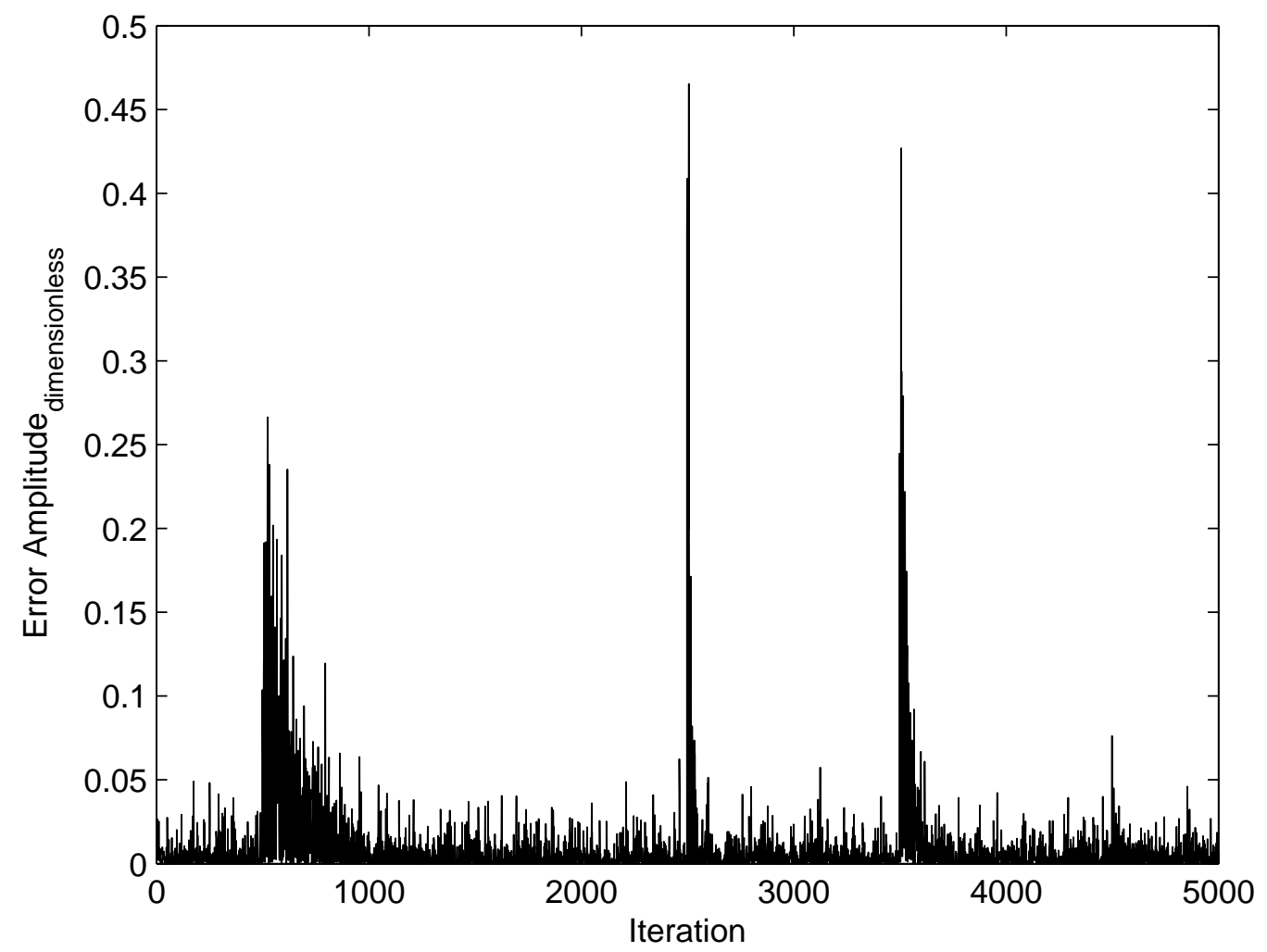

Fonte: Autor.

Como pode ser visto neste artigo (PARK; YANG, 2004), nenhum modelo de sinal foi mostrado. Aparentemente o autor utilizou diretamente o sinal coletado do sensor de pressão e detonação. O algoritmo de tratamento desenvolvido neste artigo utilizou filtros passa-baixa e passa-alta para então aplicar a transformada Wavelet, como mostrado pelo autor nas equações:

$$
\begin{aligned}
& A_{0}[f(t)]=f(t) \\
& A_{j}[f(t)]=\sum_{k} H(k-2) * A_{j-1}[f(t)] \\
& D_{j}[f(t)]=\sum_{k} G(k-2) * A_{j-1}[f(t)]
\end{aligned}
$$

onde, $t=1,2, \ldots N, j=1,2, \ldots J, J=\log _{2} N \cdot H(t)$ e $G(t)$ são um par de filtros espelhados de quadratura para a decomposição: $H(t)$ é um filtro passa-baixa e $\mathrm{G}(\mathrm{t})$ é um filtro passa-alta. $A_{j}[f(t)]$ e $D_{j}[f(t)]$ representam a estimativa e conteúdo do sinal, 
respectivamente. O modelo de reconstrução do sinal pode ser encontrado em (PARK; YANG, 2004).

O autor mostra que o sinal resultante após o tratamento, como pode ser verificado nas Figuras 53 e 52, visivelmente apresenta variações, muito mais do que as mostradas nas Figuras 40 e 41. Portanto, as principais diferenças com o trabalho aqui exposto são:

- O autor obteve melhores resultados com o sensor de pressão mas, como explicado anteriormente, este sensor não condiz com a realidade do mercado brasileiro.

- Os resultados obtidos com o sensor de detonação apresentaram muitas variações, muito além do que as obtidas como os métodos propostos neste trabalho, como por exemplo no cenário 1.

- Este artigo somente mostra o tratamento feito diretamente ao sinal real, o mesmo não apresenta um modelo de simulação do sinal de detonação.

4. Modelo de média móvel auto regressivo paramétrico para tratamento do sinal de detonação (Parametric ARMA model for Knock Signal Treatment) (ETTEFAGH et al., 2008)

Neste trabalho, o autor baseia seu argumento por um modelamento do motor utilizando um algoritmo $A R M A$ na qual a detonação alteraria os coeficientes de tal modelo. Os coeficientes são achados utilizando o algoritmo de Yule Walker. A identificação da detonação é feita através do cálculo da média e variância dos coeficientes encontrados pelo algoritmo Yule Walker. Para verificação do equacionamento do autor por favor verifique (ETTEFAGH et al., 2008) para mais detalhes. Com base neste artigo, as principais diferenças identificadas são:

- O modelo ARMA é utilizado como um preditor assim como o algoritmo proposto neste trabalho, porém a identificação da detonação não é obtida de forma direta pois a mesma somente é feita após se calcular a média dos coeficientes de tal algoritmo.

- O modelo ARMA é um filtro IIR, o que é mais genérico que os filtros adaptativos aqui propostos (FIR). No entanto, o fitro IIR pode ser mais difícil de ser implementado em um sistema embarcado tendo em vista sua maior complexidade e possível instabilidade com precisão finita, ao passo que os filtros FIR são mais robustos para este tipo de aplicação.

- O número de métodos utilizados para extrair a informação de ocorrência de detonação é maior do que os apresentados neste trabalho. Foram apresentados 2 métodos na seção 3.7.1: filtros adaptativos e estimação de potência, mas mesmo com apenas o primeiro método já possível se ter uma caracterização razoável do fenômeno como mostrado na seção 5.2. Análise do custo computacional não faz parte deste trabalho.

- O modelamento apresentado pelo autor não deixa claro se o método proposto 
pelo mesmo é capaz de fornecer o tempo de duração de detonação ou seu comprimento, como o presente trabalho se propõe.

Figura 52 - A transformada de wavelet do sinal do sensor de detonação
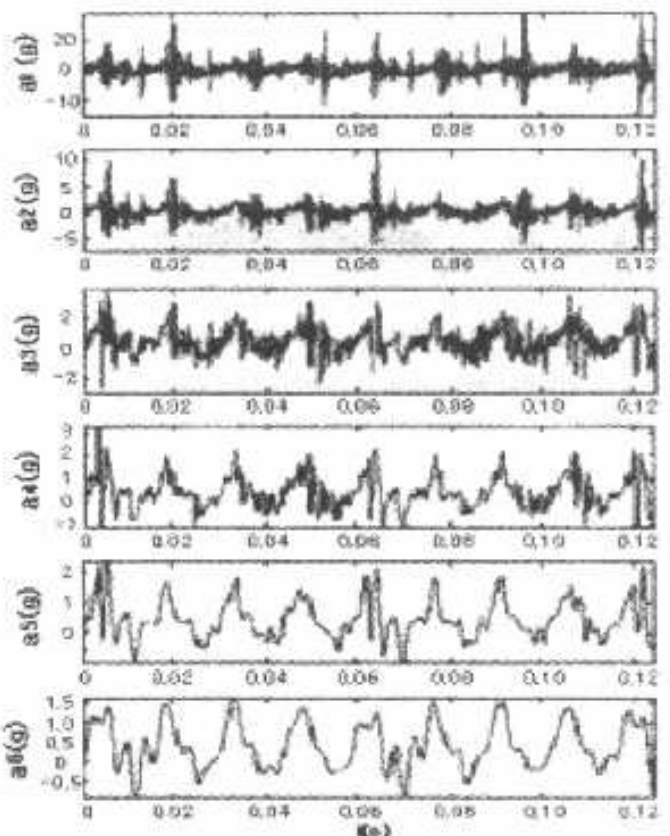
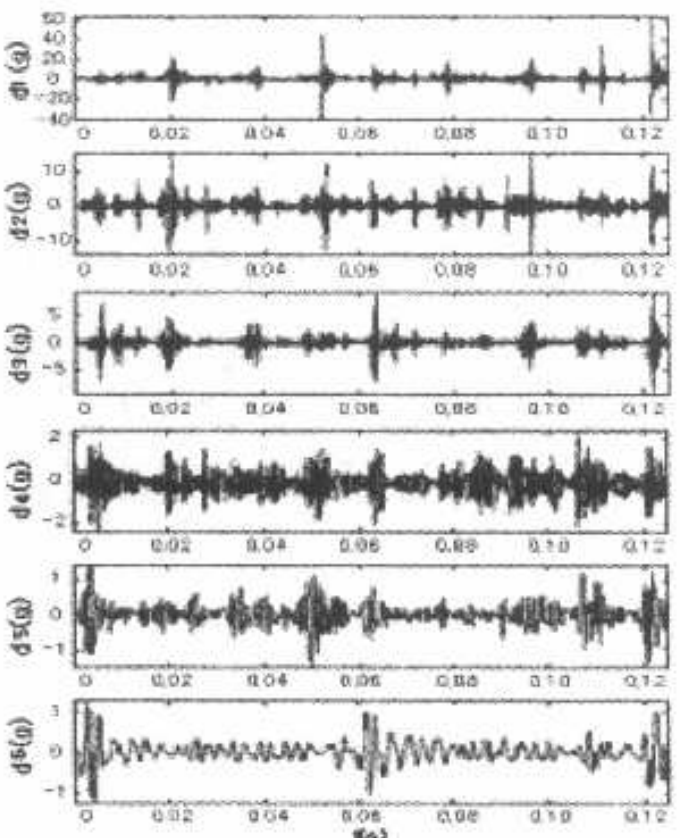

Fonte: (ETTEFAGH et al., 2008). 
Figura 53 - A transformada de wavelet do sinal do sensor de pressão
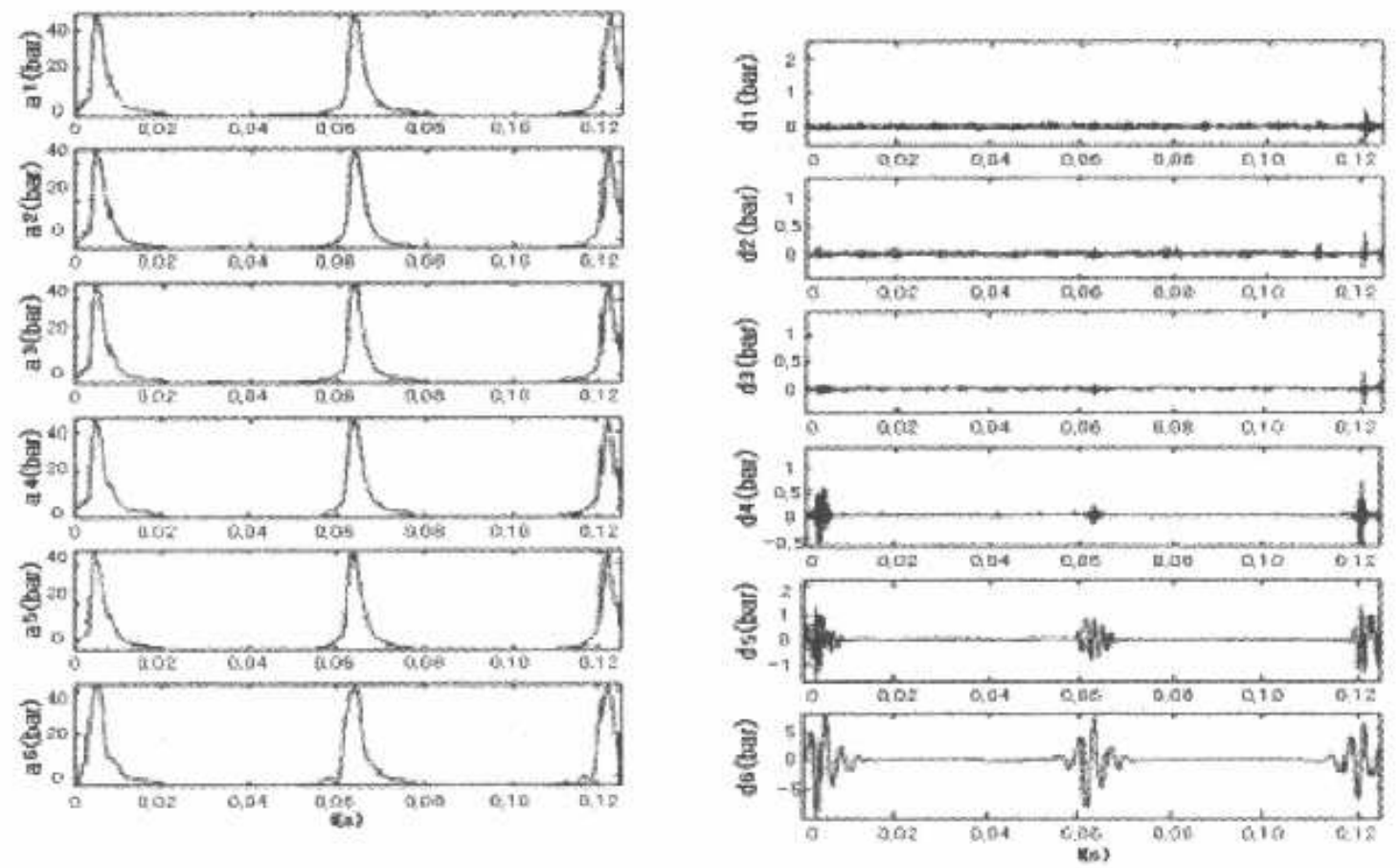

Fonte: (ETTEFAGH et al., 2008). 


\section{Conclusões e perspectivas}

Este capítulo resume as principais conclusões desta dissertação e também apresenta algumas sugestões para pesquisas futuras.

\subsection{Conclusões: simulações com o sinal modelado}

- O modelo proposto de sinal do sensor de detonação é útil para representar o fenômeno

Foi apresentado um método que possibilita a caracterização do fenômeno de detonação. A caracterização consiste em indicar as diferentes intensidades e duração de ocorrência do fenômeno. Também foi apresentado um modelo para testes de algoritmos de tratamento para o sinal de detonação. O modelo foi projetado sob a premissa de que o sensor apresenta ruído branco na ausência do fenômeno e uma senóide amortecida somada ao ruído branco no momento de ocorrência do mesmo, assim foi mostrado que o sinal resultante é semelhante ao real.

- O método proposto para caracterizar o fenômeno de detonação é eficiente para tal finalidade

O método proposto para o tratamento de tal sinal, composto de filtros adaptativos e um estimador de potência, mostrou-se eficiente para tal caracterização tanto se utilizado de forma individual (onde o sinal foi aplicado aos filtros adaptativos NLMS e $L M S$ utilizados em modo de predição assim como ao estimador de potência) e também de maneira combinada entre si.

A resposta prática dos algoritmos adaptativos, provinda de simulações, mostrou que as demonstrações feitas na seção 4.2.2 estão corretas. Considerando o erro de aproximação estocástica introduzida nos algoritmos, o valor obtido nos coeficientes foi próximo de zero em caso de não detonação e com valores bem maiores que zero para a ocorrência de detonação.

- Com baixa $S N R$ no sinal de entrada, os algoritmos adaptativos são superiores ao estimador de potência

Os algoritmos adaptativos se mostraram mais eficientes na remoção do ruído de fundo e também possibilitaram uma distinção mais evidente entre ruído de fundo e detonação para os casos em que estes sinais possuíam amplitudes próximas, ou baixa $S N R$. Tal fato é justificado devido aos filtros, em modo predição, apresentarem em seus coeficientes valores diferentes de zero, para o caso de ocorrência de detonação e 
também por conta da separação do sinal de banda estreita do sinal de banda larga possibilitada por tais algoritmos. Em contrapartida, no cenário de baixa $S N R$, o estimador de potência apresentou níveis de amplitude semelhantes para os dois sinais.

\section{- Os filtros adaptativos apresentaram bom desempenho na atenuação de} ruídos

A ação de denoising realizada pelos filtros adaptativos foi eficiente para enaltecer o amortecimento causado pela detonação simulada, o que foi comprovado pela medição do ganho da $S N R$ obtida na saída estimada de tais algoritmos, no entanto, o sinal proveniente de tal saída não servia como ferramenta imediata para a caracterização do fenômeno por apresentar muitas variações.

\section{- $L M S$ não é aplicável, pois diverge em um dos cenários propostos}

O LMS mostrou-se ineficiente para um dos cenários de teste por conta de sua baixa velocidade de convergência, fato que se deve ao pequeno tamanho de passo necessário para que este algoritmo não divirja em um dos cenários de testes propostos. No entanto, para os demais cenários, o $L M S$ apresentou bom desempeho com valores de passo maiores. Apenas um valor de passo pode ser escolhido para implantação deste algoritmo, fator que inviabiliza a aplicação deste em sistemas microcontrolados / microprocessados, uma vez que tais sistemas são programados somente uma vez quando utilizados em campo.

\section{- Estimador de potência é insuficiente como caracterizador único do fenô-} meno

O estimador de potência, embora fornecesse uma caracterização com poucas variações do sinal aplicado, não reproduziu com fidelidade os picos rápidos que foram criados em alguns cenários. Além da falta de fidelidade em cenários com baixa $S N R$.

\section{- $N L M S$ é o mais robusto como caracterizador único do fenômeno}

Dentre os 3 algoritmos apresentados, considerando o desempenho individual somente, o que apresentou maior robustez e eficiência foi o $N L M S$ por caracterizar o fenômeno de forma razoável, seja em seus coeficientes ou em sua saída estimada, nos 3 cenários de teste propostos.

\section{- A combinação entre algoritmos é a melhor forma de se caracterizar o} fenômeno

A combinação entre os algoritmos mostrou-se como a melhor opção de caracterização pois, em geral, foi possível extrair as características positivas dos algoritmos propostos. Devido aos filtros adaptativos serem sensíveis à estatística dos sinais e por 
conta disto terem apresentado melhor desempenho no cenário de detonação e ruído branco com amplitudes próximas, o estágio inicial da combinação de algoritmos foi escolhida como sendo composta por tais filtros.

Mesmo tendo o $L M S$ divergindo em um caso, os experimentos foram continuados como uma figura de estudo do desempenho deste algoritmo, o que revelou desempenho satisfatório na combinação com o estimador de potência. No entanto, com fidelidade de caracterização não tão boa quanto a obtida com a combinação do NLMS com o estimador de potência.

- A combinação do $N L M S$ com o estimador de potência é o melhor método proposto para se caracterizar o fenômeno de detonação

A combinação $N L M S$ com estimador de potência foi a melhor observada, onde grande parte das variações devidas ao ruído branco e aproximações estocásticas foram suavizadas. No entanto, a fidelidade de representação de picos rápidos obtida na saída estimada do $N L M S$ foi parcialmente perdida devido à combinação com o estimador de potência.

- Baixa ordem necessária viabiliza implementação em sistemas de tempo real

A baixa ordem obtida ( $M=2$ ou 1$)$ assim como valores de tamanho de passo não tão pequenos ( $\mu$ de 0.25 a 1 ), para uma caracterização razoável (não necessariamente as melhores obtidas) viabilizam a aplicação em sistemas microcontrolados / microprocessados por não demandarem muita carga de processamento, se comparados a filtros de ordens mais altas.

\subsection{Conclusões: simulações com o sinal real}

As simulações com o sinal real comprovaram que a combinação da saída do $N L M S$ com o estimador de potência é a melhor forma de caracterizar o fenômeno. Os coeficientes do filtro não apresentaram indicações inteligíveis de ocorrência de detonação, no entanto, mostraram que se comportam de acordo com as derivações feitas que justificam a utilização de preditores adaptativos. Os resultados obtidos por combinação de algoritmos foi muito semelhante ao obtido utilizando apenas o estimador de potência, no entanto, a combinação com o NLMS ainda é válida pois este seria eficiente para o cenário de detonação e ruído branco com amplitudes próximas, como foi mostrado nas simulações com o sinal de detonação modelado. 


\subsection{Perspectivas}

\section{- Melhoria no controle do motor de combustão interna}

A caracterização do fenômeno de detonação pode possibilitar um controle de malha fechada otimizado dos instantes de injeção e ignição para se obter o máximo torque possível sem que haja o fenômeno, ou que o mesmo ocorra de forma sútil desde que tal acontecimento não cause danos ao motor.

\section{- Diagnóstico de um sensor de detonação fora de vida útil}

A parametrização dos tempos de decaimento do sinal, viabilizado pela caracterização obtida neste trabalho, pode fornecer um indicador de tempo de vida do sensor uma vez que o mesmo apresentará diferentes respostas de conversão de energia mecânica em elétrica no decorrer de sua vida útil.

\section{- Determinação de limiares para detecção do fenômeno}

Com o desenvolvimento deste trabalho, é possível escolher ou desenvolver outros métodos para determinação de um limiar de detecção do fenômeno e combinado com o aqui apresentado, além de determinar as diferentes intensidades e tempos de duração da detonação, detectar a ocorrência e não ocorrência do mesmo.

\section{- Estudos para viabilização do uso do $L M S$}

O caso de divergência do $L M S$ pode ser revertido se otimizações neste algoritmo forem feitas, estudando o comportamento dos autovalores de sua entrada no cenário de teste crítico aplicado neste trabalho, assim como melhoria de seu desempenho para sinais não estacionários.

- Estudos para viabilidade de simulador físico de sinais de detonação para ECUs

O modelo de sinais apresentado neste trabalho se implementado em uma plataforma eletrônica, pode simular sinais físicos de detonação para testes de ECUs.

\section{- Estudos para viabilidade de implantação em sistemas de tempo real}

A escolha da ordem, tamanho de passo e demais parâmetros dos filtros deve ser avaliada sob a perspectiva de custo benefício para a escolha mais adequada das configurações propostas neste trabalho. Por fim, deve-se aprofundar os experimentos dos algoritmos propostos em ambiente real para se avaliar as respostas dos mesmos para sinais reais, para que finalmente seja possível sua implementação em um sistema de tempo real. 


\section{Referências}

ALBALADEJO, F. S. Desenvolvimento de uma unidade de gerenciamento eletrônico para motores de combustão interna do ciclo OTTO. Dissertação (Mestrado) - PSI, Escola Politécnica, USP, 2013. Citado 4 vezes nas páginas 10, 11, 12 e 13.

AUTOMOTIVE-BUSINESS. Demanda por airbag e ABS avança no Brasil. 2011. Acesso em: 1 Ago. 2013. Disponível em: http://goo.gl/H7HT7m. Citado na página 1.

AUTOMOTIVE-BUSINESS. DHL inaugura centro de competência automotiva em São Paulo. 2012. Acesso em: 1 Ago. 2013. Disponível em: http://www.mercedes-benz.com. br/ModeloDetalhe. aspx?categoria=171\&conteudo=13044. Citado na página 2.

BASTIAN, R. Indústria competitiva. 2013. Acesso em: 1 Ago. 2013. Disponível em: http://www.midianews. com.br/conteudo.php?sid=262\&cid=170496. Citado na página 2.

BASTOS, J. T. Geografia da Mortalidade no Trânsito no Brasil. Dissertação (Mestrado) - Engenharia de Transportes, Escola de Engenharia de São Carlos, USP, 2011. Citado na página 1.

BBC. Indústria automobilística contra-ataca com motores pequenos. 2012. Acesso em: 1 Ago. 2013. Disponível em: http://goo.gl/pKVi6. Citado na página 1.

BOSCH, R. Automotive Electronics. Germany, 2006. Product Information Knocking Signal Evaluation - CC195. Citado 2 vezes nas páginas 28 e 32.

CHADE, J. Consumo de combustiveis cresceu 6.1 \% em 2012 diz ANP. 2013. Acesso em: 1 Ago. 2013. Disponível em: http://goo.gl/71U1zx. Citado na página 1.

CHADE, J. Frota mundial de veículos atinge a marca de 1 bi de unidades. 2013. Acesso em: 1 Ago. 2013. Disponível em: http://goo.gl/N5KBM0. Citado na página 1.

CUT. Carros 1.0 deixam de ser preferência nacional. 2011. Acesso em: 1 Ago. 2013. Disponível em: http://goo.gl/gXYD8U. Citado na página 1.

DINIZ, P. S. Adaptive Filtering Algorithms and Practical Implementation. 3rd. ed. United States of America: Springer, 2008. Citado na página 36.

ETTEFAGH, M. et al. Knock detection in spark ignition engines by vibration analysis of cylinder block: A parametric modeling approach. Mechanical Systems and Signal Processing, v. 22, p. 19, 2008. Citado 4 vezes nas páginas 82, 86, 87 e 88.

EUROPA.EU. Redução das emissões poluentes dos veículos ligeiros. 2013. Acesso em: 1 Ago. 2013. Disponível em: http://goo.gl/dQzVF. Citado na página 1.

FRADEN, J. Handbook of modern sensors: physics, designs, and applications. 3rd. ed. Nova York: Springer-Verlag, 2004. Citado 4 vezes nas páginas 29, 30, 31 e 32.

FRANCO, C. Faltam recursos para cadeia automotiva se desenvolver. 2013. http://goo.gl/o18gaq. Acesso em: 1 Ago. 2013. Disponível em: http://goo.gl/o18gaq. Citado na página 2. 
FURREY, J. H. Patent no. 4346586. 1980. United States of America. Citado na página 28.

HAYKIN, S.; VEEN, B. V. Signals and systems. University of California: Wiley, 1999. Citado 2 vezes nas páginas 37 e 38.

HEYWOOD, J. B. Internal Combustion Engine Fundamentals. United States of America: Mc Graw Hill Series, 1988. Citado 10 vezes nas páginas 1, 14, 19, 20, 21, 22, 23, 24, 25 e 40 .

IBAMA. Programas de controle de emissões veiculares. 2013. Acesso em: 1 Ago. 2013.

Disponível em: http: //www. ibama.gov.br/areas-tematicas-qa/programa-proconve. Citado na página 1.

JANSHOFF, A.; STEINEM, C. Piezoelectric transducers for vibration control and damping. Germany: Springer, 2007. Citado na página 30.

KAWAHARA, N.; TOMITA, E. Visualization of auto-ignition and pressure wave during knocking in a hydrogen spark-ignition engine. International Journal of Hydrogen Energy, v. 34, p. 3I56-3I63, 2009. Citado na página 17.

KIENCKE, U.; NIELSEN, L. Automotive Control Systems, For Engine, Driveline, and Vehicle. Germany: Springer, 2005. Citado 2 vezes nas páginas 17 e 18.

KOSHITA, S. et al. High-order center-frequency adaptive filters using blockdiagram-based frequency transformation. ICASSP, p. 4, 2011. Citado na página 59 .

KUTNEY, P. Ford mostra EcoSport global projetado no Brasil. 2012. Acesso em: 1 Ago. 2013. Disponível em: http://goo.gl/N6KuyQ. Citado na página 2.

KUTNEY, P. Continental começa a montar ABS no Brasil. 2013. Acesso em: 1 Ago. 2013. Disponível em: http://goo.gl/Fhxvrg. Citado na página 2.

KUTNEY, P. Nacionalização tecnológica próxima do impossível. 2013. Acesso em: 1 Ago. 2013. Disponível em: http://www . automotivebusiness .com.br/artigo/692/ nacionalizacao-tecnologica-proxima-do-impossivel. Citado na página 2.

LOPES, C. G. et al. Order-adaptive frequency trackers for direct-to-earth mars communications. IEEE/SP 15th Workshop on Statistical Signal Processing, p. 4, 2009. Citado na página 59.

LOPES, C. G. et al. Adaptive carrier tracking for mars to earth communications during entry, descent, and landing. IEEE TRANSACTIONS ON AEROSPACE AND ELECTRONIC SYSTEMS, v. 46, p. 15, 2010. Citado 2 vezes nas páginas 37 e 48.

MANAVELlA, H. J. Controle Integrado do Motor. Argentina: Fundação Biblioteca Nacional, 2000. Citado 4 vezes nas páginas 4, 10, 11 e 13.

MERCEDES-BENZ. Pela segunda vez consecutiva Mercedes-Benz é a empresa do ano no prêmio Auto Data. 2012. Acesso em: 1 Ago. 2013. Disponível em: http:// www . mercedes - benz. com . br/ModeloDetalhe . aspx? categoria=171\&conteudo=13044. Citado na página 2. 
MME et al. Biocombustíveis. 2013. Acesso em: 1 Ago. 2013. Disponível em: http://www . brasil.gov.br/sobre/economia/energia/matriz-energetica/biocombustiveis. Citado na página 2.

MOHEIMANI, S. R.; FLEMING, A. J. Piezoelectric transducers for vibration control and damping. Germany: Springer, 2006. Citado na página 29.

MURATA, E. Tabela de modos de vibração de materiais piezelétricos. 2012. Acesso em: 1 Ago. 2013. Disponível em: www.murata.com/products/resonator/basic/ceralock/ vibration.html. Citado na página 31.

OPPENHEIM, A. V.; R., B. J. Discrete-time signal processing. 2nd. ed. Upper Sadle River, New Jersey: Prentice-Hall Inc., 1999. Citado na página 49.

PAPOULIS, A.; PILLAI, S. U. Probability, random variables, and stochastic processes. 4th. ed. Singapore: McGraw Hill Higher Education, 2004. Citado na página 49.

PARK, S. T.; YANG, J. Engine knock detection based on wavelet transform. IEEE Korus, 2004. Citado 3 vezes nas páginas 84, 85 e 86.

PENIDO, P. Os Motores a Combustão Interna. 3rd. ed. Belo Horizonte, Brasil: Lemi S.A., 1991. Citado 8 vezes nas páginas 4, 6, 7, 8, 9, 15, 16 e 25.

PEREIRA, B. C. F. Unidade Eletrônica de Gerenciamento de um Motor Volkwagen 2.0L: Projeto Otto II. Monografia (Graduação) — PSI, Escola Politécnica, USP, São Paulo, 2013. Citado na página 51.

PERUZZO, F. M.; CANTO, E. L. d. Química na Abordagem do Cotidiano. 3rd. ed. São Paulo: Editora Moderna, 2003. Citado na página 18.

SAYED, A. H. Adaptive Filters. United States of America: IEEE Press, 2008. Citado 8 vezes nas páginas 33, 34, 35, 36, 48, 49, 53 e 67.

STOTSKY, A. Statistical algorithms for engine knock detection. Automotive Technology, v. 8, p. 10, 2007. Citado 5 vezes nas páginas 39, 40, 52, 82 e 83.

STOTSKY, A. Statistical engine knock modelling and adaptive control. Journal of Automotive Engeneering, v. 222, Part D, p. 10, 2007. Citado 2 vezes nas páginas 39 e 40.

UOL. Gasolina em veículos emite cerca de 70 milhões de toneladas de CO2 em 2012. 2013. Acesso em: 1 Ago. 2013. Disponível em: http://goo.gl/3Jr7GA. Citado na página 1.

URLAUB, M.; BOHME, J. F. Evaluation of knock begin in spark-ignition engines by least-squares. ICASSP, 2005. Citado 2 vezes nas páginas 40 e 84 . 

Apêndices 


\title{
APÊNDICE A - Códigos MATLAB
}

\author{
$\% \% \% \% \% \% \% \% \% \% \% \% \% \% \% \% \% \% \% \% \% \% \% \% \% \% \% \% \% \% \% \% \% \% \% \% \% \% \% \% \% \% \% \% \% \% \% \% \% \% \% \% \% \% \% \% \% \%$ \\ $\% \quad \%$ \\ $\%$ Rafael L. Silva $\%$ \\ $\% \quad \%$ \\ $\% \quad 11 / 11 / 2013 \quad \%$
}

$\% \% \% \% \% \% \% \% \% \% \% \% \% \% \% \% \% \% \% \% \% \% \% \% \% \% \% \% \% \% \% \% \% \% \% \% \% \% \% \% \% \% \% \% \% \% \% \% \% \% \% \% \% \% \% \% \% ~$

\%Function Name: Lab

$\%$

$\%$ This function calls the other scripts to allow series connection

$\%$ between algorithms and easy change of parameters

$\%$

function lab

clear all;

NumberofExperiments $=1$;

\%Algorithm Order (valid for adaptive filters)

$\mathrm{M}=[]$;

$\%$ Step size

$\mathrm{mu}=[]$;

$\%$ For power estimator

alpha $=[] ; \%$

$\%\{$

$\mathrm{a}=$ Filter execution Order

1 - LMS

2 - NLMS

3 - RLS

4 - Power Estimator

$\%\}$

$\mathrm{a}=[]$;

$\%\{$

g = Signal Applied to each Filter selected on variable "a"

1 - Coefficient $W$

2 - Knock Signal 
3 - Signal from Power Estimator

4 - d output (Desired_M, for AF only)

5 - Previous InputData

6 - Knock Signal from reference file

7 - Real Signal (pass variable name)

$\%\}$

$g=[]$;

$\%\{$

Name of the variable with the real signal

$\%$ \}

name $=[]$;

$\%\{$

$\mathrm{h}=$ Option of the kind of Knock Generation (ALWAYS ESCALAR)

1 - Generates knock signal by block with random amplitude

2 - Generates knock signal by random block with random amplitude

3 - Generates knock signal by block with random amplitude and random length

4 - Generates knock signal by random block with random amplitude and random length

5 - Generates knock signal by random block with random and random frequency

6 - Generates knock signal by block with random amplitude and random length and random frequency

7 - Generates knock signal by random block with random amplitude and random length

and random frequency

8 - Generates knock signal by random block (a trial at everyone) with random amplitude and random

length and random frequency

$\%\}$

$\mathrm{h}=3$;

$\mathrm{b}=1$

\%For Power Estimator

$c=$ alpha; 
$\mathrm{d}=1$

$\%$ For NLMS and RLS

$\mathrm{e}=0.651$;

$f \quad=1$;

for $b=1:$ length (a),

$[d, f]=$ take_prev_signal $(a, b, g(b), h, M(b)$, name);

InputData $=\mathrm{d}$;

$\mathrm{d}=0$;

OutputData = InputData;

$f=f i l e \_n a m e(a(b), b)$;

knock_lab (InputData, OutputData, NumberofExperiments,

$M(b), m u(b), a(b), b, c, d, e, f)$;

end

$\operatorname{disp}('$

Finished! : )');

$\operatorname{disp}('$

Finished! $:$ )

$\operatorname{disp}($ '

') ;

end 


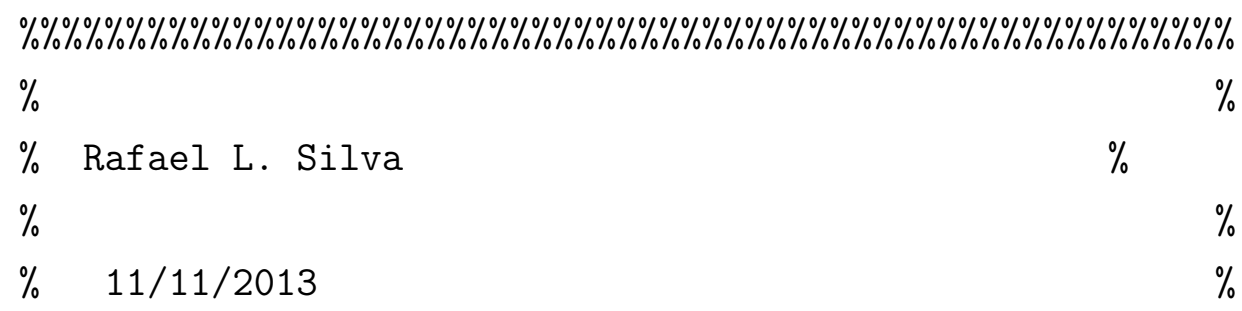

$\% \% \% \% \% \% \% \% \% \% \% \% \% \% \% \% \% \% \% \% \% \% \% \% \% \% \% \% \% \% \% \% \% \% \% \% \% \% \% \% \% \% \% \% \% \% \% \% \% \% \% \% \% \% \% \% ~$

$\%$ Function Name: take_prev_signal

$\%$

$\%$ This function takes the signal passed to it in the file $\%$ of reference,

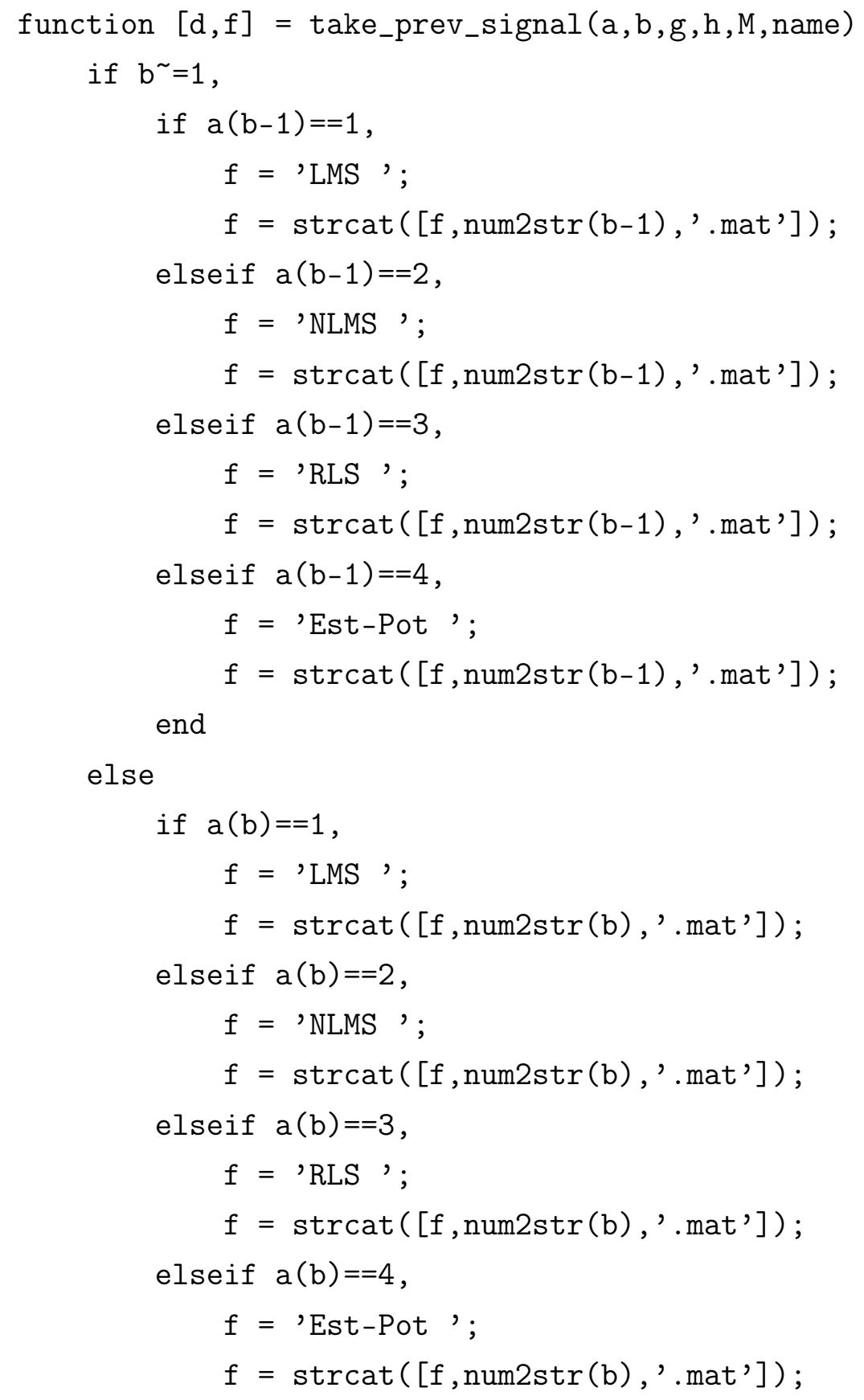


end

end

if $g==1$,

load (f , 'Wacummulated_M');

$\mathrm{d}=$ Wacummulated_M(1,: ) ;

clear Wacummulated_M;

elseif $g==2$,

$d=\operatorname{test}(h)$;

save ('knock_reference', 'd')

elseif $g==3$;

load ( $f$, ' $^{\prime}$ ');

$\mathrm{d}=\mathrm{y}$;

clear y;

elseif $g==4$;

load (f, 'Desired_M');

$\mathrm{d}$ = Desired_M;

clear Desired_M;

elseif $g==5$;

load (f, 'InputData');

$\mathrm{d}$ = InputData;

clear InputData;

elseif $g==6$;

load 'knock_reference.mat';

elseif $g==7$;

load ('real_signal.mat', name);

$\mathrm{d}=\mathrm{eval}$ (name);

$d=d * 0.0000001 ; \%$ gain used to reduce real signal amplitude

end

end 


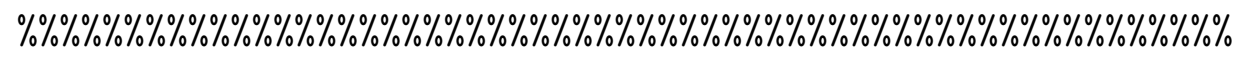

$\%$

$\%$

$\%$ Rafael L. Silva

$\%$

$\%$

$\% \quad 11 / 11 / 2013$

$\%$

$\%$

\% \% \% \% \% \% \% \% \% \% \% \% \% \% \% \% \% \% \% \% \% \% \% \% \% \% \% \% \% \% \% \% \% \% \% \% \% \% \% \% \% \% \% \% \% \% \% \% \% \% \% \%

$\%$ Function Name: file_name

$\%$

$\%$ This script passes the name of the chosen algorithm to

\%Knock_labVIEW.mat where the signals are saved in a mat file

$\%$ with the name of the chosen algorithm,

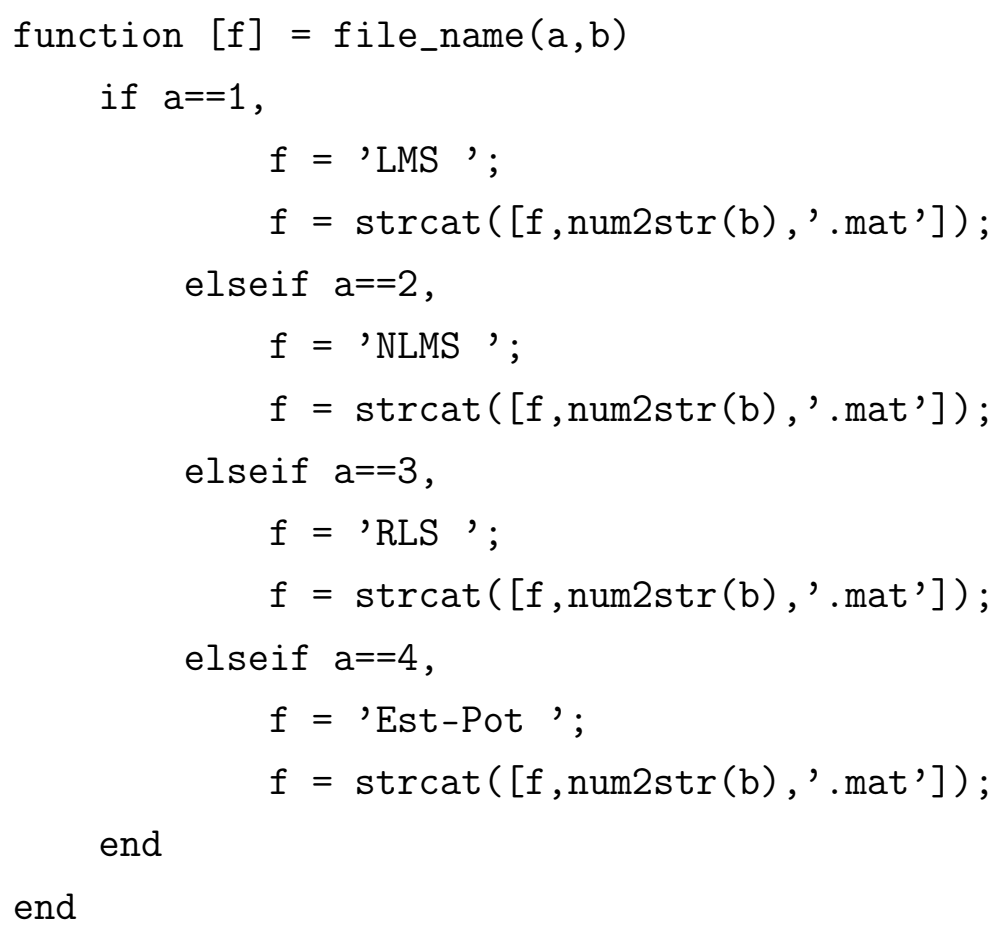




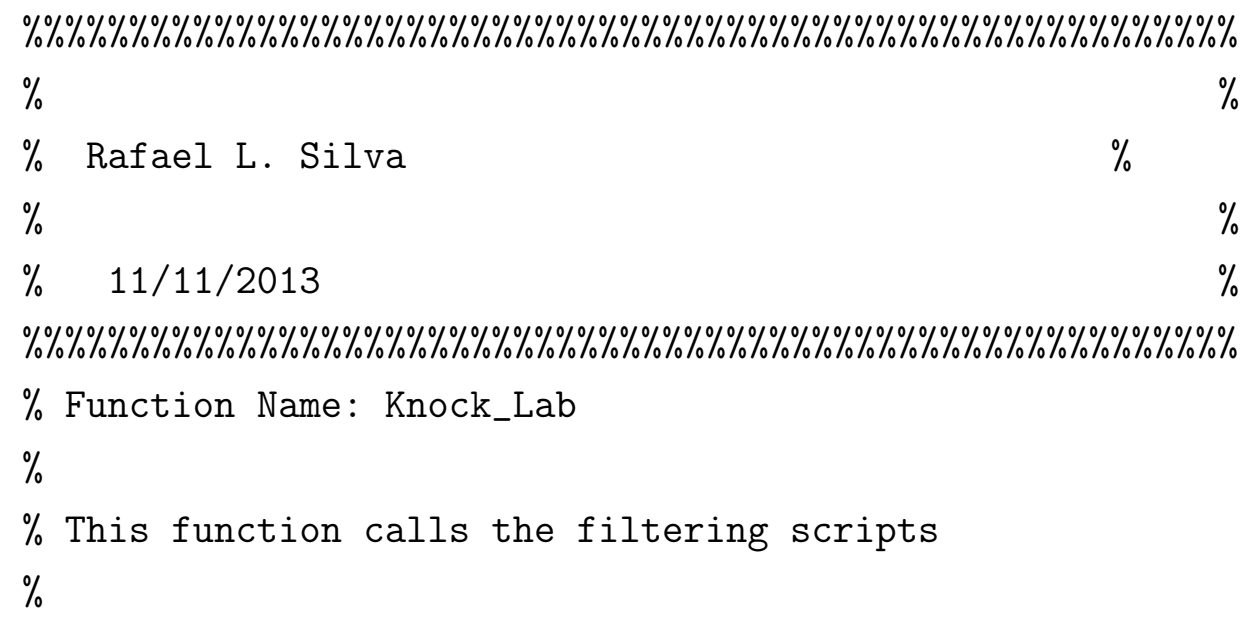




$\begin{array}{ll}\text { MSE_LC } & =\operatorname{zeros}(1, \text { NumberofSamples }) ; \\ \text { EMSE_LC } & =\operatorname{zeros}(1, \text { NumberofSamples }) ; \\ \text { MSD_LC } & =\operatorname{zeros}(1, \text { NumberofSamples }) ; \\ \text { Desired_M } & =\operatorname{zeros}(1, \text { NumberofSamples }) ;\end{array}$

\%Vector for measurement purposes

$t=\operatorname{zeros}(1$, NumberofExperiments);

$\%$ Initial condiitions for $\mathrm{w}$

$\mathrm{w}_{-} 1=\operatorname{zeros}(\mathrm{M}, 1)$;

w_1_M = zeros $(M, 1)$;

$\%$ Step Size

$\mathrm{u}=\mathrm{mu}$;

\% \% $\%$ Power Estimator (Only 1 Input) +++++++++++

$\%$ \% $\mathrm{t} \quad=\operatorname{zeros}(1$, NumberofExperiments $)$;

$\mathrm{y} \quad=0 *$ InputData;

$\%++++++++++++++++++++++++++++++++++++++++++++++++++++++++++++++++++++++++++$ $\%++++++++++++++++++++++++++++++++++++++++++++++++++++++++++++++++++++++++++$ $\%++++++++++\quad$ Filters +++++++++++++++

$\%++++++++++++++++++++++++++++++++++++++++++++++++++++++++++++++++++++++++++$ $\%++++++++++++++++++++++++++++++++++++++++++++++++++++++++++++++++++++++++++$ $\%$

$\%$ Experiment $\%$

if $a==1 \quad|| a==2 \quad|| a==3$, for $\mathrm{m}=1$ :NumberofExperiments,

$\%$ Start timer for performance measurement

tic;

if $a==1$,

[Wacummulated,w, MSE, EMSE, MSD, Desired] = lmsfilter 
(M , Numberof Samples, InputData, w_1, u , OutputData , a) ;

elseif $a==2$,

$\mathrm{e}=\mathrm{e} ;$

[Wacummulated,w, MSE, EMSE, MSD,Desired] = enlmsfilter

(M, Numberof Samples, InputData, w_1 u, e, OutputData, a);

elseif $a==3$,

$\%$ Squared matrix

$I=$ eye (M);

$\%$ Regularization Parameter

$\mathrm{e}=\mathrm{e}$;

$\%$ Lambda

$\mathrm{h}=0.995$;

\%Initial condition for $\mathrm{P}$

$P_{-} 1=(1 / \mathrm{e}) * \mathrm{I}$;

[Wacummulated, $\mathrm{w}$, MSE, EMSE, MSD,Desired] = rlsfilter

(M, Number of Samples, InputData , w_1, P_1, h, OutputData , a);

end

$\mathrm{t}(\mathrm{m})=\mathrm{toc} ;$

MSE_LC = MSE_LC + MSE;

EMSE_LC = EMSE_LC + EMSE;

MSD_LC = MSD_LC $\quad+$ MSD;

Wacummulated_M = Wacummulated_M + Wacummulated;

Desired_M = Desired_M + Desired;

w_1_M $\quad$ w $\mathrm{w}_{-}$1_M $\quad+\mathrm{w}$;

$\%$ Calculous of Learning Curve

MSE_LC $\quad=(1 /$ NumberofExperiments $) *$ MSE_LC;

EMSE_LC $=(1 /$ NumberofExperiments $) *$ EMSE_LC;

MSD_LC $=(1 /$ NumberofExperiments $) *$ MSD_LC;

Wacummulated_M = (1/NumberofExperiments $) *$ Wacummulated;

Desired_M $\quad=(1 /$ NumberofExperiments $) *$ Desired;

w_1_M $\quad=(1 /$ NumberofExperiments $) * \mathrm{w}$;

end 
$\%$

save (f , 'Wacummulated', 'Wacummulated_M', 'Desired_M', 'Desired', 'MSE_LC', 'EMSE_LC' , 'MSD_LC' , '-append' ');

$\%$

clear function;

clearvars -except $\mathrm{w}_{-}$1_M $\mathrm{t} f \mathrm{M} \mathrm{mu}$ a b c d e;

w_1_M;

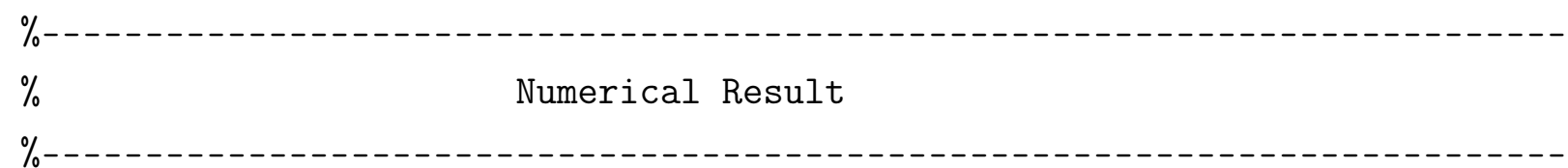

disp('Wo Coefficient for Algorithm');

$\operatorname{disp}($ '

w_1_M

clear W_1_M;

disp('Average Time of Execution for Each Experiment for Algorithm'); disp('--- $\operatorname{mean}(t)$

clearvars -except $f \mathrm{M} \mathrm{mu} \mathrm{a} \mathrm{b} \mathrm{c} \mathrm{d} \mathrm{e;}$

clear function;

elseif $a==4$,

$\%++++++++++++++++++++++++++++++++++++++++++++++++++++++++++++++++++++++++++$

$\%++++++++++++++++++++++++++++++++++++++++++++++++++++++++++++++++++++++++++$

$\%+$ Power Estimator (Only 1 Input) +++++++++++

$\%$

$\%$

$\%\{$

for $\mathrm{m}=1$ :NumberofExperiments,

$\mathrm{y}_{-} 1=0$; 
tic;

for $\mathrm{k}=1$ : Number of Samples,

$\mathrm{y}(\mathrm{k})=\mathrm{c}(\mathrm{b}) * \mathrm{y}_{-} 1+\operatorname{beta}(\mathrm{b}) * \operatorname{InputData}(\mathrm{k}) \sim 2$;

$\mathrm{y}_{-} 1=\mathrm{y}(\mathrm{k})$;

end

$t(m)=$ toc;

end

$\%\}$

$[y$, beta $]=$ pwr_estimator (NumberofSamples, NumberofExperiments, $c$, InputData,$b)$;

save( $f$, 'c', 'beta', 'y' , '-append');

clear function;

clearvars -except $t$ f $M$ mu a b c d e;

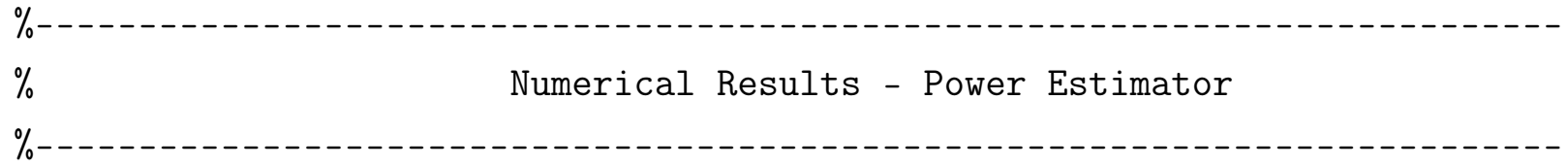

disp('Average Time of Execution for Each Experiment for Power Estimator Algorithm');

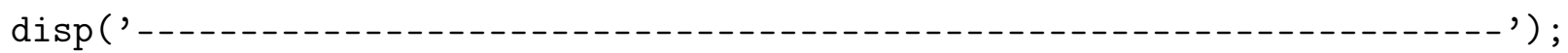

$\operatorname{mean}(t)$

clearvars -except f $\mathrm{M}$ mu a b c d e;

$\mathrm{b}$;

clear function;

dummy = uint8(0);

end

graph_knock_lab(f, M, mu, a , b , c , d,e);

end 


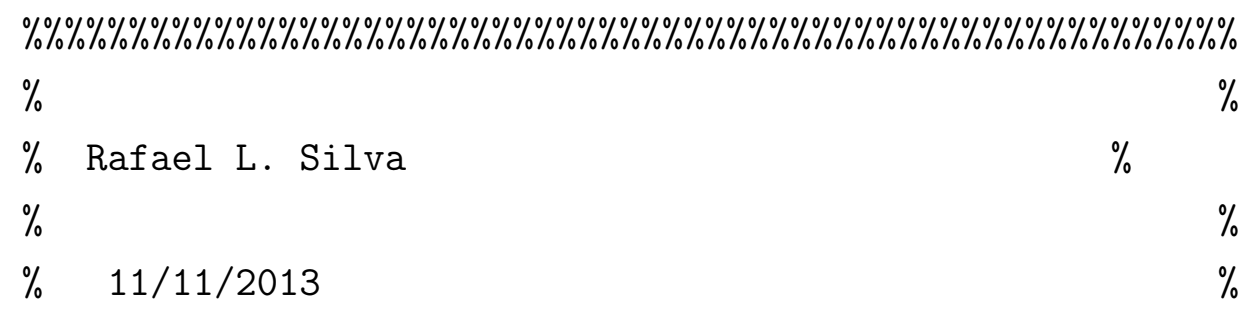

$\% \% \% \% \% \% \% \% \% \% \% \% \% \% \% \% \% \% \% \% \% \% \% \% \% \% \% \% \% \% \% \% \% \% \% \% \% \% \% \% \% \% \% \% \% \% \% \% \%$

$\%$ Function Name: Imsfilter

$\%$

$\%$ This script receives the LMS parameter and return the filter

$\%$ coefficients as well as the estimated output

function [Wacummulated,Wi, MSE_LMS, EMSE_LMS, MSD_LMS,Desired] = lmsfilter (ntaps, iterations, u, w_init,mi, d,a)

wzin = zeros (ntaps, iterations);

MSE_LMS = zeros (1,iterations);

EMSE_LMS = zeros (1,iterations);

MSD_LMS = zeros (1,iterations);

Desired $=$ zeros (1, iterations);

uSample $=\operatorname{zeros}(1$, ntaps $)$;

dSample $=\operatorname{zeros}(1$, ntaps $)$;

Wi $=w_{\text {_init }}$

for $i=1$ :iterations,

$\operatorname{wzin}(:, i)=W i$;

\%Instantaneous LMS error determination

MSE_LMS $(i)=(d(i)-($ uSample $* W i))-2$;

$\operatorname{EMSE}_{-} L M S(i)=$ MSE_LMS $(i)+0.01$;

$\% \operatorname{MSE} \_$LMS $\quad(i)=($ Wo - Wi $) ' *$ dSample $*$ dSample' $*$ (Wo - Wi $)+0.01$;

$\%$ EMSE_LMS $(i)=(\text { Wo }- \text { Wi })^{\prime} *$ dSample $*$ dSample' $*$ (Wo - Wi);

MSD_LMS $(i)=($ Wo - Wi $), *$ (Wo - Wi $)$;

$\%$

$\%$ Coefficient estimation

$\% \mathrm{Wi}=\mathrm{Wi}+\mathrm{mi} *$ uSample $*(\mathrm{dSample}-$ uSample $*$ Wi $)$; 


$$
\mathrm{Wi}=\mathrm{Wi}+(\mathrm{mi}) *(\text { uSample' }) *(\mathrm{~d}(\mathrm{i}) \quad-\text { uSample } * \mathrm{Wi}) \text {; }
$$

Desired $(i)=$ uSample $*$ Wi

uSample $=[d(i)$ uSample $(1,1:($ ntaps -1$))]$;

end

clear dSample uSample Wi_1

Wacummulated = wzin;

end 


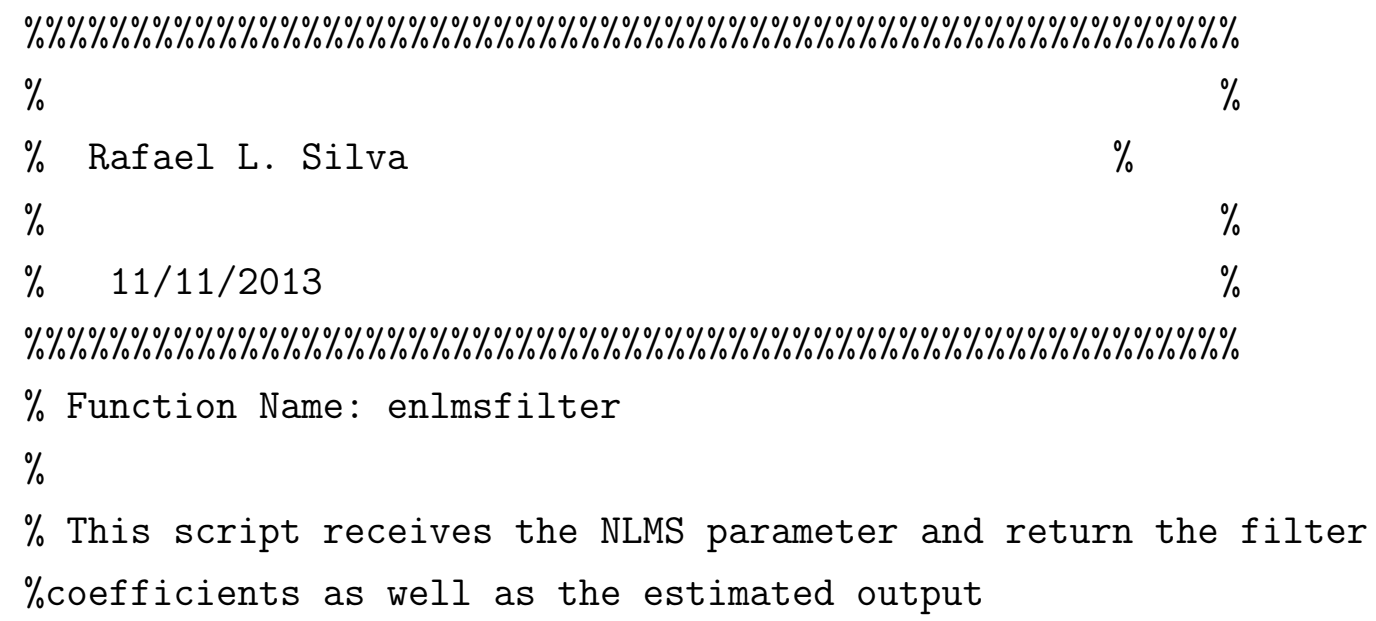


uSample' * ( d(i) - uSample *Wi $)$;

$\operatorname{Desired}$ NLMS $(i)=$ uSample $*$ Wi

uSample $=[d(i)$ uSample $(1,1:($ ntaps -1$))]$;

end

clear dSample uSample Wi_1

Wacummulated_NLMS = wzin;

end 


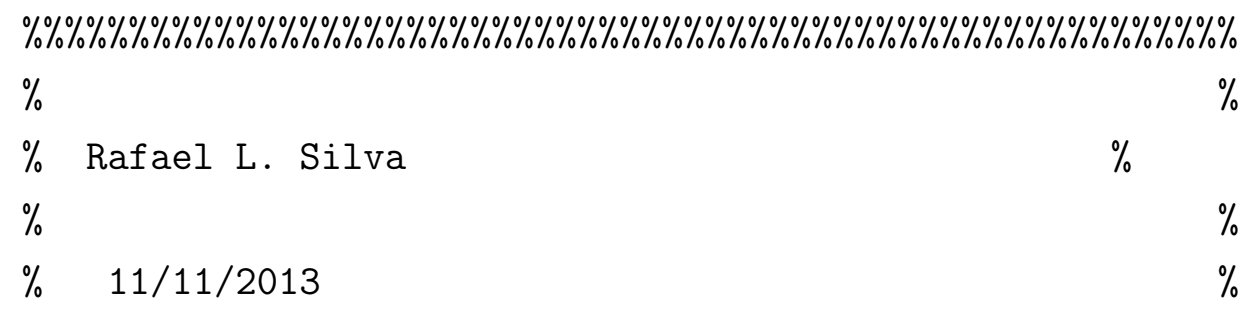

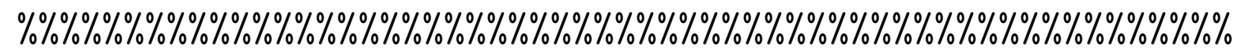

$\%$ Function Name: graph_knock_lab

$\%$

$\%$ This function prints the obtained signals

$\%$

function graph_knock_lab (a,b, d,e,f)

ifile $=$ num2str $(b)$;

filename $=\operatorname{strcat}($ 'variables_test', ifile,'.mat');

$\%\{$

$\%++++++++++++++++++++++++++++++++++++++++++++++++++++++++++++++++++++++++++$

$\%++++++++++++++++++++++++++++++++++++++++++++++++++++++++++++++++++++++++++$

$\%$ Graphical Results ++++++++++++++++

$\%++++++++++++++++++++++++++++++++++++++++++++++++++++++++++++++++++++++++++$

$\%++++++++++++++++++++++++++++++++++++++++++++++++++++++++++++++++++++++++++$

\%

memory

load (filename, 'Wacummulated_M') ;

load ('var_knock.mat', 'InputData');

if $b==1$;

figure (gcf);

else

figure $(g c f+1)$;

end

hold on;

subplot $(3,1,1)$; 


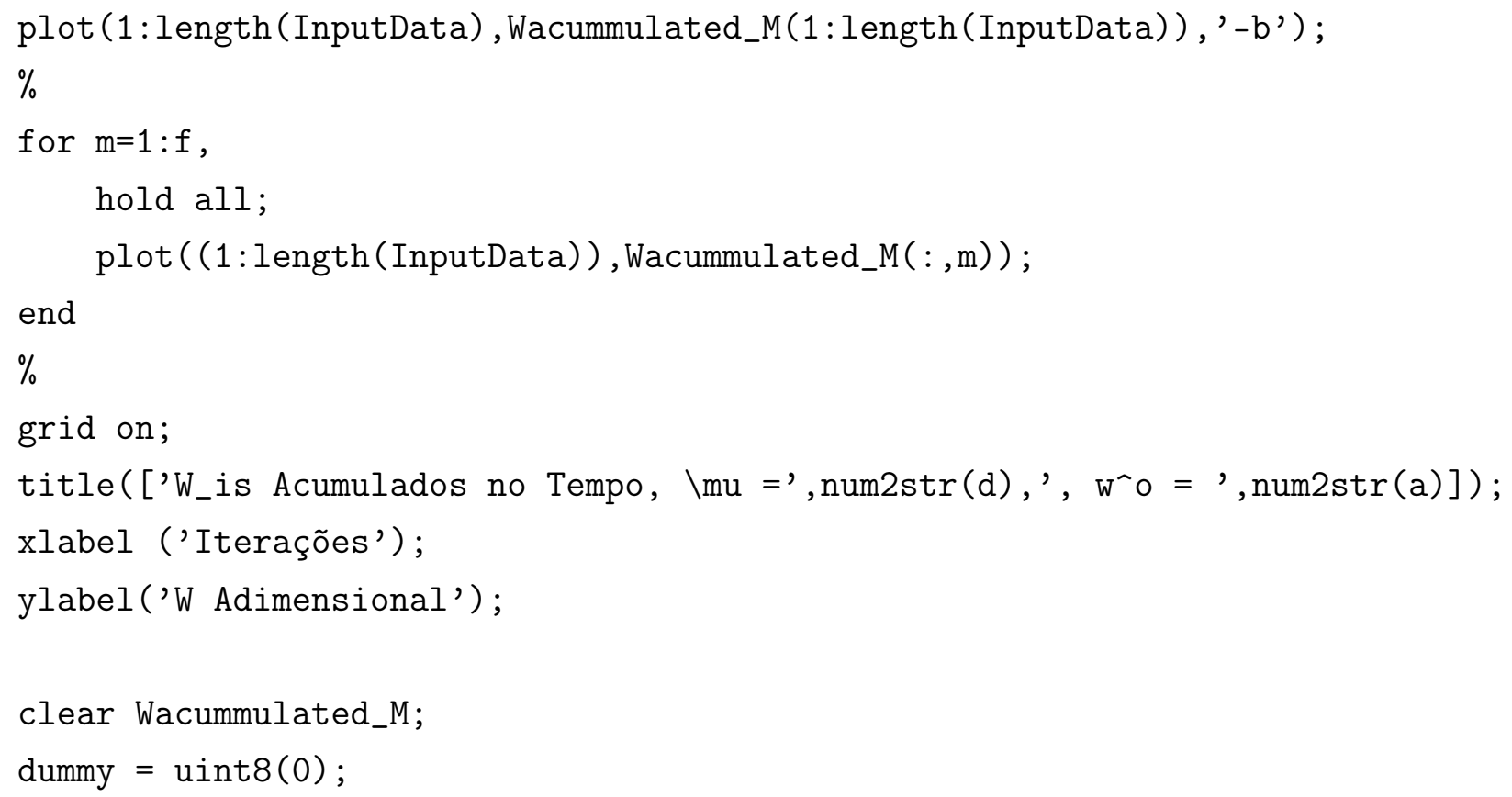


dummy $=\operatorname{uint8}(0)$;

figure (gcf-1) ;

load(filename, 'Desired_M');

subplot $(3,1,2)$;

plot (Desired_M);

grid on;

title('Saída Estimada a partir dos W_is Econtrados');

xlabel ('Iterações');

ylabel ('Saída [V]');

clear Desired_M;

dummy = uint8 $(0)$;

hold off;

$\mathrm{h}=$ figure (gcf);

graphname $=$ strcat('LMS Extra Results',ifile,'.fig');

saveas (h, graphname);

close;

dummy = uint8(0);

memory

load (filename, 'EnsembleAverage_LC');

$\%$ Uncomment if you want to have online plotting and comment the close $\%$ commands. Otherwise do it instead.

$\%$ figure $(g c f+1)$;

figure (gcf);

subplot $(4,1,2)$;

hold on;

plot ( $1:$ length (EnsembleAverage_LC), 10*log10 (EnsembleAverage_LC) , ' $-r$ ');

grid on;

title ('Curva de Aprendizado do MSE para o Algoritmo LMS');

xlabel ('Iterações');

ylabel ('MSE $\left.d B^{\prime}\right)$; 
$\%$ axis ([0 NumberofSamples -25 10]);

clear EnsembleAverage_LC

load(filename, 'EMSE_LMS_LC');

subplot $(4,1,3)$;

plot ( 1 : length (EMSE_LMS_LC), $10 * \log 10$ (EMSE_LMS_LC), '-b');

grid on;

title('Curva de Aprendizado do EMSE para o Algoritmo LMS');

xlabel ('Iterações');

ylabel ('EMSE dB');

$\% \operatorname{axis}([0$ NumberofSamples -25 10] );

clear EMSE_LMS_LC;

load (filename, 'MSD_LMS_LC');

subplot $(4,1,4)$;

plot ( 1 : length (MSD_LMS_LC), $10 * \log 10($ MSD_LMS_LC) , '-b') ;

grid on;

title('Curva de Aprendizado do MSD para o Algoritmo LMS');

xlabel ('Iterações');

ylabel ('MSD dB');

$\% \operatorname{axis}([0$ NumberofSamples -25 10]);

clear MSD_LMS_LC;

memory

hold off;

memory

$\mathrm{h}=$ figure (gcf);

graphname = strcat('LMS Results', ifile,'.fig');

saveas (h, graphname);

close;

$\%\}$

$\%++++++++++++++++++++++++++++++++++++++++++++++++++++++++++++++++++++++++++$

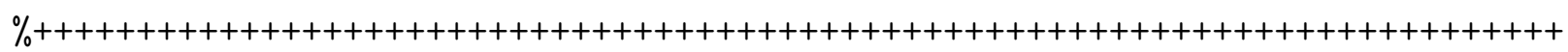

$\%$ Graphical Results ++++++++++++++++ 
$\%++++++++++++++++++++++++++++++++++++++++++++++++++++++++++++++++++++++++++$ $\%++++++++++++++++++++++++++++++++++++++++++++++++++++++++++++++++++++++++++$

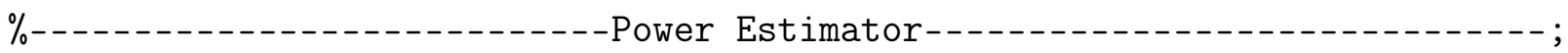

load (filename, 'alpha', 'beta', 'y');

load ('var_knock.mat', 'InputData');

figure;

hold on;

subplot $(2,1,1)$;

grid on;

plot (1:length (InputData),y);

title(['Sinal do Estimador de Potência, \alpha =', num2str(alpha), ', $\backslash$ beta $=$, num2str (beta)]);

subplot $(2,1,2)$;

plot (1: length (InputData), InputData);

$\mathrm{h}=$ figure $(\mathrm{gcf})$;

graphname $=\operatorname{strcat}($ 'LMS Results', ifile, '.fig');

saveas (h, graphname);

close;

$\%\{$

$\%++++++++++++++++++++++++++++++++++++++++++++++++++++++++++++++++++++++++++$ $\%++++++++++++++++++++++++++++++++++++++++++++++++++++++++++++++++++++++++++$ $\%$ Graphical Results ++++++++++++++++ $\%++++++++++++++++++++++++++++++++++++++++++++++++++++++++++++++++++++++++++$ $\%++++++++++++++++++++++++++++++++++++++++++++++++++++++++++++++++++++++++++$

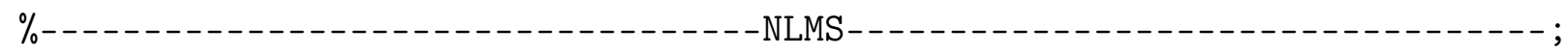
load (filename, 'Wacummulated_NLMS_M') ; load ('var_knock.mat' , 'InputData');

if $b==1$;

figure (gcf);

else

figure $(g c f+1)$; 
end

hold on;

subplot $(3,1,1)$;

plot (Wacummulated_NLMS_M(1: length(InputData)) , '-b') ;

$\%\{$

for $m=1: f$,

hold all;

plot $((1:$ length (InputData) $)$, Wacummulated_NLMS_M $(:, \mathrm{m}))$;

end

$\%$ \}

grid on;

title(['W_is Acumulados no Tempo para o Algoritmo \epsilonNLMS, \mu = ', num2str(d),' e lepsilon =', num2str(e), ', w`o $^{\wedge}$, , num2str(a)]);

xlabel ('Iterações') ;

ylabel('W Adimensional');

clear Wacummulated_NLMS_M;

load ('var_knock.mat', ' InputData');

load ('var_knock.mat', 'OutputData');

subplot $(3,1,3)$;

plot (1: length (InputData), InputData , 'b', $1:$ length (InputData), OutputData, 'r') ;

grid on;

title('Sinal Sensor de Detonação X Sinal Ignição');

\%legend ('Ignição', 'Detonação') ;

\%legend ('Detonação' , 'Ignição') ;

legend ('Detonação' , 'Detonação') ;

xlabel ('Iterações') ;

ylabel ('Tensão [V]');

figure $(g \subset f+1)$;

hold on;

subplot $(4,1,1)$;

plot (1: length(InputData), InputData , 'b', $1:$ length(InputData), OutputData, 'r') ;

grid on; 
title(['Sinal Sensor de Detonação X Sinal Ignição \mu =', num2str(d), 'e \epsilon = ', num2str (e), ', $\mathrm{w}^{\wedge} \mathrm{O}=$ ', num2str(a)]);

\%legend ('Ignição' , 'Detonação') ;

\%legend ('Detonação' , 'Ignição') ;

legend ('Detonação' , ' Detonação') ;

xlabel ('Iterações');

ylabel ('Tensão [V]');

clear OutputData InputData;

figure (gcf-1);

load(filename, 'Desired_NLMS_M');

subplot $(3,1,2)$;

plot ( 1 : length (Desired_NLMS_M), Desired_NLMS_M);

grid on;

title('Saída Estimada a partir dos W_is Econtrados');

xlabel ('Iterações');

ylabel ('Saída [V]');

clear Desired_NLMS;

hold off;

$\mathrm{h}=$ figure $(\mathrm{gcf})$;

graphname $=$ strcat ('N-LMS Extra Results', ifile,'.fig');

saveas (h, graphname);

close;

load(filename, 'NLMS_LC');

$\%$ Here it is gcf only because gcf-1 (figure 1) has been closed $\%$ figure $(g c f+1)$;

figure (gcf);

hold on;

subplot $(4,1,2)$; 
$\operatorname{plot}(1:$ length (NLMS_LC), $10 * \log 10($ NLMS_LC) , ' $-r$ ') ;

grid on;

title ('Curva de Aprendizado do MSE para o Algoritmo lepsilonNLMS');

xlabel ('Iterações');

ylabel ('MSE dB');

$\%$ axis ( [0 NumberofSamples -25 10] );

clear NLMS_LC;

load (filename, 'EMSE_NLMS_LC');

subplot $(4,1,3)$;

plot (1:length(EMSE_NLMS_LC), $10 * \log 10\left(E M S E \_N L M S \_L C\right), \quad$-b');

grid on;

title('Curva de Aprendizado do EMSE para o Algoritmo \epsilonNLMS');

xlabel ('Iterações');

ylabel ('EMSE dB');

$\%$ axis ([0 Numberof Samples -25 10]);

Clear EMSE_NLMS_LC;

load (filename, 'MSD_NLMS_LC') ;

subplot $(4,1,4)$;

plot ( $1:$ length (MSD_NLMS_LC), $10 * \log 10($ MSD_NLMS_LC) , '-b') ;

grid on;

title('Curva de Aprendizado do MSD para o Algoritmo \epsilonNLMS');

xlabel ('Iterações');

ylabel ('MSD dB');

$\%$ axis ([0 NumberofSamples -25 10]);

clear MSD_NLMS_LC;

hold off;

$\mathrm{h}=$ figure (gcf);

graphname $=\operatorname{strcat}($ 'N-LMS Results', ifile,'.fig');

saveas (h, graphname);

close; 
end 


\section{APÊNDICE B - Especificações técni- cas de um sensor de detonação comercial}




\section{Piezoelectric vibration sensors}

\section{Measurement of structure-borne noise/acceleration}

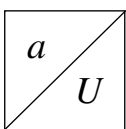

Reliable detection of structure-borne noise for protecting machines and engines.

Piezo-ceramic with high degree of measurement sensitivity.

Sturdy compact design.

\section{Applications}

Vibration sensors of this type are suitable for the detection of structure-borne acoustic oscillations as can occur for example in case of irregular combustion in engines and on machines. Thanks to their ruggedness, these vibration sensors can be used even under the most severe operating conditions.

Areas of application

- Knock control for internal-combustion engines

- Protection of machine tools

- Detection of cavitation

- Monitoring of bearings

- Theft-deterrent systems

\section{Design and function}

On account of its inertia, a mass exerts compressive forces on a ring-shaped piezo-ceramic element in time with the oscillation which generates the excitation. Within the ceramic element, these forces result in charge transfer within the ceramic and a voltage is generated between the top and bottom of the ceramic element. This voltage is picked-off using contact discs - in many cases it is filtered and integrated - and made available as a measur-ing signal. In order to route the vibration directly into the sensor, vibration sensors are securely bolted to the object on which measurements take place.

\section{Measurement sensitivity}

Every vibration sensor has its own individua response characteristic which is closely linked to its measurement sensitivity. The measurement sensitivity is defined as the output voltage per unit of acceleration due to gravity (see characteristic curve). The production-related sensitivity scatter is acceptable for applications where the primary task is to record that vibration is occurring, and not so much to measure its severity.

The low voltages generated by the sensor can be evaluated using a high-impedance AC amplifier.

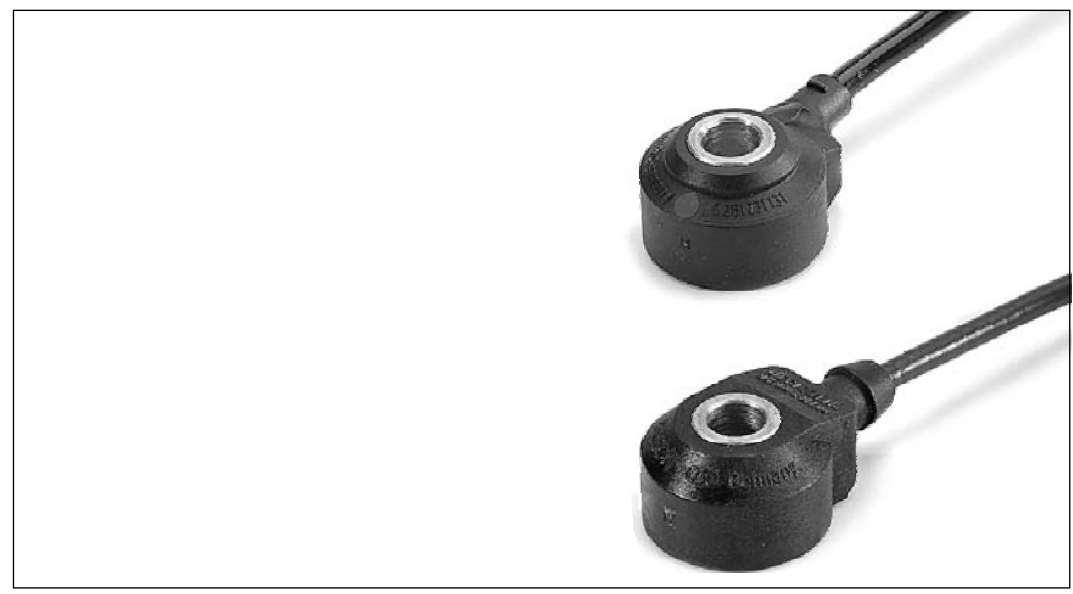

\section{Technical data}

\begin{tabular}{|c|c|}
\hline Frequency range & $1 \ldots 20 \mathrm{kHz}$ \\
\hline Measuring range & $\left.\approx 0.1 \ldots 400 g^{1}\right)$ \\
\hline Sensitivity at $5 \mathrm{kHz}$ & $26 \pm 8 \mathrm{mV} / \mathrm{g}$ \\
\hline $\begin{array}{l}\text { Linearity between } 5 \ldots 15 \mathrm{kHz} \\
\text { at resonances }\end{array}$ & $+20 /-10 \%$ of $5 \mathrm{kHz}$-value $(15 \ldots 41 \mathrm{mV} / \mathrm{g})$ \\
\hline Dominant resonant frequency & $>25 \mathrm{kHz}$ \\
\hline Self-impedance & $>1 \mathrm{M} \Omega$ \\
\hline Capacitance range & $800 \ldots 1400 \mathrm{pF}$ \\
\hline $\begin{array}{l}\text { Temperature dependence } \\
\text { of the sensitivity }\end{array}$ & $\leq 0.06 \mathrm{mV} /\left(g \cdot{ }^{\circ} \mathrm{C}\right)$ \\
\hline \multicolumn{2}{|l|}{ Operating-temperature range: } \\
\hline Type $0261 \quad 231 \quad 148$ & $\begin{array}{l}-40 \ldots+150^{\circ} \mathrm{C} \\
-40 \ldots+130^{\circ} \mathrm{C}\end{array}$ \\
\hline Permissible oscillations & $\begin{array}{l}\leq 80 g \\
\leq 400 g\end{array}$ \\
\hline \multicolumn{2}{|l|}{ Installation } \\
\hline \multirow[t]{2}{*}{ Fastening screw } & M $8 \times 25$; quality 8.8 \\
\hline & M $8 \times 30$; quality 8.8 \\
\hline Tightening torque (oiled permitted) & $20 \pm 5 \mathrm{~N} \cdot \mathrm{m}$ \\
\hline Mounting position & Arbitrary \\
\hline
\end{tabular}

\section{Range}

Vibration sensor

2-pole without cable

2-pole, with cable, length $480 \mathrm{~mm}$, up to $+130{ }^{\circ} \mathrm{C}$

0 261231153

3-pole, with cable, length $410 \mathrm{~mm}$, up to $+150^{\circ} \mathrm{C}$

0 261231118

\section{Accessories}

\begin{tabular}{|c|c|c|c|c|}
\hline Sensor & Plug housing & Contact pins & Individual gasket & $\begin{array}{l}\text { For cable } \\
\text { cross section }\end{array}$ \\
\hline \multirow[t]{2}{*}{0261231148} & 1928403137 & 1987280103 & 1987280106 & $0.5 \ldots 1.0 \mathrm{~mm}^{2}$ \\
\hline & & 1987280105 & 1987280107 & $1.5 \ldots 2.5 \mathrm{~mm}^{2}$ \\
\hline \multirow[t]{2}{*}{0261231153} & 1928403826 & 1928498060 & 1928300599 & $0.5 \ldots 1.0 \mathrm{~mm}^{2}$ \\
\hline & & 1928498061 & 1928300600 & $1.5 \ldots 2.5 \mathrm{~mm}^{2}$ \\
\hline 0261231118 & 1928403110 & \begin{tabular}{|l|lll|l|}
1 & 987 & 280 & 103 \\
1 & 987 & 280 & 105 \\
\end{tabular} & \begin{tabular}{|llllll}
1 & 987 & 280 & 106 \\
1 & 987 & 280 & 107 \\
\end{tabular} & $0.5 \ldots 1.0 \mathrm{~mm}^{2}$ \\
\hline
\end{tabular}

Note: A 3-pole plug requires 1 plug housing, 3 contact pins, and 3 individual gaskets.

In automotive applications, original AMP crimping tools must be used. 
Vibration sensor (design).

1 Seismic mass with compressive forces $F$

2 Housing, 3 Piezo-ceramic,

4 Screw, 5 Contact, 6 Electrical connection,

7 Machine block, V Vibration.

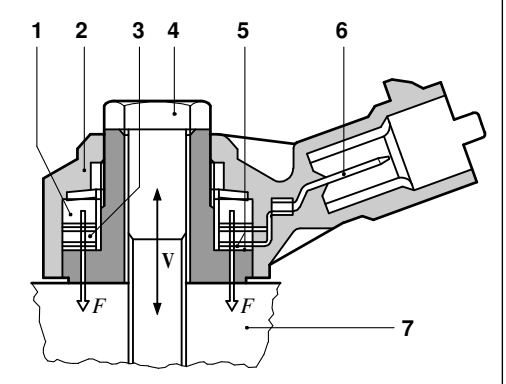

Dimension drawings.

a Contact surface.

0 261231148
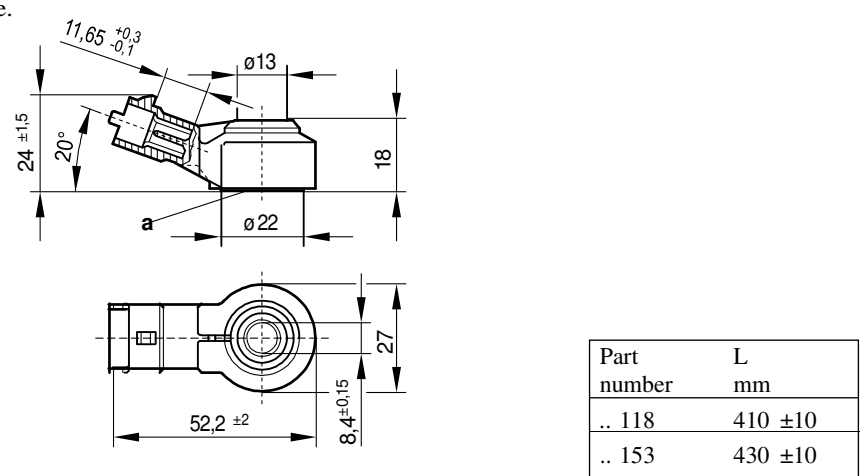

0 261231118

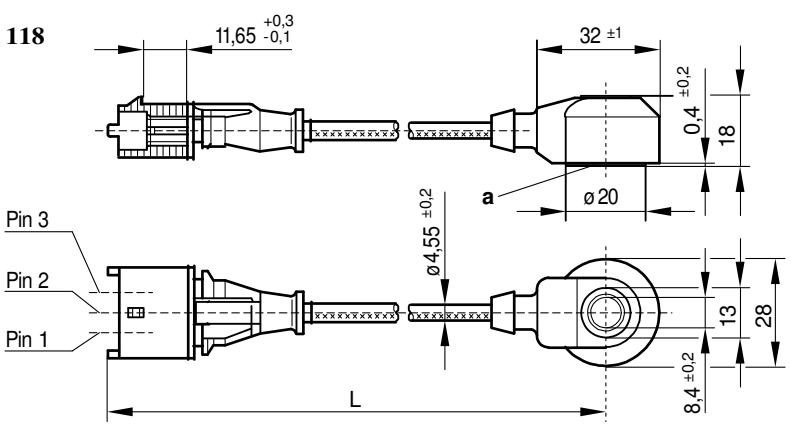

0 261231153
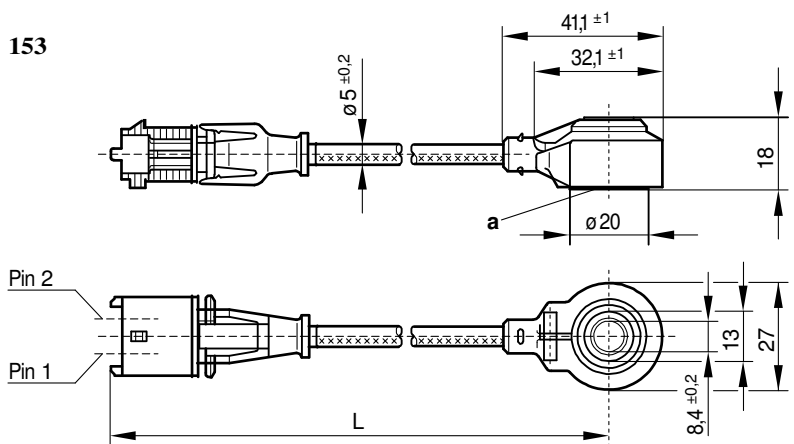

Mounting hole.
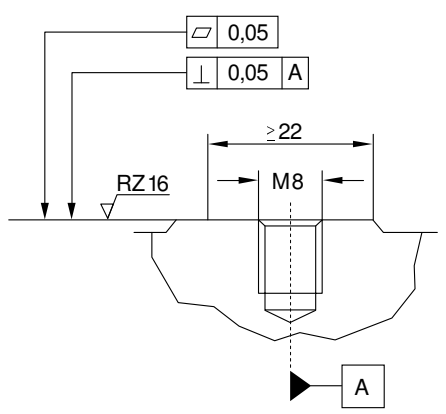

Evaluation

The sensor's signals can be evaluated using an electronic module.

This is described on Pages 26/27.

Installation instructions

The sensor's metal surfaces must make direct contact. No washers of any type are to be used when fastening the sensors.

The mounting-hole contact surface should be of high quality to ensure low-resonance sensor coupling at the measuring point.

The sensor cable is to be laid such that

there is no possibility of sympathetic

oscillations being generated. The sensor

must not come into contact with liquids for

longer periods.

Explanation of symbols

E Sensitivity

$f \quad$ Frequency

$g \quad$ Acceleration due to gravity

Connector-pin assignments

Pin 1, 2 Measuring signal

Pin 3 Shield, dummy 